II.

Aus dem pharmakologischen Institut der Universität Jena.

\title{
Die Blutdurchströmung der Lunge unter dem Einfluss einiger Arzneistoffe, gemessen an der Blutung einer Lungenwunde.
}

\author{
Von \\ Priv.-Doe. Dr. med. Ernst Frey, \\ Assistent am Institut. \\ (Mit \& Abbildung und 23 Curven im 'lext.)
}

\section{Einleitung.}

Wohl mit Recht ist man geneigt, dem grossen Kreislaufe eine erheblichere Selbstständigkeit zuzuschreiben als dem Lungenkreislaufe; man nimmt an, dass die Blutströmung im grossen Kreislaufe hauptsächlich von der Herzleistung und dem Zustande der Gefässe abhängt, der klcine dagegen ausserdem noch wesentlich durch die Verhältnisse des grossen modificirt wird. Doch könnten sich beide Gefässsysteme bei dem Umlauf des Blutes gegenseitig beeinflussen, nur ist der kleine Kreislauf in viel weiterem Umfange von dem grossen abhängig als umgekehrt. Und wenn bei erschwerter Exspiration, wie Husten, Blasen, die grossen Venenstämme anschwellen, so ist nicht die Erschwerung der Blutströmung durch die Lungen das Haupthinderniss, sondern der starke positive Druck, der unter diesen Umständen auf dem Ausflussende der Venen des grossen Kreislaufes lastet.

Der Blutdruck in der Arteria pulmonalis ist zunächst, wie derjenige in der Aorta, abhängig von der Herzleistung, d. h. der Zah] und Grösse der Herzcontractionen, und der Spannung der Gefässwände. Sodann kommt aber auch in Betracht: der Vorrath an Blut, aus welchem die rechte Kammer schöpft, d. h. die Blutfülle des rechten Vorhofes und der grossen Venen, und zweitens die Entleerung des linken Vorhofes, in welchen das Blut aus der Lunge sich ergiesst. Durch zablreiche Untersuchungen ist festgestellt, dass die Spannung der Lungengefässe nur einen geringen Einfluss auf den Blutdruck ausübt, dass desto grössere Bedeutung aber dem Zufluss aus dem rechten Vorhof und dem Abfluss aus dem linken Vorhof zukommt. Der Blutdruck in der Lungenarterie steigt also erstens, wenn die Blutströmung aus den Körpervenen zu- 
nimmt, zweitens, wenn der linke Ventrikel nicht genügend Blut aus seinem Vorhof schöpft, wenn es zur Rückstauung kommt.

Betrachtet man nun nicht den Blutdruck in der Arterie, sondern die Blutdurchströmung eines Organes, so ist diese wiederum von zwei Factoren abhängig, dem Blutdruck und der Gefässweite. Diese Verhältnisse compliciren sich aber insofern, als sich jene beiden massgebenden Factoren selbst gegenseitig beeinflussen, und es ist daher sehr wohl denkbar, dass durch ein Mittel, welches die Gefässe verengt und dadurch den Blutdruck in die Höhe treibt, die Durchblutung eines Organs in keiner Weise geändert wird; das Herz könnte dann durch gesteigerte Leistung den höheren Widerstand überwinden und auf diese Weise gleich viel Blut durch das Organ treiben. Aber es sind auch local - in einem bestimmten Organ - die beiden anderen Möglichkeiten vorhanden: Erstens kann bei erhöhtem Blutdruck mehr Blut ein Organ durchströmen, trotzdem sich die Gefässe auch in dieser Stelle verengern; und zweitens kann trotz gesteigertem Blutdruck in Folge von starker Gefässverengerung weniger Blut durch das Organ fliessen. Entscheidend für das, was eintritt, ist das Verhalten der übrigen Gefässprovinzen. Sind die anderen Capillargebiete mehr verengt, so wird die Durchblutung grösser; betrifft die Gefässconstruction am stärksten das beobachtete Organ, so fliesst weniger Blut durch dasselbe. Dass sich diese Betrachtungen realisiren, werden die folgenden Beobachtungen lehren. Aber es sind solche Verhäitnisse auch schon mehrfach in der Literatur beschrieben. Wir wissen rom grossen Kreislauf, dass in der Regel eine Gefässverengerung oder -Erweiterung die verschiedenen Gefässprovinzen verschieden stark betrifft und so Verschiebungen der Blutströmung schafft. Das ist beim kleinen Krcislauf wohl kaum der Fall; denn "an der Lunge müssten doch wohl alle Gefässprovinzen, " wie Gerhardt ${ }^{1}$ ) sagt, „in gleicher Weise aul das Gift reagiren und", so fährt er bei Erörterung der Möglichkeit einer medicamentösen Gefässcontraction fort, "damit entstünde begreiflicherweise eine grosse Störung des ganzen Kreislaufes wie sie für den Organismus kaum gleichgültig wäre."

Man hat bisher den kleinen Kreislauf in der Weise studirt, dass man den Blutdruck in Lungenarterie und Lungenvene gemessen hat, um so Aufschluss über eine Volumensänderung der Lungengefässe zu erhalten. Einige Untersuchungen haben auch nur den Blutdruck in der Arteria pulmonalis neben dem im grossen Kreislaufe bestimmt. In diesem Fall können vielleicht Feststellungen über die Durchblutungsgrösse der Lunge eine Antwort auf eine Reihe von Fragen geben, welche die Methoden der Druckmessung offen lassen, da sie eine Ergänzung zu den schon mitgetheilten Daten geben.

Die vorliegende Studie sollte zunächst eine Untersuchung darstellen, inwieweit Arzneistoffe eine Lungenblutung zu beeinflussen im Stande sind. Es wurde dabei die Grösse der Blutung einer Lungenwunde durch

1) Gerhardt, Ueber die Einwirkung von Arzneimitteln auf den kleinen Kreislauf. Verhandlungen des XX. Congresses für innere Medicin. 1902, S. 336. Wiesbaden. Bergmann. 
Vergleich des Hb-Gehalts der die Wunde berieselnden Spülflüssigrreit unter dem Einfluss von verschiedenen Stoffen verfolgt. Wenn auch die Resultate eindeutig in Bezug auf die Beurtheilung des Einflusses eines Mittels auf die Blutung - und zwar auch auf die Lungenblutung des Kranken (s. u.) — sind, so ist ihre Auslegung in physiologischer Hinsicht nur im Verein mit den schon ermittelten Aenderungen des Druckes in der Lungenarterie möglich. Und ich möchte hier nochmals betonen, dass diese Art der Untersuchung, d. h. die angewandto Methodik, lediglich eine Erweiterung unserer Kenntniss darstellen soll, dass diese Versuchsanordnung aber nur die Menge Blut bestimmt, die in der Zeiteinheit durch die Lunge fliesst, aber keinen Aufschluss über die Gefässweite ete. für sich allein zu geben im Stande ist.

Ich war bestrebt, einige objective Werthe zahlenmässig zu ermitteln und ihre zeitlichen Aenderungen festzustellen, um eine Beurtheilung zu ermöglichen, besonders da es sich um die Anwendung einer Methode handelt, die nicht allgemein üblich ist und die ich von Lisin ${ }^{1}$ ) übernahm. Anfangs glaubte ich, dass diese Methode nur approximative Werthe liefert, uud war erstaunt, wie sich die Fehlergrössen als relativ klein erwiesen. Eine kurze Discussion der Resultate habe ich an die Versuche angeschlossen, weil die Beurtheilung der Ausschlaggrösse, der eventuellen Fehlerquellen Sache der Frfahrung sind. Auf der anderen Seite habe ich von der Vornahme grösserer Untersuchungsreihen dann Abstand nehmen zu können geglaubt, wenn deutliche Ausschläge nach einer bestimmten Richtung sich nicht zeigten, weil in diesen Fällen die angewandte Methode eine constante und darum bindende Antwort zu geben nicht versprach.

\section{Zur Methodik.}

Aufschluss über die Blutdurchströmung der Lunge können wir auf zwei Wegen erhalten, einmal direct, indem wir die Blutmenge messen, welche aus einer Lungenvene strömt, oder die Blutung verfolgen, welche aus einer Wunde der Lunge stattfindet, zweitens indirect dadurch, dass wir die Factoren bestimmen, welche die Blutdurchströmung beherrschen, nämlich den Blutdruck in der Pulmonalarterie und die Weite der Lungengefässe. Da nun die letztere nicht zu ermitteln ist, so kann man auf den Contractionszustand oder vielmehr auf Aenderungen desselben nur dann schliessen, wenn man die Druckschwankungen in der Pulmonalis, also den Druck vor dem in Rede stehenden Gefässgebiet, mit denen im linken Vorhof, also dem Druck hinter dem betreffenden Gefässgebiet, vergleicht. Selbst mit dieser umfassenden Methode lässt sich aber ein absolut sicherer Schluss auf die Gefässweite nicht ziehen. Denn wenn man den Druck in der Arteria pulmonalis - also vor der Lunge steigen und den im linken Vorhof - also hinter der Iunge - sinken sieht, und daraus den Schluss auf eine Gefässcontraction zieht, so lässt

1) F. Lisin, Recherches expérimentales sur les médicaments cardiovasculaires. Archives internat. de Pharmacodynamie et de Thérapie. 1907. Bd. XVIl. Heft 5-6. S. 465 . 
sich dagegen noch cinwonden, dass cine Steigerung der Herzarbeit dieselbe Folge haben muss: erhöhte Thätigkeit des roehten Ventrikels fördert mehr Blut in die Lungenarterie und der linke Ventrikel schöpft bei gesteigerter Leistung mehr Blut aus dem Vorhof. Steigen beide Drucke, in der Lungenarterie und im linken Vorhof, so handelt es sich wohl meist um Rückstauung vom linken Herzen her, entweder weil der linke Ventrikel bei stark erhöhtem Blutdruck in der Aorta nicht mehr alles ihm zuströmende Blut aus dem Vorhof in die Aorta weiterbefördert oder weil bei gesunkenem Blutdruek die Herzkraft erlahmt. In der That haben durch die gleichzeitige Messung des Pulmonalisdruckes und des Druckes im linken Vorhof einige Fälle von Steigerung des Pulmonalisdruckes bei gleichzeitigem Sinken des Carotisdruckes, eine Beobachtung, die man als Zeichen einer Gefässverengerung in der Lunge ansprach, ihre Erklärung als Rückstauung gefunden. In allen solchen strittigen Fällen, die man als Gefässcontraction deuten könnte, wird aber die hier angewandte Methodik, die Messung der Durchblutung der Lunge Aufschluss geben, ob nicht doch entweder eine gesteigerte Herzthätigkeit (s. o.) oder eine Rückstauung die Contraction der Lungengefässe vortäuscht. Denn es liegen beweisende Versuche für das Vorhandensein von vasoconstrictorischen Einflüssen bei den Lungengefässen nur in sehr spärlicher Zahl vor; ihr Vorhandensein scheint aber durch den Befund von Strubelli1) bewiesen, der nach Anwendung von Strophantin "Sinken des Arteriendruckes, Sinken des Druckes im linken Vorhofe, geringes Steigen des Druckes in der Arteria pulmonalis, beträchtliches Steigen im rechten Vorhofe" beobachtete, - wenn man nicht das Zusammenwirken mehrerer Ursachen annehmen will, was nicht zu gezwungen erscheint, da nur unter ganz bestimmten Umständen dic "Vasomotoren" in Aktion treten. Soviel steht fest, dass die Gefässe auf die im grossen Kreislaufe wirksamen Eingriffe (Erstickung, sensibler Reiz) nicht reagiren (Openchowski²).

\section{Versuchsanordnung.}

Um quantitativ die Aenderungen in der Grösse der Blutdurchströmung festzustellen, habe ich nach dem Vorgange Lisin's die Blutung einer Wunde durch Vergleich des Hb-Gebaltes in den einzelnen Portionen einer gerinnungshemmenden Spülflüssigkeit, mit der die Wunde berieselt wurde, verfolgt. Als Spülflüssigkeit dient eine 1 proc. Lösung von oxalsaurem Natron, die körperwarm aus einer Mariotte'schen Flasche durch cinen Gummischlauch mit Quetschschraube aus einem Glasrohr tropfte. Die abfliessende bluthaltige Flüssigkeit wird in einem Reagensrohr aufgefangen und dieses alle Minuten gewechselt. Die Bestimmung der Blutmenge geschieht in der Weise, dass die Flüssigkcit in jedem Reagensrohr auf dasselbe Volumen aufgefüllt wird und davon ein aliquoter Theil,

1) Strubell, Vasomotorische Einflüsse im kleinen Kreislaufe. Verhandlungen des XX. Congresses für innere Medicin. 1902. S. 406.

2) Openchowski, Ueber die Druckverhältnisse im kleinen Kreislạfe. Pflüger's Archiv. 27. 233. 1882. 
etwa $10 \mathrm{ccm}$, in Gläser von genau demselben Durchmesser abgemessen wird. Zweckmässig ist es, die Spülung so einzurichten, dass in schneller Tropfenfolge in der linute etwa $25 \mathrm{ccm}$ die Wunde bespülen, sodass man pro Minute nur ein Reagensrohr voll Flüssigkeit bekommt. Zum bequemen Vergleich der Hb-Lösungen ist es erforderlich, die Verdünnung beim folgenden Auffüllen auf ein bestimmtes Volumen ziemlich weit zu treiben, wenn die Spülflüssigkeit im Reagensrohr sehr dunkelroth ist, also beispielsweise auf 100 bis $150 \mathrm{ccm}$; denn der Vergleich nur wenig gefärbter Lösungen ist viel genauer als der von concentrirten. Sodann titrirt man die Blutlösungen in der Weise, dass man aus einer Bürette destillirtes Wasser solange zufliessen lässt, bis alle Flüssigkeiten in den gleichweiten Röhren die gleiche Farbenintensität - die der am wenigsten gefärbten Probe -- aufweisen. Bei der Berechnung dieser Titration bin ich so verfahren, dass ich den $\mathrm{Hb}$-Gehalt der dünnsten Lösung gleich 10 gesetzt habe. Wurden nun in einem zweiten Glase noch $5 \mathrm{ccm}$ Wasser verbraucht, d. h. zu den $10 \mathrm{ccm}$, die als aliquoter Theil von den aufgefüllten Lösungen abgemessen wurden, zufliessen gelassen, bis die Farbe beider Röhrchen die gleiche war, so wurde der Hb-Gehalt des zweiten Röhrchens gleich 15 gesetzt. Nur einige wenige Male, wo Schwankungen um das 20 fache vorkamen, habe ich die dunkleren Röhrchen gegeneinander titrirt, und sodann die helleren auch gegeneinander, und erst dann durch Auswerthung der hellen gegen die dunkle Standardlösung die Zahlen auf dieselbe Einheit umgerechnet.

Es handelt sich also dabei stets um relative Werthe, sodass nur die Zahlen eines und desselben Versuches gegeneinander Gültigkeit haben, nicht aber der Werth 10 aller Versuche dieselbe absolute Grösse bedeutet. Die Menge $\mathrm{Hb}$ in absolutem Maass zu geben, wäre ja bei den verschieden grossen Wunden zwecklos. Um Missverständnissen vorzubeugen, habe ich daher jedesmal in den Protokollen "relativer Hb-Gehalt" überschrieben.

Diese Bestimmungen des Hb-Gehaltes, also auch der Schwankungen der Blutung sind recht genau, wie man sich leicht durch öfteres Titriren derselben Ausgangslösung überzeugen kann. Jedenfalls liegen die Ungenauigkeiten der Methode auf anderem Gebiet; die Blutung selbst wird man nach den Zahlen ziemlich sicher beurtheilen können. Aber sie bleibt während der Normalperiode nicht absolut gleich, sondern zeigt häufig Schwankungen. Zunächst blutet es in den allermeisten Fällen zuerst am stärksten, und die Blutung nimmt anfangs in regelmässiger Weise, aber häufig erheblich ab. Dies beruht wohl auf Gerinnung in cinzelnen kleinen Gefässen, die auch die Berieselung mit der gerinnungshemmenden Flüssigkeit nicht ganz verhindern kann. Zum Theil mag auch eine anatomische Veränderung an dem verletzten Gefäss dazu beitragen, etwa Loslösung der Intima und Einrollung oder dergleichen. Man thut also gut, nach Anlegung der Wunde erst einige Minuten die Wunde zu bespülen, ehe man mit dem eigentlichen Versuch, der Feststellung einiger Normalwerthe, beginnt. Dies ist auch in den meisten Fällen geschehen. Dann sioht man die Blutung auf ein ungefähr gleiches Niveau sich einstellen. Manchmal findet eine weitere ganz allmähliche 
Alnahme der Blutung statt, selten nimmt die Blutung später ganz geringfügig zu. Diese Veränderungen verlaufen sehr allmählig, sind ohne Weiteres erkennbar und geben zu Täuschungen wohl kaum Anlass. Ebenso habe ich einmal bei längerer Beobachtung (1/2 Stunde) constante Normalwerthe nicht erhalten können, weil der Blutdruck regelmässige Schwankungen in Form der Traube-Hehring'schen Wellen zeigte und die Blutung ebensolche Schwankungen aufwies - wie es schien, in Abhängigkeit von denen des Blutdruckes. Aber dies rechnet ja nicht eigentlich unter die Fehler, sondern ist nur bei Beurtheilung der Blutungsgrösse heranzuzieben. Die Hauptfehlerquelle stellt wohl die Art des Bespülens dar, weshalb man sorgfältig darauf achten muss, dass die Tropfen frei auf die Wundo fallen. Dies ist leicht zu erreichen bei einer Wunde der Zunge, die ich in einigen Versuchen zum Studium des grossen Kreislaufes anlegte, dagegen schwieriger bei einer Lungenwunde, da sich die Lunge unter dem Einfluss der künstlichen Athmung hin- und her bewegt und der Brustwand so nahe liegt, dass ohne sorgfältiges Aufmerken die Spülflüssigkeit an der inneren Brustwand oder benachbarten Theilen der Lunge herabfliessen kann. Endlich muss man selbstverständlich darauf achten, dass nicht Blut aus dem grossen Kreislauf in die Spülflüssigkeit hineingeräth. Dies kann aber nur dann der Fall sein, wenn vorher nicht blutende Gefässe plötzlich unter der Wirkung eines Arzneistoffes zu bluten beginnen. Ich habe dies bei Chlorbarium und Hydrastinin beobachtet.

Die Versuchsanordnung im Einzelnen, wie ich sie an der Lunge gestaltete, war folgende:

Die Kaninchen wurden - wie früher schon - durch intravenöse Injection von/ Urethan ${ }^{1}$ ) oder durch subcutane Einspritzung von Paraldehyd tief narkotisirt. Letzterer Stoff hatte den Vortheil, dass er in den hohen Dosen, in denen er zur Verwendung kam, die Athmung lähmte, was bei Einleitung der künstlichen Athmung vơn Vortheil ist. Denn nach einer etwas zu niedrigen Gabe Urethan kann es vorkommen, dass noch spontane Athemzüge zu Beginn der künstlichen Athmung auftreten. Auf der anderen Seite zwingt Paraldehyd aus obigem Grunde manchmal zu schleuniger Einleitung der künstlichen Athmung, da häufig sehe kurze Zeit nach der subcutanen Injection die Athmung steht und der Blutdruck sich bedenklich senkt; leitet man dann schnell künstliche Athmung ein, so hebt sich der Blutdruck wieder. Ein fernerer Nachtheil des Paraldehyds ist die Schmerzhaftigkeit der subcutanen Beibringung. Sonst aber ist die Narkose sehr tief und tritt sehr prompt ein. Immerhin ist es ja nur von Vortheil, verschiedene Narcotica angewandt zu haben.

Nachdem die Narkose eingetreten ist, wird zunächst die rechte Carotis zur Blutdruckmessung blossgelegt, ebenso die linke Vena jugularis zur Injection mit einer Canüle versehen. Auf dem rotirenden Papier

1) Neuerdings haben Nerking und Schürmann (Intravenöse Narkose. Med. Klinik. 1907. No. 46. S. 1760) die Aufmerksamkeit auf dis intravenöse Urethannarkose gelerkt. 
eines Kymographions wurde der Blutdruck fortlaufend während des ganzen Versuches mit meinem vervielfältigten Quecksilbermanometer ${ }^{1}$ ) aufgeschrieben, während eine Chr Secunden markirte. Durch Ausmessen und Auszählen der Curve sind die Werthe für den Blutdruck, die Pulszahl und Pulshöhe erhalten; dabei wurde die Zahl der Pulse in 6 Secunden mit 10 multiplicirt und als "Pulse in der Minute" angegeben, die Pulshöhe direct (ohnc Multiplication mit 2) von der Curve abgelesen. Letztere Zahl hat ja nur ein relatives Interesse.

Ferner wird in die Trachea eine Canüle zur künstlichen Athmung eingeführt. Darauf wird nach Unterbindung der beiden Art. mammariae die Bauchhöhle quer unterhalb des Schwertfortsatzes eröffnet und das Sternum von einem Längsschnitt aus blossgelegt. Alsdann habe ich mit dem im folgenden Abschnitt näher beschriebenen "Pendeltrichter" die künstliche Athmung eingeleitet, durch Ablösung des Zwerchfells rom Rippenbogen beide Pleuraböhlen cröffnet und den untersten Theil des Sternums nebst Schwertfortsatz entfernt. Darauf wird das Zwerchfell quer durch Knopfnähte mit dem unteren Wundrand der Bauchdecken vernäht, sodass Leber und Magen bedeckt sind und die Bauchhöhle wieder geschlossen ist. In dem hinteren Wundwinkel, dor vom Rippenbogen einerseits, von der Naht des Zwerchfells an die Bauchdecken andererseits gebildet wird, wird ein trichterförmiges Gefïss eingenäht, welches die Spülflüssigkeit aus der Brusthöhle in ein Reagensrohr abzuleiten gestattet. Dieses Gefäss muss nahezu an dem ticfsten Punkt der Brusthöhle zu liegen kommen, wenn das Thier sich in Rückenlage befindet. Damit das trichterartige Gefäss leicht und wasserdicht befestigt werden kann, giebt man ihm eine Glockenform, wie sie z. B. das Aufsatzrohr am Kipp'schen Apparat besitzt. Non schneidet man ein kleines Stück des Zipfels eines Lungenflügels ab und bespült die blutende Fläche mit 1 proc. körperwarmer Lösung von Na. oxalicum. Um diese Spülung - - was sehr wichtig ist — in durchaus gleichmässiger Weise zu gestalten, wird durch eine Schraubenklemme der Zufluss und dureh Anwendung einer Mariotte'schen Flasche als Reservoir der Druck für den Versuch eingestellt. Es genügt das Abtragen eines kleinen Stückes von Lungengewebe; sonst kann es vorkommen, dass durch Anschneiden eines grösseren Bronchus soviel Luft austritt, dass ein Sprudeln und Schäumen der blutigen Flüssigkeit eintritt, was natürlich zur Vermeidung von Verlusten verhütet werden muss. Die künstliche Athmung wird dadurch übrigens in keiner Weise gestört.

\section{Ein Apparat zur künstlichen Athmung von Thieren, „Pendel- trichter".}

Es existiren viele gut functionirende Apparate zur künstlichen Athmung am Thier, dass ein Bedürfniss nach einem neuen Apparat in dieser Hinsicht sicherlich nicht vorliegt. Wohl aber sind immer wieder

1) Frey, Der Mechanismus der Salz- und Wasserdiurese. Pflüger's Archiv. Bd. 112. S. 18 und Der Mechanismus der Coffeindiurese. Pflüger's Arch. Bd. 115. S. 194 . 
neue Apparate beschrieben worden, welche das Ziel mit einfacheren Mitteln zu erreichen suchten. Ich erinnere nur an die Athmungsapparate von Lobmann ${ }^{1}$ ), Straub ${ }^{2}$ ) und Volhardt ${ }^{3}$. Das Prineip der künstlichen Athmung, die man durch Einblasen von Luft in die Lunge von Thieren hervorruft, ist allemal das gleiche. Man lässt die Lunge dureh die einströmende Luft ausdehnen, wobei der Druck in der Trachea steigt, und giebt nun in einem bestimmten Moment eine seitliche Oeffnung des Systems frei, sodass die Luft ausströmen kann und durch die Elasticität der Lungen (und des Thorax) eine Exspiration zu Stande kommt. Es wird also die Exspiration von der Elasticität der Lunge selbst besorgt, während die Inspiration durch Druckerhöhung in der Trachea hervorgerufen wird.

Dieses Oeffnen des Luftstromes wird bei Lohmann durch das Oeffnen eines Ventiles auf elektrischem Wege, bei Straub durch einen elektrisch betriebenen rotirenden Hahn, bei Volhardt durch das Ueberwinden eines Quecksilberventiles erreicht, wobei ein Hin- und Herströmen des Quecksilbers in geeigneten Gefässen durch das Entweichen der Luftblasen hervorgerufen, einen Rhythmus erzeugt.

Wenn ich es nun wage, einen neuen Apparat zu beschreiben, der auf dem gleichen Princip beruht und Vortheile in seiner Function vor den bisher angegebenen nicht besitzt, so geschieht es deswegen, weil die einfache Anordnung desselben leicht in jedem Laboratorium ohne nennenswerthe Kosten zu bewerkstelligen ist und mir der Apparat beim Studium der Blutdurchströmung der Lunge bei weit eröffnetem Thorax gute Dienste geleistet hat.

Es handelt sich darum, in einem continuirlichen Luftstrom, den das Wasserstrahlgebläse licfert und dem seitlich die Trachea angeschlossen ist, rhythmische Druckschwankungen hervorzurufen ${ }^{4}$ ), Druckschwankungen, deren eines Extrem 0 beträgt und deren Gipfel den Elasticitätsverhältnissen des Lungengewebes angepasst ist. Dabei kam es mir hauptsächlich darauf an, keine weitere treibende Kraft nöthig zu haben, sondern den Luftstrom selbst zum Hervorbringen der Druckschwankungen zu benutzen. Ich verband zu diesem $Z$ weck den Luftstrom endständig durch einen elastischen Gummischlauch mit einem beweglichen Gefäss, welches unten weit geöfnet in Wasser tauchte und durch das allmähliche Anfüllen mit Luft einen Auftrieb bekam, der das Gefäss zum Umkippen nach oben zwang. Auf diese Weise entweicht die Luft plötzlich, der Druck sinkt dabei auf 0 und das Gefäss pendelt wieder vermöge seiner Schwere nach unten in das Wasser hinein. Die Trachea des Thieres

1) Lohmann, Pflüger's Archiv. Bd. 106. S. 459. 1904.

2) Straub, Pflüger's Archiv. Bd. 119. 1907.

3) Volhardt, Münch. med. Wochenschr. 1908. No. 5. S. 209.

4) Auf einem ähnlichen Princip beruht der Apparat von H. Schulz (Pflüger's Archiv. Bd. 120. 1907. S. 51.) zum Messen des bei der Gährung gebildeten Gases. Auch dort wird bei einem bestimmten Druck ein V'entil elektrisch geöffnet und der Druck sinkt auf 0 . Nur dient der Apparat nicht zur Erzeugung von Druckscbwankungen im System, sondern zur exacten Aufzeichnung der gebildeten Gasmengen. 
ist dabei seitlich an den Luftstrom angesehlossen, und es treten in ihr daher die gleichen Druckschwankungen ein.

Bei Anwendung dieses Princips kommt es darauf an, das Gewicht des Gefässes so gross zu wählen, dass Druckschwankungen von ausreichender Grösse zu Stande kommen. Zweitens müssen die pendelnden Bewegungen des Gefässes regelmässig erfolgen, das Gefäss muss also zwangsläufig in eine Führung eingeschlossen sein; und drittens muss ein wirkliches Pendeln des Gefässes eintreten, es darf sich nicht in einer Mittelstellung einstellen und die zugeführte Luft in kleinen Blasen entweichen lassen, d. h. es muss die Capacität des Gefässes in cinem bestimmten Verhältniss zur einströmenden Lultmenge stehen, sodass in häufiger Folge Bewegungen des Gefässes auftreten. Ith habe alle diese Punkte empirisch ermittelt.

Fig. 1.

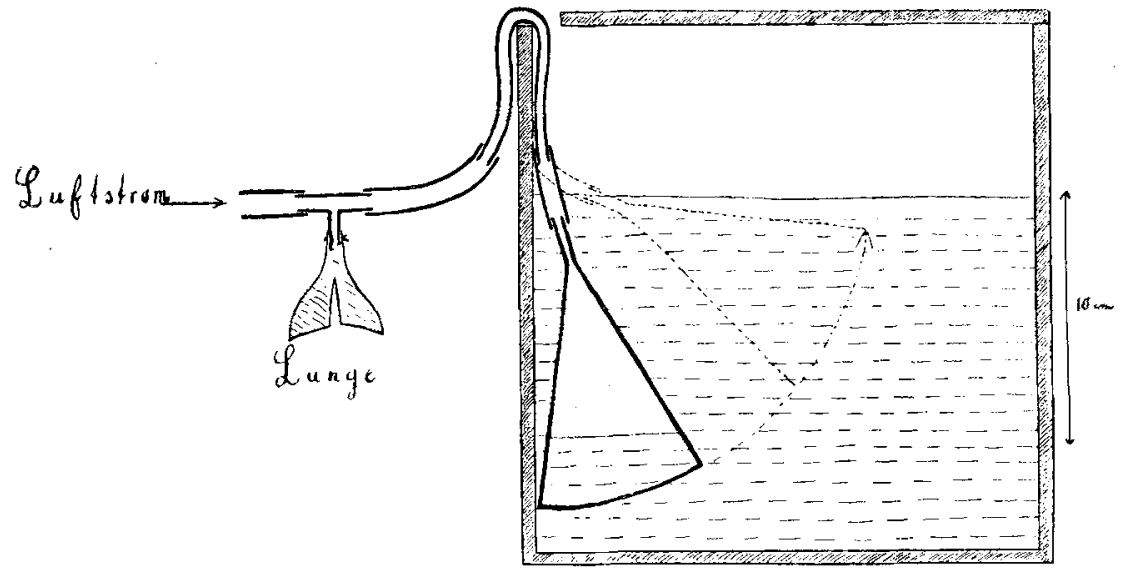

Als pendelndes Gefäss wählte ich einen Glastrichter; zur Führung desselben benutzte ich ein rechteckiges Sammlungsgefäss aus Glas, wie solche für Spirituspräparate im Handel zu haben sind. Der Querdurchmesser dieses Glaskastens muss ein wenig grösser sein als der Durchmesser des Trichters, sodass letzterer ungehindert Bewegungen in der Längsrichtung des Glaskastens ausführen kann. Das Schwierigste war das Hervorrufen regelmässiger Bewegungen des Glastrichters.

Der Luftstrom des Wasserstrahlgebläses wird durch ein gebogenes Glasrohr, welches in siedendem Wasser ruht, erwärmt, dann in eine T-Canüle geleitet, deren rechtwinklig abgebogenes Rohr in die Trachea des Thieres eingebunden wird. Der ausströmende Luftstrom wird durch einen Gummischlauch mit einem Bleirohr verbunden, welches über den Rand des Glaskastens weggeführt wird, sodass das im Innern des Glaskastens befindliche Ende des Bleirohres senkrecht nach unten in der Mitte der Querwand des Kastens sieht. Dort stellt ein gewöhnlicher Gummischlauch die Verbindung mit dem Ausflussrohr eines ungestülpten Glastrichters dar, dessen weite Oeffnung nach unten geriehtet ist. Ein Glastrichter hat sich als zweckmässiger erwiesen als ein Glasrohr und 
zwar aus dem Grunde, weil der Trichter beim Umkippen nach oben sich auf einmal schnell entleert, während ein Glasrohr in Mittelstellung kleine Luftblasen rasch hintereinander entweichen lässt, also grössere Druckschwankungen auf diese Weise nicht zu Stande kommen. Die Anwendung eines Trichters einerseits und dann des Princips des Pendelns unter Wasser ist das eigentlich Wesentliche bei der Construction des Apparates; daher habe ich ihm den Namen "Pendeltrichter" gegeben. Man kann nun die Gestalt des Trichters in verschiedener Weise modificiren; es lässt sich das Pendeln mit einem gewöhnlichen Trichter von $45^{\circ}$ erreichen, besser eignet sich ein solcher in Form eines Spitzglases, wie ihn die Abbildung zeigt. Zur Probe habe ich auch eine flache Schale mit längerem Rohr - in Form der flachen Sektschalen - verwandt, aber regelmässiges Pendeln damit nicht erreichen können. $\mathrm{Zu}$ dem Hinuntergehen in die Anfangsstellung, welches hauptsächlich durch die Schwere des (wieder mit Wasser angefüllten) Trichters hervorgerufen wird, trägt auch die Elasticität des kurzen Gummischlauches bei, der ihn mit dem Bleirohr verbindet. Wenigstens erfolgt der Herabgang bei Anwendung eines Gummischlauches viel besser als wenn man ihn durch ein leicht bewegliches drehbares Metallgelenk ersetzt, wie ich mir ein solches aus Messing habe anfertigen lassen. Endlich habe ich auch das specifische Gewicht der Flüssigkeit erhöht, indem ich eine gesättigte $\mathrm{K}_{2} \mathrm{CO}_{3}$-Jösung anwandte, die beinahe das specifische Gewicht 2 hat. Dadurch werden die Druckschwankungen in dem Luftstrom grösser; es hat sich aber - beim Kaninchen - für die Circulationsverhältnisse in der Lunge als zweckmässig erwiesen, wenn man reines Wasser anwendet, dann betragen die Druckschwankungen ungefähr $10 \mathrm{~cm}$ Wasser. Um die absoluten Maasse zu vervollständigen, sei erwähnt, dass der Trichter an seinem weiten Ende einen Durchmesser von $7 \mathrm{~cm}$ aufweist.

$$
\text { Versueh } 1 .
$$

Kaninchen, männl., $2100 \mathrm{~g}$. $7 \mathrm{cem}$ Paraldehyd subcutan.

1/2 Stunde später Operation. Künstliche Athmung nach Aufhören der spontanen eingeleitet. Künstliche $A$ thmung seit 5 Minuten.

\begin{tabular}{c|c||c|c|c}
\hline \hline Nach Min. & Blutdruck & Nach Min. & Blutdruck & Bemerkungen \\
\hline & 98 & 30 & 70 & \\
5 & 96 & 40 & 62 & Thorax eröffnet. \\
10 & 95 & 52 & 55 & \\
15 & 88 & 65 & 61 & \\
20 & 80 & 69 & 61 &
\end{tabular}

Der Apparat erweist sich also sowohl bei uneröffnetem wie eröffnetem Thorax für meine Zwecke als brauchbar.

Ich habe auch versucht, den Apparat in einer der physiologischen Athmung: mehr entsprecheuden Weise zu verwenden, indem ich bei uneröffnetem Thorax einen negativen Druck in der Trachea herstellte und durch Pendeln des Trichters die gleichen Druckschwankungen in der Lunge hervorrief. Dies gelingt leicht in der Form, dass man den Glaskasten mit einer aufgekitteten Glasplatte oben verschliesst und das Bleirohr durch eine etwas weitere Bohrung der Glasplatte hindurchleitet. Dann habe ich 
über das Loch der Glasplatte, das neben dem Bleirohr noch bequem der Luft Durchtritt gestattet, einen Trichter umgekehrt aufgekittet und nun an diesem mit der Wasserstrahlluftpumpe gesaugt. Während sich also sonst die Anordnung so gestaltet, dass zuerst das Gebläse, dann die Lunge, dann der Pendeltrichter kommt, ist die Schaltung bei letzterem Versuch so, dass der Pendeltrichter den Anfang des Röhrensystems bildet, dann die Lunge und schliesslich die Luftpumpe das System fortsetzt. Auch bei dieser Anordnung treten naturgemäss pendelnde Bewegungen auf und damit auch Druckschwankungen in der Lunge. Aber sie scheinen für eine ausreichende Ventilation nicht zu genügen. Ich habe in 2 Versuchen am uneröffneten Thorax den Apparat in der letzten Anordnung angewandt und die Thiere nicht am Leben erhalten können. Allerdings habe ich Dosen von Paraldehyd gegeben, die die Athmung lähmten, und durch solche grosse Gaben - wenigstens nach einiger Zeit - auch die Circulation leiden sehen; man muss aber die spontane Athmung vollständig ausschliessen, da sonst das Thier aus der vorbeiströmenden Luft eben selbst athmet. Dass diese Dosen des Narcoticum selbst schwer schädigend waren, geht übrigens daraus hervor, dass - wenigstens das zweite Thier - sich auch nach Einleitung ron künstlicher Athmung mit dem Handgebläse nicht erholte. Uebrigens war der Ersatz des Wassers im Glaskasten durch $\mathrm{Ka}_{2} \mathrm{CO}_{3}$-Lösung, wodurch die Druckschwankungen fast auf das Doppelte steigen, gleichgültig; ich wandte diese Modification an, weil ich zuerst meinte, der Thorax, der starrer ist als die Lunge, beanspruche auch grössere Druckschwankungen - wenigstens wenn man saugt. Dies scheint ja in der That der Fall zu sein; wenigstens genügen beim Ueberdruckverfahren Schwankungen von $10 \mathrm{~cm}$ $\mathrm{H}_{2} \mathrm{O}$, beim Unterdruckverfahren -.. also in letzterem Falle - nicht. Da mir der Apparat in der ersten Modification gute Dienste leistete, habe ich bei dem negativen Ausfall der 2 Versuche mit der zuletzt erwähnten Anordnung von der Vornahme weiterer Experimente (z. B. nach Curaresirung) abgesehen.

\section{Blutung im grossen Kreislaufe.}

Zunächst habe ich, wie das $\left.\operatorname{Lisin}^{1}\right)$ gethan hat, einige orientirende Versuche über dic Beeinflussung der Blutung einer Wunde im grossen Kreislaufe ausgeführt, um selbst ein Urtheil über die Aenderungen der Blutung unter dem Einfluss einiger Substanzen zu gewinnen. Nach Lisin ${ }^{1}$ ) wächst die Blutung aus einer Wunde mit dem Blutdruck, der Pulszahl und der Grösse der Herzschläge und erweist sich ausserdem vom Contractionszustand der Gefässe abhängig. Ich habe daher in den folgenden Versuchen die drei ersten Faktoren jedesmal gemessen, um sie bei der Beurtheilung der Ergebnisse verwenden zu können. - Die Durchblutung zeigt aber in verschiedenen Gefässprovinzen unter dem Einfluss von Arzneistoffen theils verschieden starke Aenderungen, theils sogar entgegengesetztes Verhalten, und es ist daher ein Schluss von einem Organ auf das andere unzulässig. Darauf hat schon Fr. Pick²) aufmerksam gemacht, als er die Ausflussgeschwindigkeit des Blutes aus den Venen gemessen hat. Er erstreckte daher seine Feststellungen der Durchblutung auf verschiedene Gefässregionen und bestimmte die Ausflussgeschwindigkeit in der Vena femoralis, mesenterica und jugularis bei Hunden, deren Blut defibrinirt war. Auch Lisin ${ }^{1}$ ) maass die Blutung

1) F. Lisin, Recherches expérimentales sur les médicaments cardiovasculaires. Archives internat. de Pharmac. et de Thérapie. 1907. Bd. XVII. H. 5 u. 6. S. 465.

2) Fr. Pick, Ueber die Beeinflussung der ausströmenden Blutmenge durch die Gefässweite ändernde Mittel. Archir f. exp. Path. u. Pharm. 1899. Bd. 42. S. 399. 
an zwei verschiedenen Stellen, der Lippe und dem Darm von Hunden. Ferner hat Gerhardt ${ }^{1}$ ) bei der Untersuchung des Suprarenins den Druck in der $V$. jugularis und $V$. femoralis gemessen, um die Verschiedenheiten in der Reaction der verschiedenen Gefässprovinzen - des Hirnes und der Körperperipherie - zu erweisen. Auf die Resultate der Autoren, deren Feststellungen, wic ich gleich bemerken will, sich mit den meinen decken, komme ich bei Erörterung des Einflusses dor einzelnen Stoffe zu sprechen.

Ich habe zu diesen orientirenden Versuchen die Zunge zur Anlegung einer Wunde gewählt, weil beim Kaninchen andere Gefässgebiete wohl kaum genügend Blut geliefert hätten. Die Zunge wurde, um die Spülflüssigkeit auffangen zu können, an einem Faden durch die Zungenspitze mit einer Péan'schen Klemme, deren Griffe nach oben gerichtet waren, so fixirt, dass die Spitze der Zunge den tiefsten Punkt einnahm. Auf diese Weise lief die Flüssigkeit ohne Verlust in das untergehaltene Reagensrohr. Der Kopf des Thieres, das sich in Rückenlage befand, war dabei etwas zur Seite geneigt.

Von vornherein lässt sich auch bei Mitteln, deren Wirkungsweise gut studirt ist, nicht sagen, in welchem Sinne sie die Blutung einer Wunde beeinflussen. So wird die Blutung nach intravenösen Suprareningaben trotz Erhöhung des Blutdruckes durch die starke Gefässcontraction im allgemeinen stark vermindert, und man könnte sich dies so erklären, dass die primäre Wirkung, die Gefässcontraction, über die Folge derselben, die Steigerung des Blutdruckes, obsiegt. Doch kommt dabei auch eine directe Herzwirkung des Suprarenins im Sinne einer Vergrösserung der Herzleistung in F'rage (siehe Gottlieb ${ }^{2}$ ) und Gerhardt ${ }^{3}$ ). Und Lisin ${ }^{4}$ ) hat denn auch, ebenso wie Velich5) unter besonderen Umständen eine Verstärkung der Blutung gesehen. Aber im allgemeinen scheint doch die Verminderung der Blutung ganz auffallend zu sein, und nur, wenn sich andere Gefässgebiete noch stärker contrahiren als das untersuchte, kann die Durchblutung des letzteren grösser werden.

Jedoch bei einem in anderem Sinne wirkenden Mittel wie dem Amylnitrit trifft diese Betrachtung nicht $z u$. Denn seine primäre Wirkung ist die Erweiterung der Gefässe, und dadurch kommt eine Senkung des Blutdruckes zu Stande. Es müsste also eine Wunde nach Amylnitrit-Einathmung stärker bluten als vorher. Doch sehen wir, dass eine ähnlich starke Wirkung wie nach Suprarenin - in umgekehrtem Sinne - nicht eintritt. Pick ${ }^{6}$ ) sah die Ausflussgeschwindigkeit der Körpervenen ungeändert bleiben und Lisin ${ }^{4}$ ) konnte sogar manchmal deutlich weniger Blut der Wunde entströmen sehen. Auch ich habe

1) Gerhardt, Archiv für experimentelle Path. u. Pharm. 44.

2) Gottlieb, Archiv f. exp. Path. u. Pharm. Bd. 38 u. 43.

3) Gerhardt, Archiv f. exp. Path. u. Pharm. Bd. 44.

4) Lisin, l. c.

5) Velich, Wiener med. Blätter. 1896. Citirt nach Gerhardt, Archir f. exp.

Path. u. Pharm. Bd. 44.

6) Pick, l. c. 
einmal eine ganz geringfügige Verminderung der Blutung der Zunge bemerkt. Es besteht also entweder diese Auffassung nicht zu Recht, welche die primäre Wirkung in den Vordergrund rückt, oder die schädigende Wirkung des Amylnitrits auf das Herz selbst hat einen nicht zu vernachlässigenden Antheil an der Blutdrucksenkung.

Wenn sich also schon nicht sagen lässt, nach welcher Richtung der Ausschlag erfolgen wird, wenn wir Gefässweite und Herzleistung betrachten, so kommt für den grossen Kreislauf als weitere Schwierigkeit das graduell verschiedeno Verbalten der einzelnen Gefässgebiete dazu, welches von der Beeinflussung der Blutströmung durch ein Mittel im Ganzen zu sprechen nicht gestattet, sondern immer nur die localen Aenderungen zu beurtheilen zulässt.

Versuch 2.

Kaninchen, $1700 \mathrm{~g}$. $3 \mathrm{~g}$ Urethan intravenös. Einschnitt in der Zunge.

\begin{tabular}{|c|c|c|c|c|c|}
\hline $\begin{array}{l}\text { Nach } \\
\text { Min. }\end{array}$ & $\begin{array}{l}\text { Blutdruck } \\
\text { Carotis } \\
\mathrm{mm} \mathrm{Hg}\end{array}$ & $\begin{array}{l}\text { Pulse } \\
\text { in der } \\
\text { Minute }\end{array}$ & $\begin{array}{l}\text { Pulshöhe } \\
\text { maximal } \\
\mathrm{mm}\end{array}$ & $\begin{array}{c}\text { Hb-Gehalt } \\
\text { relatir }\end{array}$ & Bemerkingen \\
\hline $\begin{array}{l}0 \\
1 \\
2 \\
3 \\
4 \\
5 \\
6\end{array}$ & $\begin{array}{l}106 \\
108 \\
132 \\
128 \\
128 \\
122 \\
120\end{array}$ & $\begin{array}{l}250 \\
250 \\
240 \\
240 \\
240 \\
230 \\
230\end{array}$ & $\begin{array}{c}1 / 2 \\
12 \\
\text { sehr klein } \\
1 / 4 \\
1 / 4 \\
1 / 4 \\
1 / 4\end{array}$ & $\begin{array}{c}10,0 \\
7,9 \\
0,301 \\
0,47 \\
0,45 \\
0,39\end{array}$ & $\begin{array}{l}\text { Blutung längere Zeit gleich. } \\
0,1 \mathrm{mg} \text { Suprarenin in die Vena jug. }\end{array}$ \\
\hline
\end{tabular}

Einige Zeit vorher hatte das Thier Salz intravenüs crhalten (s. später).

Man sieht aus diesem Versuch, dass die intravenöse Eingabe von Suprarenin sofort dic Blutung auf den dreissigsten Theil sinken Versuch 3 .

Kaninchen, weibl., 1200 g. 2 g Urethan intravenüs. Einschnitt in der Zunge.

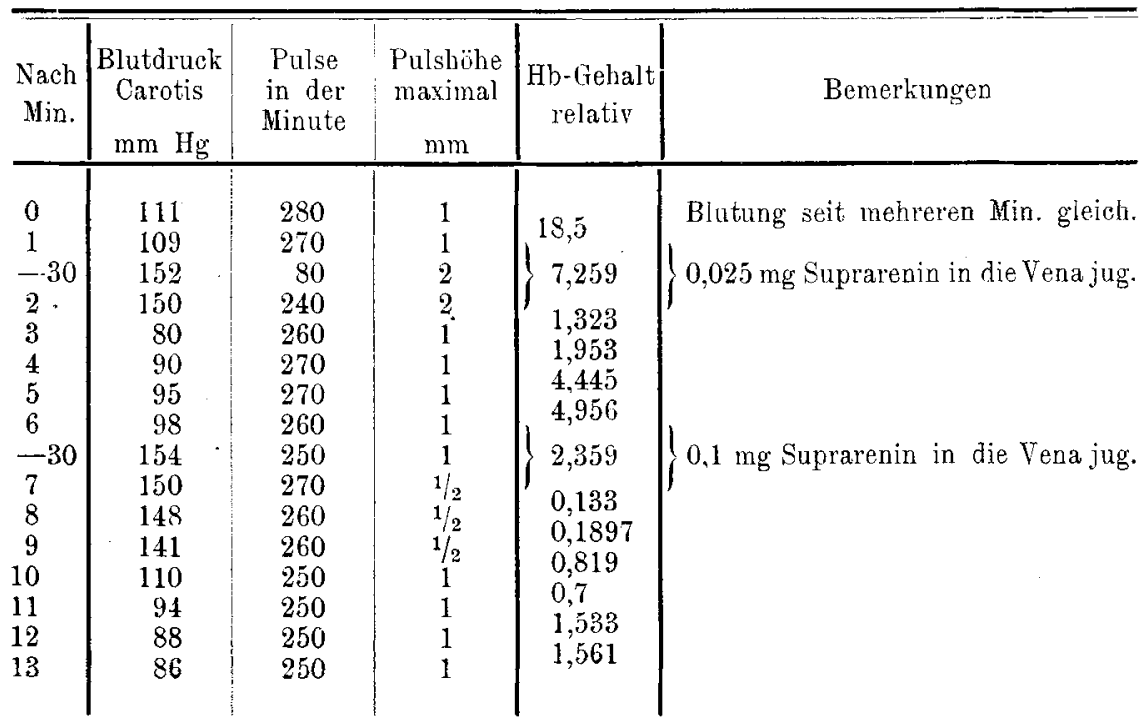

Einige Zeit vorher hatte das Thier Salz intravenüs erhalten. 
lässt. Das stimmt mit den Untersuchungen Lisin's überein, der an der Lippe und dem Darm von Hunden die Blutung verfolgte; er bezeichnet das Suprarenin als un parfait hémostatique.

Die Suprareningaben treiben auch hier (Versuch 3) den Blutdruck beide Male in die Höhe unter starker Vorminderung der ausfliessenden Blutmenge. Erst mit dem Absinken des Blutdruckes wird auch die Blutung wieder bedeutender. Der Blutdruck steigt nach der kleinen und nach der grossen Gabe ungefähr gleich hoch, nur dauert dic Steigerung bei der grossen Gabe länger. Die relative Verminderung der Blutung ist nach der grösseren Menge Suprarenin bei wcitem erheblichor als nach der Injection der kleineren Dosis.

Vorsuch 4.

Kaninchen, männl., $1250 \mathrm{~g}$. 1,8 g Urethan intravenös. Die Zunge blutet.

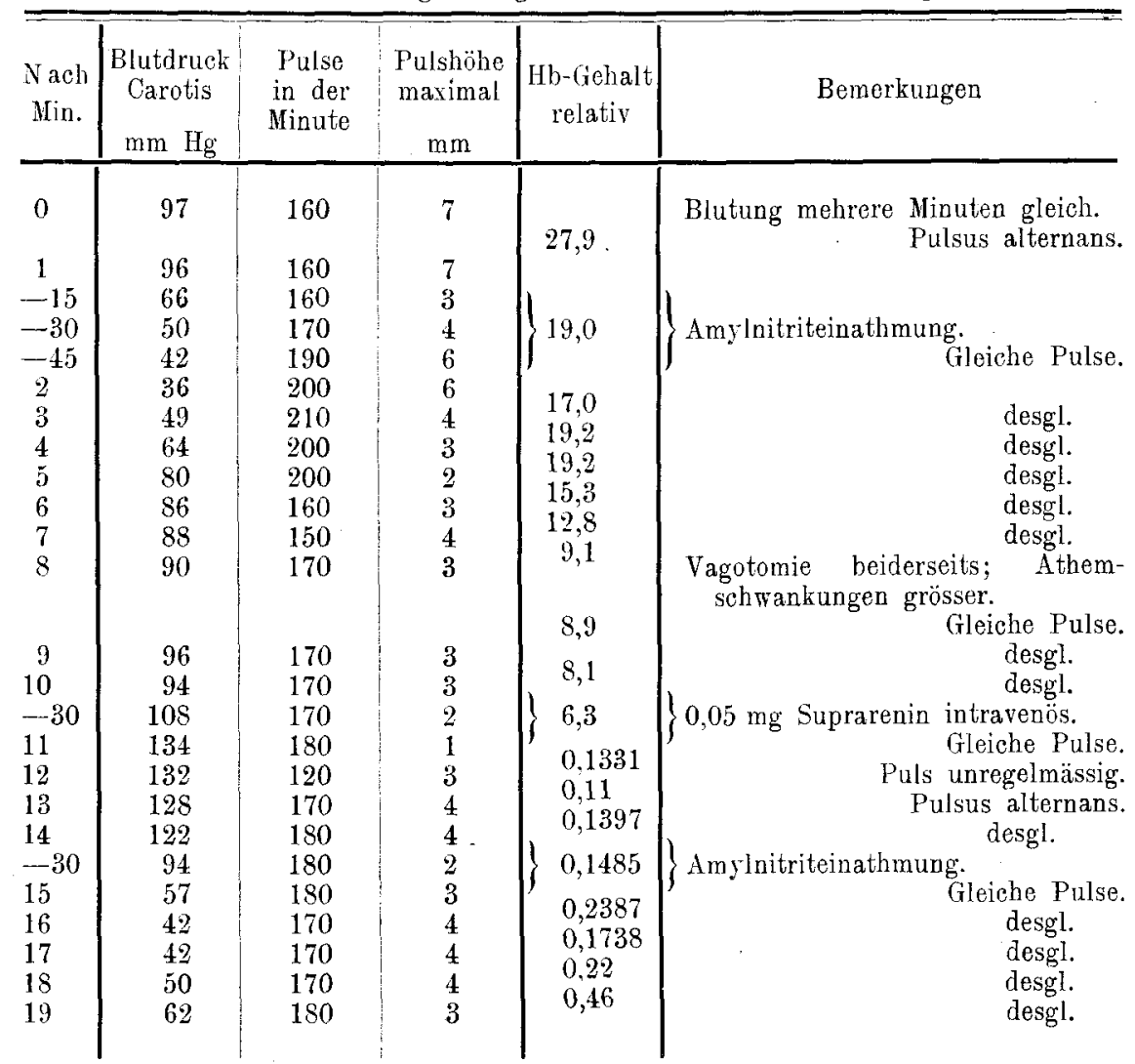

Einige Zeit vorher hatte das Thier Salzlösung intravenös erhalten.

Die zweite Substanz, deren Wirkung auf eino Blutung im grossen Kreislauf ich kurz prüfte, ist $\Lambda$ mylnitrit. Es lässt dic eingeleitete Amylnitrit-Einathmung den Blutdruck stark sinken. Der Einfluss auf die Blutung aus der Zunge ist dagegen sehr gering. Fine kleine Delle nach unten macht sich auf der auch sonst schon fallenden Curve der Blutung bemerkbar. Es scheint also im grossen Ganzen dieselbe Menge Blut in der Zeiteinheit die Organe (wenigstens die Zunge) zu durch- 
fliessen, indem die beiden im entgegengesetzten Sinne auf die Blutströmung wirkenden Veränderungen, die Abnahme der treibenden Kraft einerseits und die Abnahme des Widerstandes andererseits sich compensiren. Lisin ${ }^{1}$ ) hat mitunter deutlichere Ausschläge im Sinne einer Abnahme der Blutung, die in dem eben angeführten Versuch nur angedeutet ist, gesehen, während Fr. $\mathrm{Pick}^{2}$ ), wie gesagt, aus den Körpervenen wenigstens, den Austluss ungeändert fand.

Im Verfolg der Wirkung des Suprarenins hat Lisin ${ }^{1}$ ) in einem Versuch beobachtet, dass nach Durchschneidung der Vagi die Blutung nach Suprarenin zunahm. Dies könnte nun darauf beruhen, dass hier an der Blutdrucksteigerung die Herzwirkung des Suprarenins einen bedeutenden Antheil hätte, worauf Gottlieb ${ }^{3}$ ) und Gerhardt*) aufmerksam gemacht haben. Es ist sehr wohl denkbar, dass die beiden Factoren in quantitativ wechselnder Weise an der Blutdrucksteigerung betheiligt sind, indem einmal die Gefässcontraction überwiegend wäre, das andere Mal die Steigerung der Herzleistung. Das Verhalten des Blutdrucks könnte dabei beide Vlale das gleiche sein, aber im ersten Fall würde eine Blutung authören, im zweiten vermehrt werden. Häufiger scheint nun die Gefässcontraction nach Suprarenin den Ausschlag zu geben; denn in dem hier angeführten Versuche ist auch bei durchtrennten Vagi prompt ein Absinken der Blutmenge aus der Wunde eingetreten. Jedenfalls ist der Befund Lisin's in dieser Richtung nichts Gesetzmässiges. Sodann hat der Autor nach vorhergehender Atropineingabe am Darm die Blutung durch Suprarenin steigern können. Hierbei spielt wohl die graduell verschiedene Gefässconstriction in verschiedenen Gebieten eine Rolle, und man könnte an eine schon vorher durch das Atropin gesetzte Gefässverengerung im Splanchnicusgebiet denken, was so fern ja nicht liegt; denn die Erregbarkeit des Vasomotorencentrums nimmt nach Atropin zu. Dann würden sich die schon verengten Gefässe des Unterleibes relativ weniger zusammenziehen als die Gefässe der Peripherie, was eine Zunahme der Blutung wohl erklären könnte, cine Zunahme gegenüber der unter Atropinwirkung festgestellten Normalzahl. Denn durch dic relativ grössere Contraction der anderen Gefässe auf Suprarenin würde der Blutdruck in die Höhe getrieben, und durch das schon verengte Splanchnicusgebiet treibt der höhere Blutdruck mehr Blut als vorher hindurch. - Der späteren Einwirkung von Amylnitrit in dem obigen Versuch, wodurch der Blutdruck stark sinkt, möchte ich betreffs ihres Einflusses auf dic Blutung keine Auslegung geben, da die Verhältnisse sich zu complicirt gestalten. Immerhin geht soviel aus den gewonnenen Zahlen hervor, dass ein nennenswerther Linfluss auf die Blutung dem Amylnitrit nicht zukommt, selbst wenn es auf ein verengtes Gefässsystem zur Wirkung kommt, wo seine Beeinflussung der Gefässe sich noch stärker geltend machen kann als in der Norm.

1) Lisin, 1. c.

2) Fr. Pick, 1. c.

3) Gottlieb, l. c.

4) Gerhardt, Archiv für exp. Path. u. Pharm. Bd. 44. 
Die Blutdurchströmung der Lunge unter dem Einfluss einiger Arzneistoffe ete. 23

Versuch 5.

Kaninchen, weibl, 1900 g. 4,0 g Urethan intravenös. Die Zunge blutet.

\begin{tabular}{|c|c|c|c|c|c|}
\hline $\begin{array}{c}\text { Nach } \\
\text { Min. }\end{array}$ & $\begin{array}{c}\text { Blutdruck } \\
\text { Carotis } \\
\mathrm{mm} \mathrm{Hg}\end{array}$ & $\begin{array}{l}\text { Pulse } \\
\text { in der } \\
\text { Minute }\end{array}$ & $\begin{array}{c}\text { Pulshöhe } \\
\text { maximal } \\
\mathrm{mm}\end{array}$ & $\begin{array}{c}\text { Hb-Gehalt } \\
\text { relativ }\end{array}$ & Bemerkungen \\
\hline $\begin{array}{l}0 \\
1 \\
2 \\
21 / 4 \\
23 / 4 \\
3 \\
31 / 2 \\
4 \\
5 \\
6 \\
7 \\
8\end{array}$ & $\begin{array}{r}116 \\
118 \\
118 \\
110 \\
61 \\
138 \\
157 \\
143 \\
124 \\
117 \\
116 \\
118\end{array}$ & $\begin{array}{l}320 \\
300 \\
310 \\
330 \\
- \\
220 \\
- \\
250 \\
250 \\
230 \\
260 \\
260\end{array}$ & $\begin{array}{l}1 / 2 \\
1 / 2 \\
1 / 2 \\
1 / 2 \\
\frac{1}{1} \\
\frac{1}{1 / 2} \\
12 \\
11 / 2 \\
1 / 2 \\
1 / 2\end{array}$ & $\left\{\begin{array}{l}48,8 \\
45,1 \\
29,3 \\
10,0 \\
11,5 \\
13,3 \\
13,3 \\
12,6\end{array}\right.$ & $2 \mathrm{ecm} 1$ proc. $\mathrm{BaCl}_{2}$ in die Vena jug. \\
\hline
\end{tabular}

Versuch 6.

Kaninchen, männl., 1600 g. 3 g Urethan intravenös. Einschnitt in der Zunge.

\begin{tabular}{|c|c|c|c|c|c|}
\hline $\begin{array}{c}\text { Nach } \\
\text { Min. }\end{array}$ & $\begin{array}{c}\text { Blutdruck } \\
\text { Carotis } \\
\mathrm{mm} \mathrm{Hg}\end{array}$ & $\begin{array}{l}\text { Pulse } \\
\text { in der } \\
\text { Minute }\end{array}$ & $\begin{array}{c}\text { Pulshöhe } \\
\text { maximal } \\
\mathrm{mm}\end{array}$ & $\left|\begin{array}{c}\text { Hb-Gehalt } \\
\text { relativ }\end{array}\right|$ & Bemerkungen \\
\hline $\begin{array}{c}0 \\
1 \\
2 \\
3 \\
-30 \\
4 \\
5 \\
6 \\
7 \\
8 \\
9 \\
10\end{array}$ & $\begin{array}{l}126 \\
127 \\
126 \\
126 \\
166 \\
158 \\
151 \\
150 \\
144 \\
144 \\
136 \\
135\end{array}$ & $\begin{array}{l}220 \\
220 \\
220 \\
230 \\
240 \\
230 \\
220 \\
230 \\
230 \\
230 \\
220 \\
230\end{array}$ & $\begin{array}{l}2 \\
2 \\
2 \\
2 \\
3 \\
3 \\
3 \\
3 \\
3 \\
3 \\
3 \\
3 \\
3\end{array}$ & $\begin{array}{r}16,3 \\
19,3 \\
16,5 \\
15,8 \\
12,4 \\
10,0 \\
12,3 \\
12,5 \\
13,9 \\
13,7\end{array}$ & $2 \mathrm{cem} 1$ proc. $\mathrm{BaCl}_{2}$ in die Vena jug. \\
\hline
\end{tabular}

Ein Mittel, welches wie Suprarenin die Gefässe zur Contraction bringt, ist Bariumchlorid. Wie die beiden vorhergehenden Versuche lebren, sind auch die Folgen der Gefässverengerung dieselben: Steigen des Blutdruckes und Sinken der ausfliessenden Blutmenge. Doch ist der Einfluss des Bariums auf die Blutung bei Weitem nicht so erheblich wie die des Suprarenins. Er tritt zwar deutlich horvor, aber nicht entfernt in der Stärke, wie man ihn nach Nebennierenextract sieht. Zum Schluss bemerkt man in allen Versuchen (auch den späteren an der Thoraxmusculatur) wieder eine Zunahme der Blutung. Auch Pick ${ }^{1}$ ) sah die Blutmenge, die aus der $\mathrm{V}$. femoralis ausfloss, nach Bariumchlorid etwas abnehmen, nur im ersten Noment nach der Injection floss mehr Blut aus, ein Zeichen, dass zuerst dic Blutdrucksteigerung über die Gefässcontraction überwiegt, wenn man an den Einfluss beider auf die Blutströmung denkt. Dies liegt vielleicht an dem sich häufig

1) Pick, Archiv f. exp. Path. u. Pharm, 1899. Bd. 42. S. 433. 
ändernden Pulsbild während des Ansteigens des Blutdruckes. Eine Andeatung dieses Verhältnisses, d. h. ein geringes Zunehmen der Blutung vor der deutlicheron Verminderung kann man aus den folgenden Versuchen 10 und 11 entnehmen, wenn man auf kleine Ausschläge Werth legen will.

VI. Verschiedenheit in der Wirkung der gefässverengernden Mittel, je nachdem, ob es sich um eine schon stehende Blutung oder eine noch blutende Wunde handelt.

Bei den späteren Versuchen mit $\mathrm{BaCl}_{2}$ an der blutenden Lunge habe ich beobachtet, dass die Muskelwunde an der Aussenseite des Thorax, die längst nicht mehr blutete, wieder zu bluten begann, wenn man $\mathrm{BaCl}_{2}$ injicirte. Es erinnert dieser Befund an die Mittheilung von Velich und Gerhardt (siehe Gerhardt'), dass Muskelwunden oder Hautwunden nach Suprarenineingabe stärker bluteten. Es widersprechen sich also diese Beobachiungen, dass gefässverengende Stoffe die Blutung (an der Zunge) abnehmen lassen und andererseits (an dem Thorax) wieder entfachen.

Das könnte einmal an der Verschiedenheit der untersuchten Stellen liegen, sodann aber an dem Umstande, dass in dem einen Falle die Wunde wegen des Spülens mit einer gerinnungswidrigen Flüssigkeit noch

$$
\text { Versuch } 7 \text {. }
$$

Dasselbe Thier wie Versuch 6. Es wird 10 Minuten die Wunde der Zunge mit Watte comprimirt. Darauf nach 10 Minuten beträgt der Blutdruck 135 (wie vorher); Einspritzung von 2 ecm 1 proe. $\mathrm{BaCl}_{2}$; nach (im Ganzen) 101/2 Min. Blutdruck 172, nach 12 Min. 146, nach 16 Min. $142 \mathrm{~mm}$. Während der Blutdrucksteigerung bildet sich der Blutstropfen schneller an der Zungenspitze.

Um diese Beobachtung ubjectiver zu gestalten, werden darauf die Tropfen gezählt und die Zeit notirt.

\begin{tabular}{|c|c|c|c|c|c|}
\hline Nach Miv. & Blutdruck & $\begin{array}{c}\text { Tropfen fallt: } \\
=+\end{array}$ & Zeit $\mathrm{zW}$ & hen 2 Tropfen & Bemerkungen \\
\hline $\begin{array}{l}0 \\
3 \\
4 \\
51 / 2 \\
71 / 2 \\
10 \\
10^{1 / 2} \\
11 \\
111^{1 / 2} \\
14 \\
16^{1 / 2} \\
18^{1 / 2} \\
21 \\
23 \\
24 \\
25 \\
28 \\
31\end{array}$ & $\begin{array}{l}134 \\
\overline{134} \\
\overline{134} \\
132 \\
200 \\
161 \\
- \\
136 \\
140 \\
136 \\
134 \\
136 \\
200 \\
142 \\
120 \\
102\end{array}$ & $\begin{array}{l}+ \\
+ \\
+ \\
+ \\
+ \\
+ \\
+ \\
+5 \\
+ \\
+ \\
+ \\
+ \\
+ \\
+ \\
+ \\
+\end{array}$ & $\left\{\begin{array}{l}3 \\
21 / 2 \\
2 \\
21 / 2 \\
11 / 2 \\
\\
\\
21 / 2 \\
21 / 2 \\
2 \\
21 / 2 \\
2 \\
3 \\
2 \\
3 \\
3\end{array}\right.$ & $\begin{array}{l}\text { auten } \\
\text { " } \\
: \\
: \\
" \\
" \\
" \\
" \\
" \\
" \\
"\end{array}$ & 2 ecm 1 proc. $\mathrm{BaCl}_{2}$. \\
\hline
\end{tabular}

1) Gerhardt, Archiv f. exp. Path. u. Pharm. Bd. 44. S. 176. 
blutete, im anderen Fall aber schon aufgehört hatte zu bluten. Damn würde dic Wirkung eines Stoffes verschieden sein, je nachdem er auf eine Blutung einwirkt oder auf Gerinnselpfröpfe.

Zunächst suchte ich den Einfluss der gefässverengenden Stoffe, welche die Blutung einer Zungenwunde beim Bespülen mit oxals. Na, herabsetzen, auf die Blutung derselben Stelle ohne Spülung feststellen. Ich beobachtete daher die Wirkung von $\mathrm{BaCl}_{2}$-Lösung auf dieselbe Wunde der Zunge, die vorher in Versuch 5 beim Bespülen nach $\mathrm{BaCl}_{2}$ ein Nachlassen der Blutung gezeigt hatte. Jetzt ohne Spülung blutet die Wunde nach der ersten Injection stärker.

Nach der zweiten lnjection bleibt die Vermehrung der Blutung aus. Ich glaubte anfangs, dies liege daran, dass die Wunde eben noch blutet und so hinsichtlich ihres Gerinnungszustandes in der Mitte steht zwischen den bciden Extremen, bespülte Wuode und geronnene Wundfläche. Aber auch an garnicht mehr blutenden Wunden erwies sich Suprarenin und $\mathrm{BaCl}_{2}$ nicht immer als blutungsverstärkend, wie der folgende Versuch lehrte.

Versueh 8 .

Kaninchen, $1000 \mathrm{~g} .2 \mathrm{~g}$ Urethan. Einschnitt in die Zunge. Es blutet nicht mehr.

\begin{tabular}{|c|c|c|c|}
\hline $\begin{array}{l}\text { Nach } \\
\text { Min. }\end{array}$ & $\begin{array}{c}\text { Blutdruck } \\
\text { Carotis } \\
\mathrm{mm} \mathrm{Hg}\end{array}$ & Wunde & Bemerkungen \\
\hline 0 & 100 & blutet nicht & \\
\hline 5 & 98 & desgl. & \\
\hline 10 & 101 & desgl. & $0,1 \mathrm{mg}$ Suprareniu in die Vena jugularis. \\
\hline 11 & 154 & desgl. & \\
\hline-30 & 150 & desgl. & \\
\hline 14 & 82 & desgl. & \\
\hline 15 & 50 & desgl. & $0,2 \mathrm{mg}$ Suprarenin in die Vena jugularis. \\
\hline-30 & 124 & desgl. & \\
\hline 16 & 131 & desgl. & \\
\hline 17 & 123 & desgl. & Wunde gewischt, es bildet sich cin Blutstropfen. \\
\hline 20 & 52 & desgl. & Der Blutstropfen wird nicht grösser. \\
\hline 25 & 56 & desgl. & $\begin{array}{l}\text { Der Blutstropfen ist noch nieht grösser; } 2 \mathrm{cem} \\
1 \text { proc. } \mathrm{BaCl}_{2} \text { in die Vena jugularis. }\end{array}$ \\
\hline 26 & 92 & desgl. & \\
\hline 27 & 110 & desgl. & \\
\hline 30 & 90 & desgl. & \\
\hline 35 & 90 & desgl. & Der Blutstropfen ist noch nicht grösser. \\
\hline
\end{tabular}

Endlich habe jeh noch Suprarenin bei einer blutenden, unbespülten Zungenwunde gegeben, die längere Zeit mit Watte bedeckt worden war, um eine ausgedehnte Gerinnselbildang anzuregen. Der Versueh verlief ebenfalls negativ.

Es kann also vorkommen, dass die Wirkung eines Stoffes auf dieselbe Wunde eine verschiedene ist: Die Zungenwunde, in der schon theilweise Gerinnung eingetreten ist, blutet unter der Wirkung von $\mathrm{BaCl}_{2}$ stärker, während vorher beim Bespülen mit eincr gerinnungshemmenden Flüssigkeit $\mathrm{BaCl}_{2}$ die Blutung verminderte. Doch wiederholte sich dies nicht gesetzmässig. 
Versueh 9.

Kaninchen, $2200 \mathrm{~g}$. $3 \mathrm{~g}$ Urethan intravenös. Die Zunge blutet.

\begin{tabular}{|c|c|c|c|c|}
\hline $\begin{array}{l}\text { Nach } \\
\text { Min. }\end{array}$ & $\begin{array}{c}\text { Blutdruck } \\
\text { Carotis } \\
\text { mm Hg }\end{array}$ & $\begin{array}{l}\text { Tropfen fällt: } \\
=+\end{array}$ & $\begin{array}{l}\text { Zeit zwischen } \\
2 \text { Tropfen }\end{array}$ & Bemerkungen \\
\hline $\begin{array}{l}0 \\
2 \\
3 \\
51 / 2 \\
71 / 2 \\
10^{1 / 2} \\
17 \\
\\
171 / 2 \\
18 \\
19 \\
231 / 2\end{array}$ & $\begin{array}{l}102 \\
108 \\
113 \\
114 \\
113 \\
114 \\
114 \\
\\
146 \\
174 \\
140 \\
110\end{array}$ & $\begin{array}{l}- \\
- \\
+ \\
+ \\
+ \\
+ \\
+ \\
- \\
- \\
+\end{array}$ & $\begin{array}{l}\text { Wunde abgewischt. } \\
2^{1 / 2} \text { Minuten } \\
2 \\
3 \\
6^{1 / 2} ", \\
\left\{\begin{array}{l}1 / 2 \\
\}\end{array}\right.\end{array}$ & $\begin{array}{l}0,1 \mathrm{mg} \text { Suprarenin in } \\
\text { die Vena jugularis. }\end{array}$ \\
\hline
\end{tabular}

Auf der anderen Seite bestimmte ich die Blutung an der Thoraxmusculatur während der Spülung unter dem Einfluss von $\mathrm{BaCl}_{2}$, dessen blutungsbegünstigende Wirkung an dieser Stclle ich mehrfach beobachtet hatte. Damit entschied jch auch die Frage, ob die verschiedenen Gefässgebiete der Zunge und der Thoraxmusculatur sich gegenüber $\mathrm{BaCl}_{2}$ verschieden verhalten. Es wurde in eine Hauttasche das trichterähnliche Gefäss (s. o.) eingenäht, sodass die Spülflüssigkeit quantitativ in ein vorgelegtes Reagensrohr lief.

Versuch 10.

Kaninchen, $2000 \mathrm{~g} .2 \mathrm{~g}$ Urethan intravenös. Die Thoraxmusculatur blutet.

\begin{tabular}{c|c|c|c|c|c}
\hline \hline Nach & $\begin{array}{c}\text { Blutdruck } \\
\text { Carotis }\end{array}$ & $\begin{array}{c}\text { Pulse } \\
\text { in der }\end{array}$ & $\begin{array}{c}\text { Pulshöhe } \\
\text { maximal }\end{array}$ & $\begin{array}{c}\text { Hb-Gehalt } \\
\text { relativ }\end{array}$ & Bemerkungen \\
Min. & mm Hg & Minute & mm & & \\
\hline 0 & 92 & 250 & 3 & 19,0 & \\
1 & 93 & 230 & 3 & 18,0 & 2 ccm 1 proc. $\mathrm{BaCl}_{2}$ in die Vena jug. \\
2 & 88 & 230 & 3 & & \\
-15 & 106 & 220 & 4 & & \\
-30 & 134 & 160 & 7 & 19,7 & \\
-45 & 148 & 170 & 5 & & \\
3 & 145 & 150 & 7 & 12,3 & \\
4 & 124 & 170 & 4 & 11,8 & \\
5 & 92 & 180 & 4 & 10,6 & 2 ccm 1 proc. $\mathrm{BaCl}_{2}$ in die Vena jug. \\
6 & 84 & 190 & 3 & & \\
-15 & 94 & 180 & 2 & 1 & \\
-30 & 94 & 160 & 3 & 10,0 & \\
-45 & 114 & 140 & 4 & & \\
7 & 126 & 150 & 5 & 10,6 & \\
8 & 116 & 160 & 4 & 11,0 & \\
9 & 112 & 160 & 6 & 13,0 &
\end{tabular}

Man sieht in den Versuchen 10 u. 11, dass die ausfliessende Blutmenge nach $\mathrm{BaCl}_{2}$-Injection abnimmt. Diese Abnahme ist nicht sehr bedeutend und deckt sich ganz und gar in der Grösse mit der Blutungsverminderung durch $\mathrm{BaCl}_{2}$ an der Zunge. Es verhalten sich also beide Gefässgebiete 
Die Blutdurchströmung der Lunge unter dem Einfluss einiger Arzneistoffe etc. 27

Versueh 11.

Kaninchen, $2200 \mathrm{~g}$. $3 \mathrm{~g}$ Urethan intravenös. Wunde der Thoraxmusculatur.

\begin{tabular}{|c|c|c|c|c|c|}
\hline $\begin{array}{c}\text { Nach } \\
\text { Min. }\end{array}$ & $\begin{array}{c}\text { Blutdruck } \\
\text { Carotis } \\
\mathrm{mm} \mathrm{Hg}\end{array}$ & $\begin{array}{l}\text { Pulse } \\
\text { in der } \\
\text { Minute }\end{array}$ & $\begin{array}{c}\text { Pulshöhe } \\
\text { maximal } \\
\mathrm{mm}\end{array}$ & $\begin{array}{c}\mathrm{Hb} \text {-Gehalt } \\
\text { relativ }\end{array}$ & Bemerkungen \\
\hline $\begin{array}{c}0 \\
1 \\
2 \\
-30 \\
3 \\
4 \\
5 \\
6 \\
7 \\
8 \\
9 \\
10\end{array}$ & $\begin{array}{r}95 \\
94 \\
95 \\
111 \\
116 \\
114 \\
109 \\
106 \\
106 \\
104 \\
104 \\
99\end{array}$ & $\begin{array}{l}230 \\
230 \\
220 \\
160 \\
160 \\
150 \\
150 \\
150 \\
150 \\
130 \\
120 \\
100\end{array}$ & $\begin{array}{l}1 \\
1 \\
2 \\
2 \\
2 \\
3 \\
3 \\
4 \\
4 \\
5 \\
5 \\
5\end{array}$ & $\begin{array}{r}11,2 \\
11,2 \\
12,5 \\
10,0 \\
10,0 \\
13,3 \\
10,0 \\
10,0 \\
12,9 \\
20,4\end{array}$ & $1,5 \mathrm{ccm} 1$ proc. $\mathrm{BaCl}_{2}$ in die V. jug. \\
\hline
\end{tabular}

im vorliegenden Falle gleich. Und ebenso wie oben an der Zunge die Verschicdenheit der Bariumwirkung auf die Blutung sich ergeben hat, so sieht man auch an der Thoraxmusculatur dasselbe Verhalten der Blutung nach $\mathrm{BaCl}_{2}$ : Die bespülte blutende Muskelfäche lässt weniger Blut ausströmen, die geronnene Wundfläche dagegen fängt wieder zu bluten an.

Die zufällige Beobachtung, dass dic Muskelwunde nach $\mathrm{BaCl}_{2}$-Gaben wieder zu bluten anfängt, habe ich noch durch einen darauf gerichteten Versuch bestätigen wollen.

Versueh 12.

Kaninchen, männl., 2500 g. 4,5 g Urethan intrarenös. Wunde der Thoraxmusculatur.

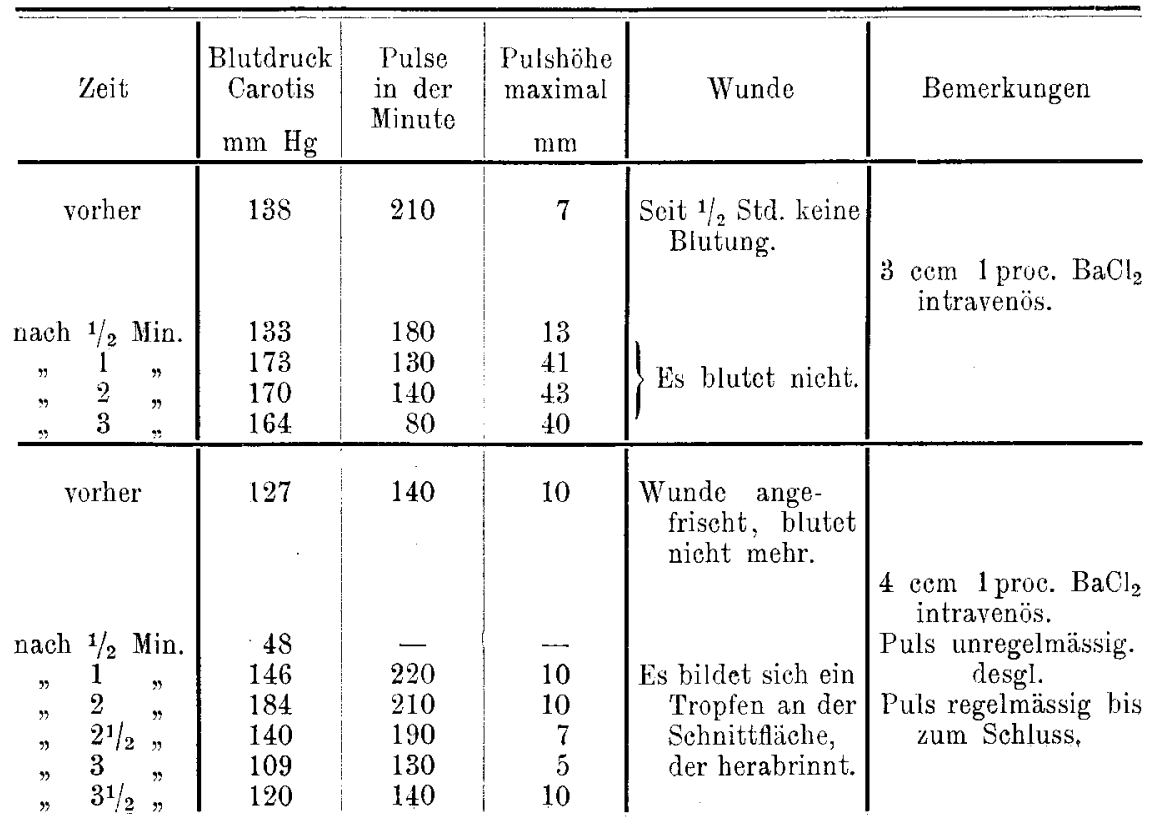


Das erste Mal trat an der geronnenen Wundfäche keine Blutung ein, das zweite Mal begann sie wieder zu bluten. Es bestätigt sich also auch hier am Thorax die oben an der Zunge gemachte Beobachtung, dass die Wiederanfachung der Blutung durch Nittel, die sie an der bespülten, also noch blutenden Wunde vermindern, eintreten kann, aber nicht muss.

Wenn wir nach einer Erklärung dieser - meines Wissens noch nirgends erwähnten - Erscheinung suchen, so liegt wohl der Grund des verschiedenen Verbaltens an der Verengerung der kleinen Gefässe, welcbe diese Stoffe verursachen und welche die Verschiedenheit des Erfolges bedingt. Bei freiem Ausströmen des Blutes muss die Blutmenge abnehmen, wenn das Kaliber der Gefässe kleiner wird. Hat sich aber in relativ weiten Gefässen ein Gerinnsel gebildet und verengt sich nun die Wand um einen solchen Pfropf, so kann es sich sehr wohl ereignen, dass die zusammenziehende Gefässmusculatur den Pfropf herausdrückt, besonders wenn der gleichzeitig erhöhte Blutdruck nachhilft und ebenfalls das Gerinnsel aus der Wunde herauszuschieben trachtet. Fester sitzende Gerinnsel werden diesen Kräften unter Umständen widerstehen können.

Jedenfalls mahnen diese Beobachtungen in praktischer Hinsicht zu Vorsicht: es ist unzulässig, die Bemühungen zur Stillung einer Blutung mit dem Bostreben gleichzustellon, eine gestillte Blutung nicht neu anzufachen. Die Stillung einer Blutung kann durch Gefässverengerung herbeigeführt werden; hat es aber aufgehört zu bluten, so hat man alles zu vermeiden, was an der Wunde eine Gefässveränderung irgend welcher Art veranlasst.

\section{Blutung im kleinen Kreislaufe.}

Die Verhältnisse des kleinen Kreislaufes liegen für das Studium der Durchblutung insofern günstiger, als nicht verschiedene Gefässprovinzen wie im Körperkreislauf in Konkurrenz treten können, sondern die Lungengefässe sich wohl unter dem Einfluss von Pharmacis gleichsinnig verhalten (siehe Gerhardt oben S. 9). Dafür weist der kleine Kreislauf jene grosse Abhängigkeit rom grossen auf. Wenn der von Basch'sche Quotient der Herzleistung - Druck in der Carotis: Druck im linken Vorhof - für die Beurtheilung der Thätigkeit der linken Kammer von Wichtigkeit ist, so haben die einzelnen Werthe für das Studium der Circulationsverhältnisse der Lunge eine ebensolche Bedeutung (Strubell ${ }^{1}$ ), da sie uns Aufschluss über eine eventuelle Rückstauung geben. Denn wir sahen schon oben, dass der Druck im Venensystem der Lunge in hohem Grade von der Thätigkeit des linken Ventrikels abhängt, während für den Druck im Arteriensystem der Lunge der Zufluss aus den Körpervenen sich wichtig erwies. - Natürlich sind dies alles nur Nebenumstände, aber sie können die Thätigkeit des rechten Ventrikels hin-

1) Strubell, Ueber vasomotorische Eintlüsse im kleinen Kreislauf. Verhandl. des XX. Congresses f. innere Medicin. 1902. S. 404. 
sichtlich des Erfolges der Blutbeförderung wesentlich beeinflussen. Openchowski ${ }^{1}$ ) hat gezeigt, dass nach Athemsuspension wie bei jeder Steigerung des Blutdruckes im grossen Kreislauf auch der Druck in der Arteria pulmonalis steigt. Diese Steigerung führt Openchowski auf eine Vermehrung des Zuflusses venösen Blutes zum rechten Herzen zurück. Andererseits hat $\mathrm{r}^{2}$ ) beobachtet, dass auch beim Abfall des Aortendruckes z. B. nach Chloralhydrat, Amylnitrit etc. eine Steigerung des Druckes in der Lungenarterie - - bedingt durch Rückstauung resultiren kann.

Wir müssen also erwarten, dass die Durchblutung der Lunge bei Steigerung des Aortendruckes ebenso wie bei Abfall desselben eine Znnahme erfahren kann, wenn auch die Ursache in beiden Fällen eine verschiedene ist.

Eine directe Wirkung von Substanzen auf die Lungengefässe ist mit absoluter Sicherheit noch nicht erwiesen worden. Dagegen hat man zejgen können, dass Stoffe, die im grossen Kreislauf stark wirksam sind, die Gefässweite des kleinen unbeeinflusst lassen, wie später noch genauer zu erwähnen sein wird. Mein Interesse für diese Frage wurde durch die zufällige Beobachtung erzeugt, dass es bei intravenösen Infusionen von Kochsalzlösung und gleichzeitigen Suprareningaben vorkommen kann, dass die Thiere an acutem Lungenödem zu Grunde gehen.

\section{Suprarenin.}

Die Wirkung des Suprarenins auf den Lungenkreislauf ist von Gerhardt ${ }^{3}$ ) und Velich ${ }^{4}$ ) studirt worden. Eine Gefässverengerung in der Lunge konnten sie nicht constatiren. Auch sah Velich die Junge nach Suprarenin nicht in ähnlicher Weise erblassen wie Gewebe dos grossen Kreislaufes. Die beiden Autoren bestimmten den Druck vor den Lungencapillaren, d. h. in der Arteria pulmonalis und gleichzeitig hinter denselben, d. h. im linken Vorhof und konnten auf diese Weise ein Bild von dem Contractionszustand der Lungengefässe erhalten. Gerhardt sah nach Suprarenin sowohl den Pulmonalisdruck als auch den Druck im linken Vorhof anwachsen. Dies könnte entweder auf einer Rückstauung vom linken Vorhof aus beruhen, indem der linke Ventrikel gegen den hohen Aortendruck nicht mehr die ihm zufliessende Blutmenge befördern kann oder auf einem vermehrten Zufluss von Blut aus den Körpervenen. Gerhardt hält das Anwachsen des Druckes im linken Vorhof und der Vena pulmonalis nicht für ausreichend zur Erklärung der relativ erheblichen Steigerung des Pulmonalisdruckes; denn nach seinen sonstigen Erfahrungen z. B. nach theilweiser Mitralverlegung bewirkt eine solch geringe Drucksteigerung im venösen Lungensystem nicht eine so ausgiebige Steigerung des Pulmonalisdruckes. Er schilesst sich daher der Ansicht Velich's an, dass die Verengerung einiger Gefäss-

1) von Openchowski, Archiv f. exp. Path. u. Pharm. 1882. Bd. 27.

2) von Openchowski, Zeitschrift f, klinische Medicin. 16.

3) Gerhardt, Archiv f. experim. Path. und Pharm. Bd. 44.

4) Velich, Wien. med. Wochenschr. Jahrg. 48. No. 26. S. 1258. 1898. 
gebiete im grossen Kreislauf durch Suprarenin und die dadurch bedingte Blutdrucksteigerung einen vermehrten Zufluss aus den grossen Venen durch weniger verengte Gefässprovinzen z. B. des Hirnes - veranlasse, sodass dem rechten Ventrikel mehr Blut zur Verfügung stehe. Nach alledem ist also eine Gefässconstriction der Lungengefässe durch Suprarenin ausgeschlossen und wie auch die Variationen des Druckes in der Pulmonalarterie zu Stande kommen - ob durch Rückstauung oder vermehrten Zufluss -, jmmer wird eine vermehrte Blutung einer Lungenwunde dadurch veranlasst werden. Wenn Tigerstedt ${ }^{1}$ ) in seiner Uebersicht über den kleinen Kreislauf betont, dass Velich nach kleinen Gaben ron Suprarenin eine Steigerung des Aortendruckes von 80 auf $260 \mathrm{~mm} \mathrm{Hg}$ beobachtete und gleichzeitig jede Erhöhung des Pulmonalisdruckes vermisste, so könnte trotzdem eine vermehrte Blutdurchströmung der Lunge als Folge des gesteigerten venösen Zuflusses zum rechten Herzen bestehen, ohne dass es bei der, wie es scheint, geringen Spannung der Lungengefässe zu einer Druckerhöhung in der Lungenarterie zu kommen brauchte. Freilich bedeutend könnte unter diesen Umständen die Vermehrung des Zuflusses nicht sein.

Dic Versuche zeigen, dass nach Suprarenininjection die Lungenwunde stärker blutet.

Versuch 13.

Kaninchen, männl., 1300 g. $4 \mathrm{ccm}$ Paraldehyd subcutan; 1/2 Stunde später Operation, künstliche Athmung. (Hierzu Curre 1).

\begin{tabular}{c|c|c|c|c|c}
\hline $\begin{array}{c}\text { Nach } \\
\text { Min. }\end{array}$ & $\begin{array}{c}\text { Blutdruck } \\
\text { Carotis } \\
\mathrm{mm} \mathrm{Hg}\end{array}$ & $\begin{array}{c}\text { Pulse } \\
\text { in der } \\
\text { Minute }\end{array}$ & $\begin{array}{c}\text { Pulshöhe } \\
\text { maximal } \\
\mathrm{mm}\end{array}$ & $\begin{array}{c}\text { Hb-Gehalt } \\
\text { relativ }\end{array}$ & Bemerknngen \\
\hline 0 & 46 & 190 & 3 & 92,2 & \\
1 & 46 & 190 & 3 & 27,0 & \\
2 & 40 & 190 & 2,5 & 22,1 & \\
3 & 39 & 190 & 2 & 15,0 & $0,3 \mathrm{ccm}$ Suprarenin (=0,3 mg) \\
-40 & 39 & 190 & 2 & & \\
-50 & 90 & - & $-5,1000)$ in die Vena jugularis. \\
4 & 128 & 230 & 0,75 & & \\
-30 & 130 & 240 & 0,75 & 38,6 & \\
5 & 122 & 230 & 0,5 & 21,9 & \\
6 & 109 & 250 & 0,5 & 10,0 & \\
7 & 93 & 230 & 0,5 & 11,5 & \\
8 & 86 & 220 & 0,5 & &
\end{tabular}

In diesem Versuch wurde die ausfliessende Blatmenge gleich nach Anlegung der Wunde bestimmt; man sieht einen starken, allmählich geringer werdenden Abfall der Curve des Blutausflusses, wohl dureh die oben auseinandergesetzten Gründe veranlasst. Trotzdem tritt die Vermehrung der Blutung nach der Suprarenininjection mit grosser Deutlichkeit hervor. Sie fällt zeitlich mit dem Anstieg des Blutdruckes zusammen.

1) Tigerstedt, Der kleine Kreislauf. Ergebnisse der Physiologie. II. Jahrg. II. Abtheil. 1903. S. 581 . 
Die Blutdurchströmung der Lunge unter dem Einfluss einiger Arzneistoffe etc. 31

Curve 1.

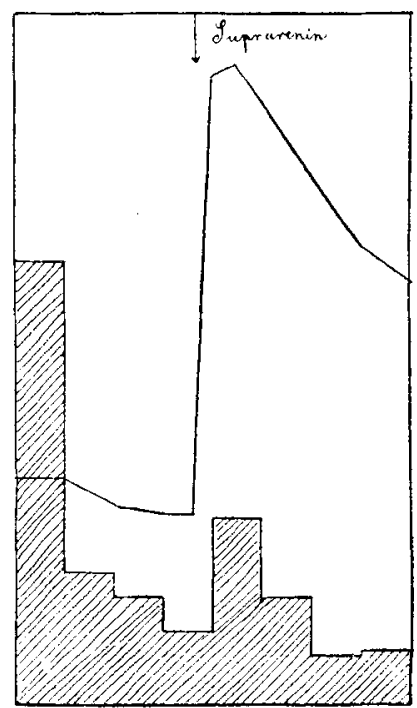

Versueh 14.

Kaninchen, männl., $1700 \mathrm{~g}$. $5 \mathrm{ecm}$ Paraldehyd subcutan. Finschnitt links. (Hierzu Curve 2).

\begin{tabular}{|c|c|c|c|c|c|}
\hline $\begin{array}{l}\text { Nach } \\
\text { Min. }\end{array}$ & $\begin{array}{c}\text { Blutdruck } \\
\text { Carotis } \\
\mathrm{mm} \mathrm{Hg}\end{array}$ & $\begin{array}{l}\text { Pulse } \\
\text { in der } \\
\text { Minute }\end{array}$ & $\begin{array}{c}\text { Pulshöhe } \\
\text { maximal } \\
\text { mm }\end{array}$ & $\begin{array}{c}\text { Hb-Gehalt } \\
\text { relativ }\end{array}$ & Bemerkungen \\
\hline $\begin{array}{l}0 \\
1 \\
2 \\
3 \\
-15 \\
--30 \\
-45 \\
4 \\
-30 \\
5 \\
6 \\
7 \\
8 \\
9 \\
10 \\
-15 \\
-30 \\
-45 \\
11 \\
-30 \\
12 \\
13 \\
14 \\
15 \\
16 \\
17 \\
18\end{array}$ & $\begin{array}{r}68 \\
68 \\
70 \\
66 \\
68 \\
75 \\
131 \\
168 \\
168 \\
164 \\
152 \\
156 \\
124 \\
111 \\
84 \\
79 \\
121 \\
154 \\
150 \\
147 \\
143 \\
136 \\
120 \\
111 \\
102 \\
95 \\
80\end{array}$ & $\begin{array}{l}210 \\
210 \\
210 \\
210 \\
200 \\
200 \\
190 \\
200 \\
200 \\
200 \\
220 \\
200 \\
200 \\
190 \\
190 \\
190 \\
200 \\
200 \\
210 \\
200 \\
210 \\
200 \\
200 \\
200 \\
190 \\
200 \\
170\end{array}$ & $\begin{array}{l}2 \\
2 \\
2 \\
2 \\
2 \\
2 \\
2 \\
1 \\
1 \\
3 \\
3 \\
3 \\
3 \\
3 \\
2 \\
2 \\
2 \\
1 \\
1 \\
1 \\
1 \\
1 \\
3 \\
3 \\
3 \\
3 \\
2 \\
2 \\
2 \\
1\end{array}$ & $\begin{array}{r}39,6 \\
51,6 \\
47,9 \\
22,1 \\
\\
44,0 \\
112,0 \\
70,2 \\
36,3 \\
18,2 \\
10,0 \\
\\
14,3 \\
\\
17,5 \\
18,4 \\
37,3 \\
18,3 \\
5,6 \\
4,9 \\
4,1\end{array}$ & $\begin{array}{l}\text { Beginn der Berieselung. } \\
0,3 \text { ccm Suprarenin } 1: 1000 \\
\quad(=0,3 \mathrm{mg}) \text { in die Vena jug. }\end{array}$ \\
\hline
\end{tabular}


Curve 2.

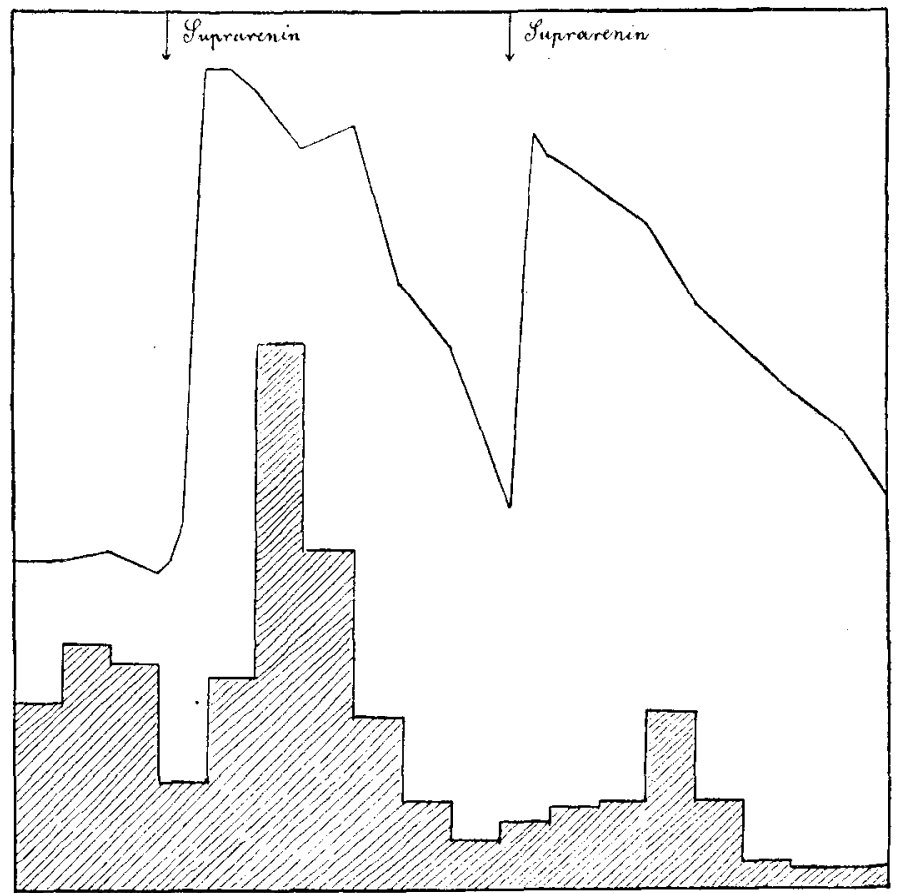

Auch in diesem Versuch trat nach beiden Suprareningaben eine starke Vermehrung der Lungenblutung ein. (Dic erste Normalzahl am Beginn der Berieselung scheint etwas zu klein zu sein.) Auffallend ist, dass diese Vermehrung das zweite Mal erst verspätet sich geltend macht. Dass die zweite Erhebung der Blutmenge geringer ist als die erste, trotz beinahe gleich grosser Blutdrucksteigerung, lässt sich quantitativ nicht verwerthen, da auch die vorhergehenden Normalzahlen der Blutung geringer sind.

Wir haben also im Suprarenin ein Mittel vor uns, dass im grossen Kreislauf die Blutung einer Wunde stark vermindert, dagegen im Lungenkreislauf eine erhebliche Steigerung der Blutung veranlasst, ein praktisch bedeutungsvoller Hinweis.

\section{Secale.}

Secale macht nach Bradford und Dean ${ }^{1}$ ) bei Senkung des Aortendruckes eine geringe, aber deutliche Drucksteigerung in der Pulmonalis. Gerhardt ${ }^{2}$ ) dagegen sah bei Anwendung von Hydrastinin und von

1) Bradford und Dean, The innervation of the pulmonary vessels. Proceedings of the Royal Society. 45. p. 369-377. 1889 und The pulmonary circulation. Journ. of physiol. 16. p. 34-96. 1894; cit. nach T'igerstedt, Der kleine Kreislauf. Erg. der Physiol. II. Jahrg. II. Abth. S. 585.1903.

2) Gerhardt, Ueber die Einwirkung von Arzncimitteln auf dem kleinen Kreislauf. Verhandl. d. XX. Congr. f. inn. Med. S. 335. 1902. 
Die Blutdurchströmung der Lunge unter dem Einfluss einiger Arzneistoffe etc. 33

Ergotin (das Extractum secalis cornut. der Pharmakopoe und das Denzel'sche Präparat) keine Blutdrucksteigerung in der Lungenarterie. Im grossen Kreislaufe jedoch beobachteten alle Autoren übereinstimmend eine Senkung des Blutdruckes. Ich habe zur Prüfung des Einflusses von Secale auf die Blutung einer Lungenwunde Secacornin und Extract. secalis cornuti fluidum verwandt und danach gleichfalls Senkung des Aortendruckes gesehen. Dabei trat eine geringe Vermehrung der Blutung einer lungenwunde ein, die wohl auf verschiedene Ursachen zurückzuführen ist.

\section{Versuch 15.}

Kaninchen, männl., 1700 g. 2,6 g Urethan intravenös. Zweiter Versuch an diesem Thier, längere Zeit nach dem ersten. (Hierzu Curve 3).

\begin{tabular}{l|c|c|c|c|c}
\hline & & & \\
Nach & $\begin{array}{c}\text { Blutdruck } \\
\text { Carotis }\end{array}$ & $\begin{array}{c}\text { Pulse } \\
\text { in der } \\
\text { Minute }\end{array}$ & $\begin{array}{c}\text { Pulshöhe } \\
\text { maximal }\end{array}$ & $\begin{array}{c}\text { Hb-Gehait } \\
\text { relativ }\end{array}$ & Bemerkungen \\
\hline mm Hg & mm & & \\
0 & 55 & 160 & 4 & 48,8 & \\
1 & 50 & 160 & 4 & 25,9 & \\
2 & 50 & 160 & 4 & 18,4 & \multirow{2}{}{} \\
3 & 50 & 150 & 4 & 28,0 & 2,0 ccm Secacornin in die Vena jug. \\
4 & 50 & 110 & 7 & 25,2 & \\
5 & 46 & 140 & 5 & 15,7 & \\
6 & 44 & 150 & 4 & 13,3 & \\
7 & 42 & 140 & 4 & 10,0 &
\end{tabular}

Curve 3.

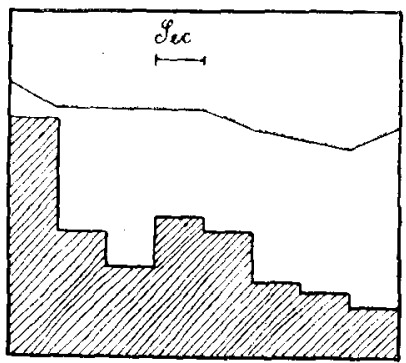

In diesem Versuch trat gleichzeitig mit der Vermehrung der Blutung der Wunde eine Verlangsamung und Vergrösserung der Pulse auf. Diese Vagusreizung beeinflusst aber die Blutung ihrerseits, und zwar ist die Wirkung der beiden erwähnten Factoren entgegengesetzt.

Man kann also aus der Aenderung der Blutung während der Vaguspulse nichts schliessen, da man nicht weiss, ob für die Blutung die Verlangsamung - in hemmendem Simne - oder die Vergrösserung der Pulse - begünstigend - maassgebender ist. Ich werde später noch ausführlich auf die Veränderungen der Blutung unter der Vaguswirkung zu sprechen kommen. Man könnte auch bei dem Sinken des Aortendruckes an eine Rückstauung denken, wenn man annimmt, dass das Herz erlahmt. Aber die Senkung des Carotisdruckes wird erst deutlich, als die Blutmenge, die der Wunde entströmt, schon wieder abnimmt. 
Versuch 16.

Kaninchen, männl., 1700 g. $2,6 \mathrm{~g}$ Urethan intravenös. Erster Versuch an diesem Thier. (Hierzu Curve 4.)

\begin{tabular}{|c|c|c|c|c|c|}
\hline $\begin{array}{l}\text { Nach } \\
\text { Min. }\end{array}$ & $\begin{array}{c}\text { Blutdruck } \\
\text { Carotis } \\
\mathrm{mm} \mathrm{Hg}\end{array}$ & $\begin{array}{l}\text { Pulse } \\
\text { in der } \\
\text { Minute }\end{array}$ & $\begin{array}{c}\text { Pulshöhe } \\
\text { maximal } \\
\mathrm{mm}\end{array}$ & $\begin{array}{c}\text { Hb-Gehalt } \\
\text { relativ }\end{array}$ & Bemerkungen \\
\hline $\begin{array}{l}0 \\
1 \\
2 \\
3 \\
4 \\
5 \\
6 \\
7 \\
8 \\
9 \\
10 \\
11 \\
12 \\
13 \\
14 \\
15 \\
16 \\
-30 \\
17 \\
18 \\
19 \\
20 \\
21 \\
22 \\
23 \\
24 \\
25 \\
26 \\
27 \\
28 \\
29 \\
30\end{array}$ & $\begin{array}{r}88 \\
90 \\
90 \\
86 \\
90 \\
86 \\
86 \\
94 \\
68 \\
66 \\
68 \\
71 \\
50 \\
44 \\
44 \\
45 \\
44 \\
50 \\
115 \\
130 \\
126 \\
122 \\
117 \\
116 \\
110 \\
106 \\
110 \\
88 \\
70 \\
79 \\
92 \\
90\end{array}$ & $\begin{array}{l}200 \\
200 \\
200 \\
210 \\
200 \\
200 \\
200 \\
170 \\
180 \\
170 \\
180 \\
180 \\
150 \\
150 \\
160 \\
160 \\
160 \\
120 \\
120 \\
120 \\
130 \\
160 \\
160 \\
150 \\
150 \\
170 \\
150 \\
140 \\
150 \\
150 \\
150\end{array}$ & $\begin{array}{l}11 / 2 \\
11 / 2 \\
11 / 2 \\
11 / 2 \\
11 / 2 \\
11 / 2 \\
11 / 2 \\
2 \\
3 \\
3 \\
3 \\
3 \\
6 \\
4 \\
4 \\
4 \\
3 \\
4 \\
4 \\
4 \\
3 \\
2 \\
2 \\
2 \\
2 \\
11 / 2 \\
11 / 2 \\
2 \\
2 \\
2 \\
2 \\
2\end{array}$ & $\begin{array}{r}15,7 \\
12,2 \\
12,5 \\
11,7 \\
10,0 \\
12,8 \\
15,1 \\
20,7 \\
17,3 \\
12,6 \\
16,4 \\
28,3 \\
26,3 \\
25,4 \\
7,7 \\
10,0 \\
20,5 \\
43,4 \\
45,7 \\
43,6 \\
29,0 \\
22,1 \\
25,9 \\
19,7 \\
2 \\
21,2 \\
30,6 \\
39,9 \\
38,8 \\
34,9\end{array}$ & $\begin{array}{l}1,5 \mathrm{cem} \text { Secacornin in die Vena jug. } \\
\text { (Ab und zu Vaguspulse.) } \\
1,5 \mathrm{ccm} \text { Secacornin in die Vena jug. } \\
2 \mathrm{ccm} 1 \text { proc. } \mathrm{BaCl}_{2} \text { in die Vena jug. }\end{array}$ \\
\hline
\end{tabular}

Curve 4.

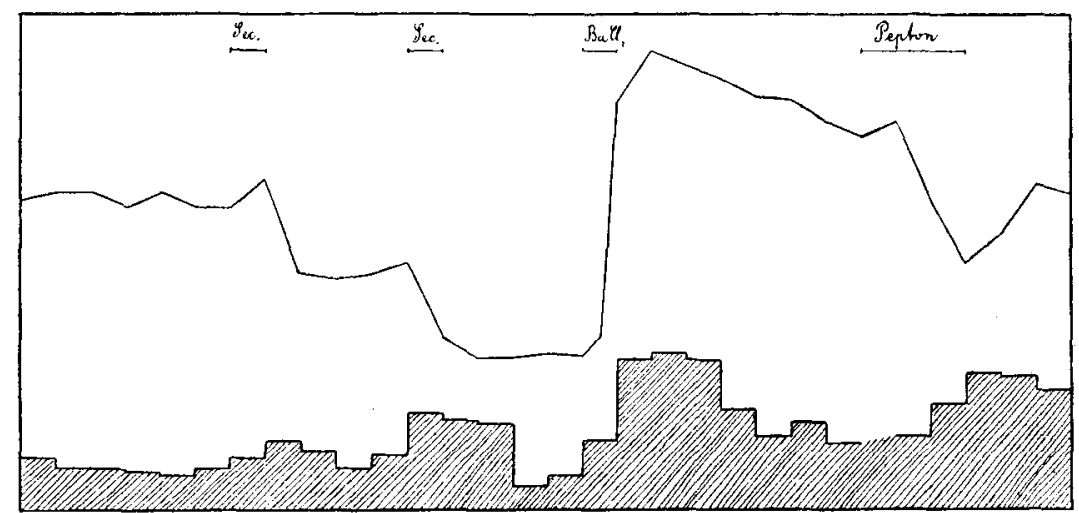

Auch hier treten gleichzeitig mit der Vermehrung der Blutung nach Secacornin Vaguspulse auf und es kommt zu einer Senkung des Blut- 
druckes im grossen Kreislaufe. Wenn auch nun durchaus nicht immer durch Vaguspulse eine Vermehrung der Blutung einer Lungenwunde hervorgerufen wird, so lässt sich andererseits ein solcher Einfluss auch nicht gänzlich ausschliessen. Immerhin ist die Verminderung der Pulszahl nicht sehr ausgesprochen, während die Vergrösserung der Pulse deutlich bemerkbar ist, mit anderen Worten, das blutungbegünstigende Moment scheint stärker hervorzutreten als das hemmende. In einem Versuch, in welchem die Blutung ciner Wunde der Zunge verfolgt wurde (Versuch No. 40, S. 61) haben sich grosse Pulse ohne gleichzeitige Frequenzänderung gezeigt: Hier ist die Blutung gestiegen. Es liegt also nahe, auch beim Auftreten solcher Erscheinungen von Seiten des Pulses nach Secacornininjection die Vermehrung der Blutung den grossen Pulsen zuzusehreiben. Sonst könnte man ja auch an Rückstauung denken, da der Blutdruck in der Carotis sinkt. Jedoch ist bei diesen Versuchen mit Secacornin ein Parallelgehen der Blutdrucksenkung mit der Blutung nicht zu beobachten. Wenn der Blutdruck seinen tiefsten Stand erreicht hat, so lässt die Blutung wieder nach. Man kann also mit einer gewissen Wahrscheinlichkeit auf die grossen Pulse als den Grund der Vermehrung der Blutung recurriren. Dies wird noch wahrscheinlicher, wenn

Versuch 17.

Kaninchen, männl., $1650 \mathrm{~g}$. 3,0 g Urethan intravenös. (Hicrzu Curve 5).

\begin{tabular}{|c|c|c|c|c|c|}
\hline $\begin{array}{l}\text { Nach } \\
\text { Min. }\end{array}$ & $\begin{array}{c}\text { Blutdruck } \\
\text { Carotis } \\
\mathrm{mm} \mathrm{Hg}\end{array}$ & $\begin{array}{l}\text { Pulse } \\
\text { in der } \\
\text { Minute }\end{array}$ & $\begin{array}{c}\text { Pulshöhe } \\
\text { maximal } \\
\mathrm{mm}\end{array}$ & $\begin{array}{c}\mathrm{Hb} \text {-Gehalt } \\
\text { relatir }\end{array}$ & Bemerkungen \\
\hline $\begin{array}{l}0 \\
1 \\
2 \\
3 \\
31 / 2 \\
4 \\
5 \\
6 \\
7 \\
8 \\
9 \\
10 \\
11 \\
12 \\
13 \\
14 \\
15 \\
16 \\
17 \\
18 \\
19 \\
20 \\
21 \\
22 \\
23 \\
24 \\
25 \\
26 \\
27 \\
28\end{array}$ & $\begin{array}{r}103 \\
126 \\
121 \\
120 \\
160 \\
196 \\
182 \\
122 \\
100 \\
94 \\
94 \\
97 \\
91 \\
92 \\
49 \\
76 \\
81 \\
81 \\
44 \\
66 \\
66 \\
66 \\
67 \\
107 \\
106 \\
100 \\
91 \\
85 \\
76 \\
76\end{array}$ & $\begin{array}{l}140 \\
130 \\
130 \\
140 \\
- \\
200 \\
170 \\
130 \\
120 \\
120 \\
120 \\
120 \\
130 \\
120 \\
130 \\
140 \\
130 \\
140 \\
130 \\
140 \\
140 \\
150 \\
150 \\
150 \\
140 \\
140 \\
150 \\
150 \\
140 \\
140\end{array}$ & $\begin{array}{l}4 \\
4 \\
4 \\
4 \\
4 \\
6 \\
4 \\
4 \\
3 \\
3 \\
3 \\
3 \\
3 \\
3 \\
2 \\
11 / 2 \\
11 / 2 \\
3 \\
21 / 2 \\
3 \\
3 \\
3 \\
3 \\
3 \\
3 \\
3 \\
21 / 2 \\
21 / 2 \\
21 / 2\end{array}$ & $\begin{array}{c}13,6 \\
10,0 \\
11,0 \\
20,3 \\
39,7 \\
34,0 \\
32,0 \\
30,6 \\
25,4 \\
21,5 \\
22,0 \\
18,1 \\
14,0 \\
16,5 \\
14,7 \\
15,1 \\
20,3 \\
23,5 \\
21,6 \\
19,6 \\
19,8 \\
29,8 \\
34,0 \\
34,2 \\
33,9 \\
25,5 \\
22,5 \\
19,0\end{array}$ & $\begin{array}{l}1 \mathrm{ccm} \text { Extr. secalis fluid. in die V.jug. } \\
2 \text { cem Extr. secalis fluid, in die V.jug. } \\
2 \mathrm{ccm} 1 \text { proc. } \mathrm{BaCl}_{2} \text { in die Vena jug. }\end{array}$ \\
\hline
\end{tabular}


wir den nächsten Versuch betrachten, in welchem ich Extractum sec. corn. fluid. intravenös gab.

Curre 5.

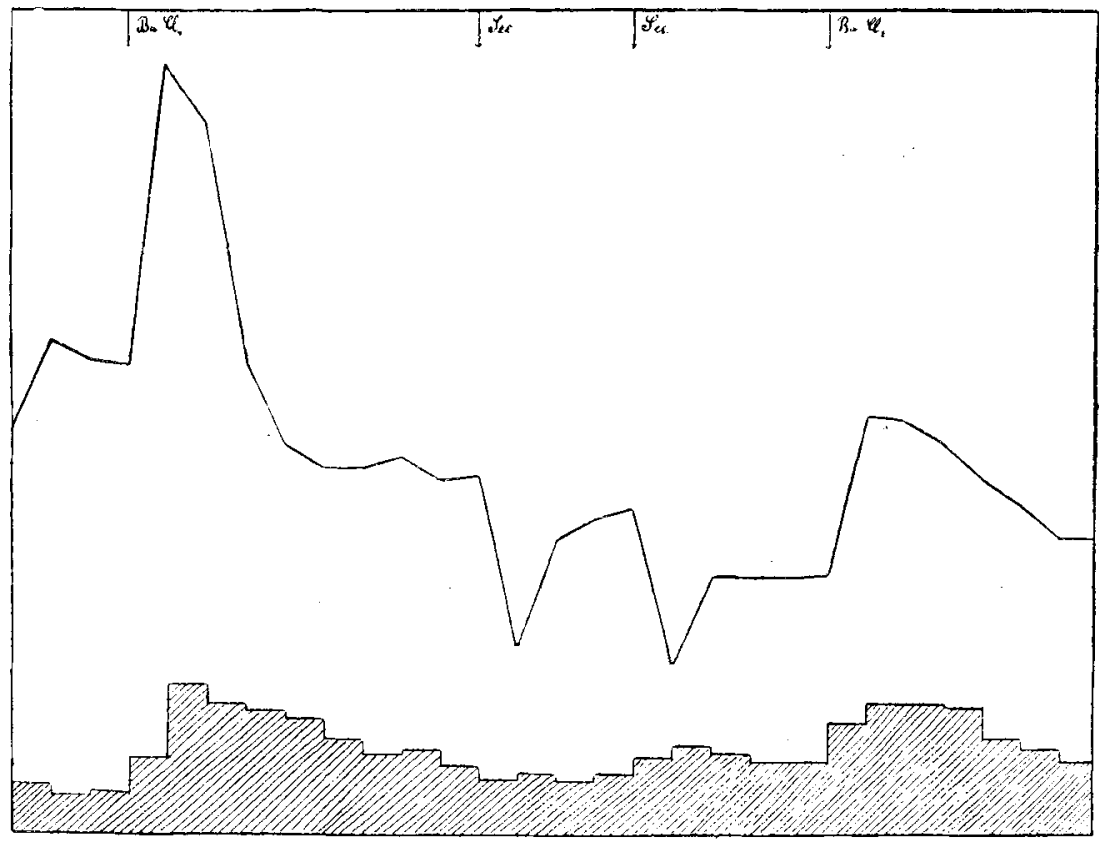

Hier senkt sich auf die beiden Injectionen von Secale hin der Blutdruck in annähernd gleicher Weise. Und, was für die Deutung wichtig ist, es findet beide Male keine Verminderung der Pulszahl statt. Die Grösse der Pulsausschläge jedoch verhielt sich verschieden. Das erste Mal blieb sie unverändert oder nahm eher ab, das zweite Mal nahm sie zu. Und nur nach der zweiten Gabe trat eine Vermehrung der Blutung ein. Man kann also wohl mit einer gewissen Berechtigung schliessen, dass die Vergrösserung der Pulse nach der intravenösen Injection der Secalepräparate der Grund für die - übrigens geringe - Vermehrung der Blutung einer Lungenwunde ist. Immerhin ist eine Rückstauung nicht absolut ausgeschlossen. Jedenfalls ist Secale nicht befähigt eine Lungenblutung zu stillen. Diese Feststellungen decken sich vollkommen mit denen der früheren Untersucher. Gerhardt sah keine Beeinflussung des Pulmonalisdruckes und Baneroft und Dean eine nur sehr geringe Steigerung; d. h. ein blutdruckbeförderndes Moment. Danach scheint Secale einen irgendwie erheblichen Einfluss auf die Lungenblutung nicht zu entfalten.

\section{Chlorbarium (und Pepton).}

Aehnlich wie Suprarenin führt Chlorbarium eine Verengerung der Gefässe herbei, welche den Blutdruck im grossen Kreislauf stark in die Höhe treibt. Gerhardt') hat, um ein "reines Vasomotorenmittel" zu

1) Gerhardt, VerhandI. d. XX. Congresses f. innere Medicin. 1902. S. 335. 
prüfen, Chlorbarium untersucht und auch nach Anwendung dieses Stoffes den Druck in der Carotis, der Arteria pulmonalis, der Vena pulmonalis und der Vena jugularis gemessen. Während cr in drei Versuchen keine Erhöhung des Pulmonalisdruckes fand, obwohl der Carotisdruck gleichzeitig um $40-50 \mathrm{~mm}$ anstieg, sah er in einem vierten Versuch den Druck in der Arteria pulmonalis um $3 \mathrm{~mm}$ steigen und gleichzeitig den Druck in der Vena pulmonalis um $1 \mathrm{~cm}$ Wasser fallen; dabei stieg der Carotisdruck inzwischen von 79 auf $200 \mathrm{~mm}$. Gerhardt schliesst daraus auf eine geringe Verengerung der Lungengefässe. Constant ist also zunächst diese Verengerung nicht. Aber sie könnte auch durch eine gleichzeitige Steigerung der Herzthätigkeit (hier des rechten und linken Ventrikels) vorgetäuscht werden. Es könnte dabei der rechte Ventrikel mehr Blut in den kleinen Kreislauf werfen und der linke Ventrikel mehr Blut aus den Lungenvenen schöpfen; auf diese Weise kämen ebenfalls die beobachteten Druckschwankungen zu stande. Eine solche Erhöhung der Herzthätigkeit durch den gesteigerten Aortendruck anzunehmen, liegt nach den Erfabrungen am isolirten Herzen nicht so fern; denn wir wissen, dass Erhöhung des Druckes der Durchspülungsflüssigkeit die Leistung des Herzens steigert ${ }^{1}$ ). Und Chlorbarium vergrössert ja den Druck im Aortensystem ausserordentlich und daher auch in den Coronararterien. Dass bei der geringen Spannung der Lungengefässe sich eine solche Zunahme der Herzkraft durch Anwachsen des Druckes in der Arteria pulmonalis documentiren kann, liegt wohl daran, dass Gerbardt eine sehr empfindliche Methode zum Nachweis einer Vergrösserung der Arbeit des rechten Ventrikels anwandte, indem er einen grossen Theil der Strombahn der Lunge durch Unterbinden ausschaltete. Er ging dabei von der Ansicht aus, dass sich unter diesen Umständen eine Wirkung der Digitalispräparate auf das rechte Herz im Sinne einer Steigerung der Leistung als Erhöhung des Druckes in der Pulmonalarterie zeigen müsste, eine Druckerhöhung, welche unter normalen Verhältnissen bei der fehlenden Wirkung der Digitaliskörper auf die Lungengelässe und bei deren Nachgiebigkeit ausblieb. Die Richtigkeit dieser Vermuthung wurde durch den Ausfall seiner Versuche bestätigt.

Ich habe nun immer nach der Injection von Chlorbarium eine Zunahme der Blutung der Lungenwunde gesehen. Dabei kam es immer zu einem erheblichen Anstieg des Carotisdruckes. In Versuch 17 trat gleichzeitig mit dem Erheben des Blutdruckes eine Zunahme der Pulszahl auf, sodass man also auch auf diese Verhältnisse als Ursache der Blutungsvermehrung zurückgreifen könnte. Aber nach der zweiten Gabe von Chlorbarium in demselben Versuch bemerkt man nur eine Blutdrucksteigerung ohne Veränderung des Pulsbildes, es handelt sich also um ein zufälliges Zusammentreffen im ersten Falle, die Blutungszunahme ist nicht durch die Aenderung der Pulso. bedingt, sie tritt auch ohne diese im zweiten Fall ein. In dem vorhergehenden Versuch 16 macht sich ebenfalls eine starke Vermehrung des Ausflusses geltend, trotzdem die Pulszahl abnahm. Es vermehrt also Chlorbarium die Blutung einer

1) Siehe auch Böhm, Archiv f. exp. Path. u. Pharm. 1875, Bd, 3. S. 216. 
Lungenwunde, ohne dass die Aenderung der Pulse dabei eine Rolle spielt. - Dabei zeigte sich, dass auf der Höhe der Blutdruckerhebung die Huskelwunde an der Aussenseite des Thorax wieder zu bluten begann, nachdem vorher längere Zeit keinerlei Blut mehr aus der Wundfläche hervortrat. Eine solche Wiederanfachung der Muskelblutung habe ich in diesen Versuchen nach Chlorbarium regelmässig gesehen. Es ist klar, dass dies leicht zu Fehlern Anlass geben kann, indem Blut aus dem grossen Kreislauf in die Spülflüssigkeit der Lungenwunde hineingeräth. Trotzdem ich natürlich besonderes Augenmerk auf diese Fehlerquelle richtete, ist es in einem Versuch vorgekommen, dass an der inneren Thoraxwand etwas Blut herabrann; den Versuch habe ich ausgelassen. In dem folgenden Experiment war durch Befestigen von Watte durch eine Reihe Péan-Klammern ein Wall gegen das Eindringen von Blut von aussen gebildet worden. Aber ich glaube auch in den vorher mitgetheilten Versuchen eine Täuschung mit Sicherheit ausschliessen zu können.

Versuch 18.

Dasselbe Thier von Versuch 17. 10 Minuten später. (Hierzu Curve 6.)

\begin{tabular}{r|c|c|c|c|c}
\hline $\begin{array}{c}\text { Nach } \\
\text { Min. }\end{array}$ & $\begin{array}{c}\text { Blutdruck } \\
\text { Carotis }\end{array}$ & $\begin{array}{c}\text { Pulse } \\
\text { in der } \\
\text { Minute }\end{array}$ & $\begin{array}{c}\text { Pulshöhe } \\
\text { maximal } \\
\mathrm{mm} \mathrm{Hg}\end{array}$ & $\begin{array}{c}\mathrm{Hb} \text {-Gehalt } \\
\text { relativ }\end{array}$ & Bemerkungen \\
\hline & & & & & \\
0 & 50 & 130 & 2 & 13,3 & \\
1 & 49 & 110 & 2 & 10,0 & \\
2 & 49 & 110 & 2 & 10,0 & $2 \mathrm{ccm} 1$ proc. $\mathrm{BaCl}_{2}$ in die Vena jug. \\
3 & 90 & 130 & $11 / 2$ & 12,7 & \\
4 & 94 & 140 & $11 / 2$ & 22,9 & \\
5 & 76 & 120 & $11 / 2$ & 26,3 & \\
6 & 36 & 120 & $11 / 2$ & 32,9 & \\
7 & 54 & 110 & $11 / 2$ & 36,2 & \\
8 & 42 & 70 & 2 & 34,5 & \\
9 & 38 & 70 & 3 & 31,7 &
\end{tabular}

Curve 6.

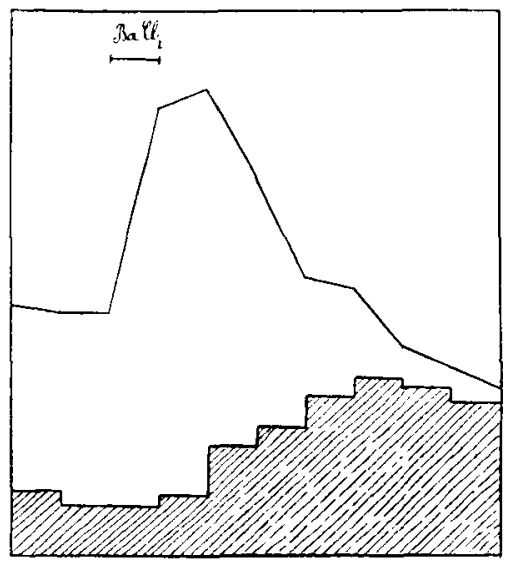


Auch hier nahm gleichzeitig mit der Blutdruckerhebung die ausfliessende Blutmenge zu. Den letzten Zahlen dieses Versuches ist insofern eine Bedeutung nicht beizulegen, als das Herz offenbar erlahmte und so eine Rückstauung eintrat. Das Erlahmen der Herzkraft schliesse ich aus dem Sinken des Blutdruckes und der gleichzeitigen Abnahme der Pulszahl. Für die Anfangswerthe und die übrigen Versuche kommt aber eine Rückstauung nach Chlorbarium als Ursache der Blutungszunahme der Lunge nicht in Frage, ich möchte bei der Aehnlichkeit der Wirkung des Chlorbariums und des Suprarenins auch hier den Grund für die Vergrösserung der Blutung in einem gesteigerten Zufluss aus den Körpervenen, besonders denen des Hirnes (Pick), sehen. Dafür sprechen auch die oben citirten Versuche Gerhardt's. Sollte dabei wirklich eine Gefässverengerung vorhanden sein, so ist sie - nach der Durchblutung beurtheilt--jedenfalls durch blutungsbegünstigende Momente übercompensirt worden.

Man hat also im Chlorbarium (wie im Suprarenin) einen Stoff vor sich, der an der Zunge, also im grossen Kreislauf die Blutung vermindert, in der Lunge die Blutung vermehrt.

Im Versuch 16 injicirte ich dem Kaninchen zum Schluss eine 10 proc. Peptonlösung in die Vene, worauf die bekannte Blutdrurksenkung im grossen Kreislaufe eintrat. Es hat nämlich, wie Tigerstedt ${ }^{1}$ ) berichtet, Nolf ${ }^{2}$ ) gleichzeitig damit eine Drucksteigerung in der Lungenarterie und einen Druckabfall im linken Vorhof beobachtet. Da mir die Arbeiten Nolf's nicht im Original zugänglich sind, so kann ich mir ein Urtheil darüber nicht erlauben. In meinem hier angeführten Versuch begann die Lungenwunde nach der Peptoninjection deutlich stärker zu bluten, was wohl auf Rückstauung beruht. Man vermisst also die erwähnte Gefässconstriction. Es wäre ja durchaus möglich, dass der Hund, an dem wohl Nolf seine Experimente anstellte, auf Pepton auch in dieser Hinsicht anders reagirt als das Kaninchen; welches ich zu den Versuchen benutzte. Bei dem negativen Ausfall dieses Versuches und der geringen praktischen Bedeutung der Frage habe ich von weiteren Untersuchungen abgesehen.

\section{Hydrastinin.}

Die Wirkung dieses Stoffes auf die Lungengefässe hat Gerhardt ${ }^{3}$ ) untersucht und keine Drucksteigerung in der Pulmonalarterie constatiren können. Allerdings betont der Autor, dass auch im grossen Kreislaufe

1) Tigerstedt, Der kleine Kreislauf. Ergeb.d. Physiol. II.Jahrgang. III. Abth. S. 581.1903 .

2) Nolf, Action des injections intraveineuses de propeptone sur la pression dans l'artère et la veine pulmonaires. Mém. cour. et autres Mém. publ. par l'Académie des Sciences de Belgique. 1903. 63. p. 1-34. - Respiration périodique et courbes vaso-motrices chez le chien propeptoné. Bull. de l'Académie des Sciences de Belgique. 1902. p. 975-978.

3) Gerhardt, Verhandl. des XX. Congresses für innere Medicin. Wiesbaden. 1902. S. 335 . 
keine nennenswerthe Drucksteigerung durch Hydrastinin hervorgerufen wurde. Ich habe in meinen Versuchen am Kaninchen stets eine Hebung des Blutdruckes in der Carotis eintreten schen, die freilich nicht immer sehr ausgiebig war. Die Ausflussgeschwindigkeit des Blutes aus den Venen hat Pick ${ }^{1}$ nach Hydrastinin verlangsamt gefunden, sodass also eine Steigerung des venösen Zuflusses zur Lunge nicht zu erwarten ist.

Versueh 19.

Kaninchen, weibl., $1600 \mathrm{~g} .2 \mathrm{~g}$ Urethan intravenös. Die Lunge blutet. (Hierzu Curve 7.)

\begin{tabular}{|c|c|c|c|c|c|}
\hline $\begin{array}{l}\text { Nach } \\
\text { Min. }\end{array}$ & $\begin{array}{c}\text { Blutdruck } \\
\text { Carotis } \\
\mathrm{mm} \mathrm{Hg} \\
\end{array}$ & $\begin{array}{l}\text { Pulse } \\
\text { in der } \\
\text { Minute }\end{array}$ & $\begin{array}{c}\text { Pulshöhe } \\
\text { maximal } \\
\mathrm{mm}\end{array}$ & $\begin{array}{c}\text { Hb-Gehalt } \\
\text { relativ }\end{array}$ & Bemerkungen \\
\hline 0 & 86 & 210 & 2 & & \\
\hline 1 & 83 & 220 & 2 & 16,1 & \\
\hline 2 & 78 & 220 & 2 & 21,7 & \\
\hline 3 & 80 & 220 & 2 & 27,6 & \\
\hline 4 & 76 & 220 & $11_{12}$ & 18,6 & \\
\hline 5 & 78 & 230 & $11 / 2$ & 21,0 & \\
\hline 6 & 78 & 250 & $11 /_{2}^{2}$ & & \\
\hline-15 & 86 & 240 & $11 / 2$ & 100 & $2 \mathrm{ccm} 1$ proc. Hydrastinin. hydrochlor. \\
\hline $\begin{array}{l}-30 \\
-45\end{array}$ & $\begin{array}{l}91 \\
91\end{array}$ & 210 & $11 / 2$ & 12,2 & in die Vena jugularis. \\
\hline 7 & $\begin{array}{l}91 \\
92\end{array}$ & 210 & $\begin{array}{l}11 / 2 \\
11 / 2\end{array}$ & & \\
\hline 8 & 94 & 220 & $11 \%$ & 10,0 & \\
\hline 9 & 91 & 210 & 2 & 13,9 & \\
\hline 10 & 90 & 200 & 2 & & \\
\hline 11 & 85 & 210 & 2 & 14,0 & \\
\hline-15 & 94 & 200 & 2 & & \\
\hline-30 & 93 & 200 & 2 & 17,2 & $3 \mathrm{ccm} 1$ proc. Hydrastinin.hydrochlor. \\
\hline-45 & 98 & 200 & 2 & & \\
\hline 12 & 98 & 200 & 2 & & \\
\hline 13 & 96 & 200 & 2 & 12,8 & \\
\hline 14 & 97 & 190 & 2 & 17,6 & \\
\hline 15 & 96 & $190^{\circ}$ & 2 & 16,0 & \\
\hline 16 & 96 & 200 & 2 & & \\
\hline-15 & 92 & 210 & 2 & & \\
\hline-30 & 90 & 200 & 2 & 23,0 & $3 \mathrm{ccon}$ lproe. Hydrastinin. hydrochlor. \\
\hline-45 & 98 & 200 & 2 & & in die Vena jugularis. \\
\hline 17 & 100 & 180 & 2 & & \\
\hline 18 & 99 & 200 & 2 & & \\
\hline 19 & 102 & 210 & 2 & $\begin{array}{l}17,8 \\
158\end{array}$ & \\
\hline 20 & 98 & 200 & 2 & & Der Blutdruck steigt bis 117 . \\
\hline
\end{tabular}

In dem Versuch 19 trat jedesmal nach der Hydrastiningabe eine Erhöhung des Blutdruckes ein. Dabei blieb während des ganzen Versuches die aus der Lunge fliessende Blutmenge gleich.

Im Versuch 20 sank dauernd die Blutung ab und zwar unbeeinflusst dureh die Gabe von 0,02 g Hydrastinin erst schnell, dann allmählich immer langsamer, wie es häufig der Fall ist. Die Blutdrucksteigerung war dabei cine geringe. - In dem folgenden Versuch 21 bemerkte ich wie früher nach der Injection von Chlorbarium, dass plötzlich nach der ersten Injection von Hydrastinin Blut an der inneren Brustwand herabrann.

1) Pick, Archiv f. exp. Path. u. Pharm. 1899. Bd. 42. S, 399. 
Die Blutdurchströmung der Lunge unter dem Einfluss einiger Arzneistoffe etc. 41

Curve 7.

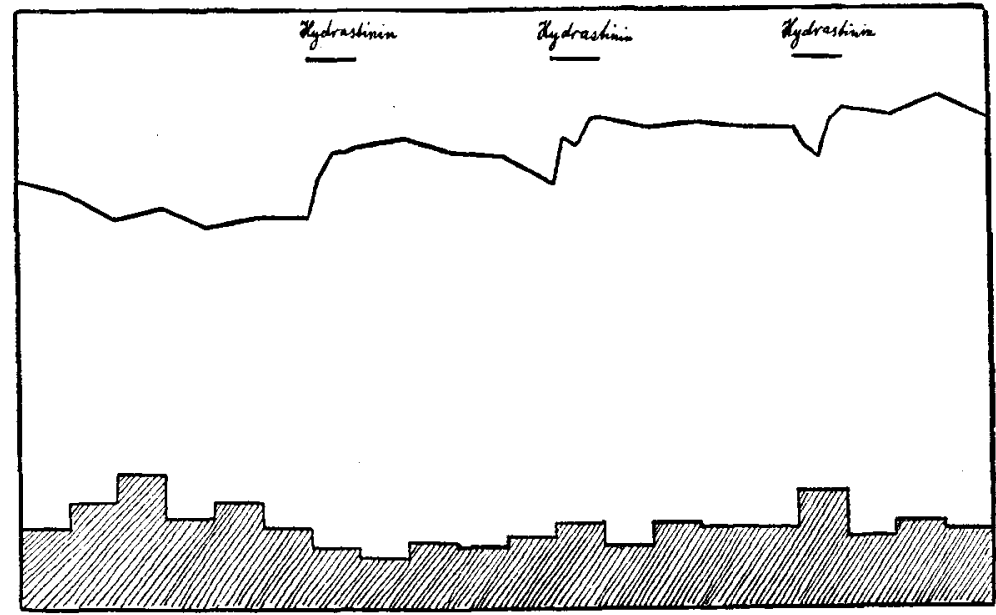

Versuch 20.

Kaninchen, weibl., $1300 \mathrm{~g} .4 \mathrm{~g}$ Urethan intravenös. Die Lunge blutet. (Hierzu Curve 8.)

\begin{tabular}{|c|c|c|c|c|c|}
\hline $\begin{array}{l}\text { Nach } \\
\text { Min. }\end{array}$ & $\begin{array}{c}\text { Blutdruck } \\
\text { Carotis } \\
\mathrm{mm} \mathrm{Hg}\end{array}$ & $\begin{array}{l}\text { Pulse } \\
\text { in der } \\
\text { Minute }\end{array}$ & $\begin{array}{c}\text { Pulshöhe } \\
\text { maximal } \\
\mathrm{mm}\end{array}$ & $\left|\begin{array}{c}\text { Hb-Gehalt } \\
\text { relativ }\end{array}\right|$ & Bemerkungen \\
\hline $\begin{array}{l}0 \\
1 \\
2 \\
-15 \\
-30 \\
-45 \\
3 \\
-15 \\
-30 \\
-45 \\
4 \\
5 \\
6 \\
7 \\
8\end{array}$ & $\begin{array}{l}83 \\
82 \\
84 \\
80 \\
54 \\
84 \\
86 \\
88 \\
88 \\
88 \\
88 \\
86 \\
84 \\
82 \\
82\end{array}$ & $\begin{array}{l}240 \\
240 \\
240 \\
230 \\
230 \\
220 \\
210 \\
230 \\
230 \\
220 \\
220 \\
220 \\
210 \\
220 \\
210\end{array}$ & $\begin{array}{l}11 / 2 \\
11 / 2 \\
11 / 2 \\
11 / 2 \\
21 / 2 \\
11 / 2 \\
11 / 2 \\
11 / 2 \\
11 / 2 \\
11 / 2 \\
11 / 2 \\
11 / 2 \\
11 / 2 \\
11 / 2 \\
11 / 2\end{array}$ & $\begin{array}{l}60,7 \\
36,0 \\
\\
26,3 \\
\\
26,3 \\
\\
22,1 \\
15,2 \\
12,6 \\
10,0\end{array}$ & $\left\{\begin{array}{l}0,02 \text { Hydrastinin. hydrochlor. in } \\
\text { die Vena jugularis. }\end{array}\right.$ \\
\hline
\end{tabular}

Und zwar hatte die Schnittfläche, die durch Loslösen des Zwerchfells von der Brustwand entstanden war, wieder zu bluten angefangen. Ich unterband daher den Zwerchfellrest parthienweise und deckte den Theil mit Watte ab, die ich durch Péan'sche Klemmen fixirte. Auf diese Weise kam mit Sicherheit nur Blut aus der Lungenwunde in die Spülflüssigkeit. Man bemerkt aber auf der Curve noch das Abklingen der Wirkung von der ersten Hydrastiningabe; der stark erhöhte Blutdruck sinkt wieder zur Norm ab, ehe die neue Hydrastinininjection ihn wieder stark steigen lässt. 
Curve 8 .

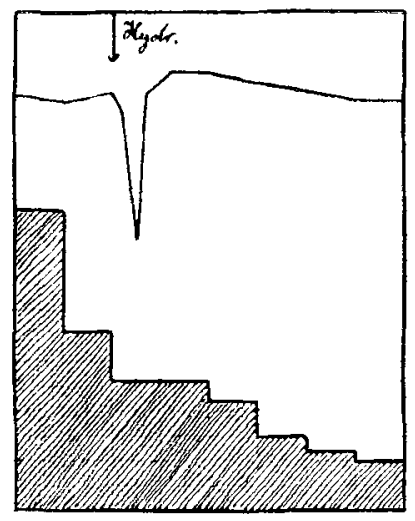

Curve 9.

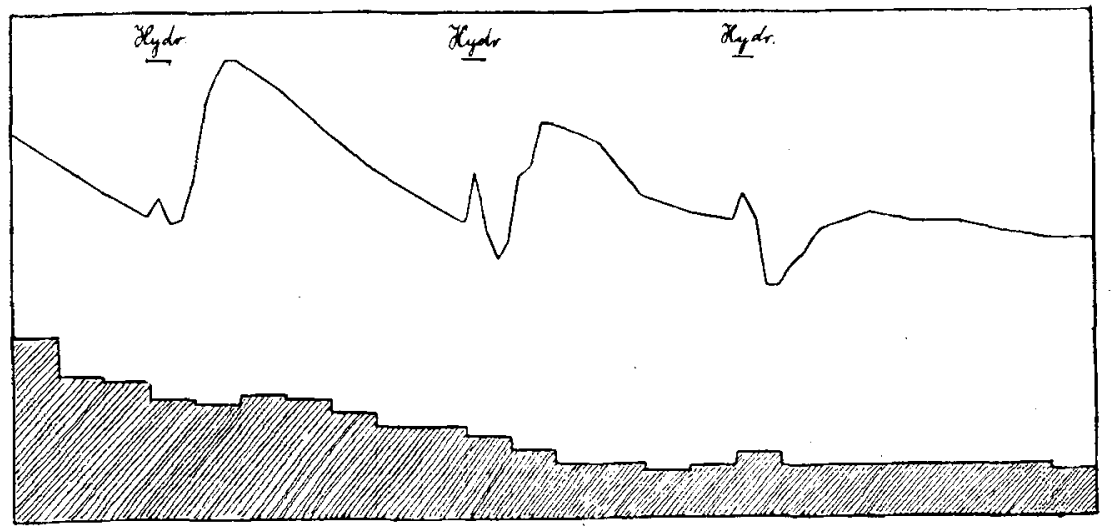

Eine Beeinflussung der Blutung durch die wiederholten Gaben von Hydrastinin hat sich auch in dem Versuch 21 nicht gezeigt. Man geht also wohl nicht fehl, wenn man annimmt, dass Hydrastinin die Blutdurchströmung der Lunge unbeeinflusst lässt.

\section{Digitalis.}

Der kleine Kreislauf ist unter dem Einfluss der Digitaliskörper relativ häufig Gegenstand des Studiums geworden. [Siehe v. Openchowski, Zeitschr. f. klin. Medicin. 16. 201. 1899 und die Zusammenfassung von Tigerstedt (l. c.)]. Man hat dabei eine Wirkung der Digitaliskörper auf die Lungengefässe vermisst. In einzelnen Fällen ist trotz Blutdrucksteigerung im grossen Kreislaufe eine solche in der Pulmonalis nicht eingetreten. Auch hat man, besonders nach grossen Gaben, ein geringfügiges Anwachsen des Druckes in der Pulmonalarterie gesehen, wie dies ja meistens bei einer Steigerung des Aortendruckes eintritt. Man hat dabei an einen vermehrten Zufluss von Blut aus den Körpervenen gedacht. Erst Gerhardt1) hat zeigen können, dass that-

1) Gerhardt, Verhandl. d. XX. Congresses f. innere Medicin. 1902. 
Die Blutdurchströmung der Lunge unter dem Einfluss einiger Arzneistoffe etc. 43

Versueh 21 .

Kaninchen, 1350 g. 2 g Urethan intravenös. Die Jinge blutet. (Hierzu Curve 9.)

\begin{tabular}{|c|c|c|c|c|c|}
\hline $\begin{array}{l}\text { Nach } \\
\text { Min. }\end{array}$ & $\begin{array}{c}\begin{array}{c}\text { Blutdruck } \\
\text { Carotis } \\
\mathrm{mm} \mathrm{Hg}\end{array} \\
\end{array}$ & $\begin{array}{l}\text { Pulse } \\
\text { in der } \\
\text { Minute }\end{array}$ & $\begin{array}{c}\text { Pulshöhe } \\
\text { maximal } \\
\mathrm{mm}\end{array}$ & $\begin{array}{c}\mathrm{Hb} \text {-Gehalt } \\
\text { relativ }\end{array}$ & Bemerkungen \\
\hline 0 & 84 & 170 & 5 & & \\
\hline 1 & 78 & 170 & 5 & 40,3 & \\
\hline 2 & 71 & 160 & 4 & 31,5 & \\
\hline 3 & 66 & 160 & 4 & & $2 \mathrm{ccm} 1$ proc. Hydrastinin. hydrochlor. \\
\hline-15 & 70 & 140 & 8 & 1 & in die Vena jugularis. \\
\hline-30 & 64 & 150 & 5 & 26,2 & \\
\hline-45 & 65 & 160 & 5 & & \\
\hline 4 & 75 & 160 & 5 & & \\
\hline-15 & 90 & 160 & 3 & ) & \\
\hline-30 & 96 & 170 & 3 & 25,5 & \\
\hline-45 & 100 & 170 & 3 & & \\
\hline 5 & 100 & 170 & 3 & & \\
\hline 6 & 93 & 160 & 3 & 27,5 & \\
\hline 7 & 84 & 150 & 4 & 26,5 & \\
\hline 8 & 76 & 160 & 4 & 23,4 & \\
\hline 9 & 70 & 160 & 4 & 20,1 & \\
\hline 10 & 66 & 150 & 4 & 20,6 & $2 \mathrm{ccm} /$ proc. Hydrastinin. hydrochlor. \\
\hline-15 & 75 & 110 & 8 & ) & in die Vena jugularis. \\
\hline-30 & 62 & 140 & 6 & 18,4 & \\
\hline-45 & 56 & 140 & 5 & & \\
\hline 11 & 60 & 140 & 5 & & \\
\hline-15 & 74 & 130 & 4 & 1 & \\
\hline-30 & 76 & 140 & 3 & 15,7 & \\
\hline-45 & 86 & 150 & 3 & J & \\
\hline 12 & 86 & 140 & 3 & 12.4 & \\
\hline 13 & 82 & 140 & 3 & $\begin{array}{l}1,4 \\
10,3\end{array}$ & \\
\hline 14 & 70 & 140 & 4 & $\begin{array}{l}12,0 \\
10.8\end{array}$ & \\
\hline 15 & 66 & 130 & 4 & 10,8 & \\
\hline 16 & 64 & 130 & 4 & & $3 \mathrm{cem} 1$ proe. Hydrastinin. hydrochlor. \\
\hline-15 & 70 & 110 & 6 & 1 & in die Vena jugularis. \\
\hline-30 & 64 & 120 & $\dot{5}$ & 14,8 & \\
\hline-45 & 50 & 130 & 5 & & \\
\hline 17 & 50 & 120 & 5 & & \\
\hline-15 & 54 & 120 & 6 & l & \\
\hline-30 & 56 & 110 & 5 & 11,7 & \\
\hline-45 & 60 & 110 & 5 & & \\
\hline 18 & 62 & 120 & 5 & 117 & \\
\hline 19 & 66 & 120 & 4 & $\begin{array}{l}11,6 \\
1118\end{array}$ & \\
\hline 20 & 64 & 120 & 4 & $\begin{array}{l}11,0 \\
11,7\end{array}$ & \\
\hline 21 & 64 & 120 & 4 & 11,1 & \\
\hline $\begin{array}{l}22 \\
23\end{array}$ & $\begin{array}{l}62 \\
60\end{array}$ & 120 & $\begin{array}{l}4 \\
4\end{array}$ & 11,0 & \\
\hline 24 & 60 & 110 & 5 & 10,0 & Athmung abgestelt, Blutdruck \\
\hline
\end{tabular}

sächlich ein Einfluss der Digitaliskörper auf den kleinen Kreislauf existirt: sie vermehren die Arbeit des rechten Ventrikels. Er engte die Strombahn in der Lunge stark ein, sodass die Ausschläge an dem in einen Ast der Arteria pulmonalis eingebundenen Manometer grösser wurden. Dabei fand nach Digitalis eine Drucksteigerung mässigen Grades in diesem Manometer statt. Bei meiner Versuchsanordnung ist also eine Veränderung der Blutung nur in ganz geringem Grade, wenn überhaupt zu erwarten. In der That hat sich ein Einfluss der Digitalis auf die Blutung nicht gezeigt. 
Versuch 22.

Kaninchen, männl., 1350 g. $4 \mathrm{ccm}$ Paraldehyd subcutan: 1/2 Stunde später Operation, künstliche Athmung. (Hierzu Curve 10.)

\begin{tabular}{|c|c|c|c|c|c|}
\hline $\begin{array}{l}\text { Nach } \\
\text { Min. }\end{array}$ & $\begin{array}{c}\text { Blutdruch } \\
\text { Carotis } \\
\mathrm{mm} \mathrm{Hg}\end{array}$ & $\begin{array}{l}\text { Pulse } \\
\text { in der } \\
\text { Minute }\end{array}$ & $\begin{array}{c}\text { Pulshöke } \\
\text { maximal } \\
\text { mm }\end{array}$ & $\begin{array}{c}\text { Hb-Gehalt } \\
\text { relativ }\end{array}$ & Bemerkungen \\
\hline $\begin{array}{l}0 \\
1 \\
2 \\
3 \\
-30 \\
-50 \\
4 \\
5 \\
6 \\
7 \\
8 \\
9 \\
10 \\
11 \\
12\end{array}$ & $\begin{array}{l}60 \\
48 \\
43 \\
36 \\
38 \\
62 \\
50 \\
37 \\
34 \\
33 \\
30 \\
30 \\
29 \\
25 \\
24\end{array}$ & $\begin{array}{l}170 \\
160 \\
170 \\
170 \\
170 \\
180 \\
180 \\
180 \\
180 \\
170 \\
160 \\
160 \\
150 \\
140 \\
170\end{array}$ & $\begin{array}{l}1 \\
0,5 \\
0,5 \\
0,5 \\
0,5 \\
1,0 \\
0,75 \\
0,5 \\
0,5 \\
0,5 \\
0,5 \\
0,5 \\
0,5 \\
0,5 \\
0,25\end{array}$ & $\begin{array}{l}51,8 \\
19,6 \\
20,9 \\
22,9 \\
18,9 \\
20,0 \\
19,7 \\
16,4 \\
18,8 \\
12,1 \\
11,7 \\
10,0\end{array}$ & 0,5 ccm Digalen in die Vena jug. \\
\hline
\end{tabular}

Curve 10.

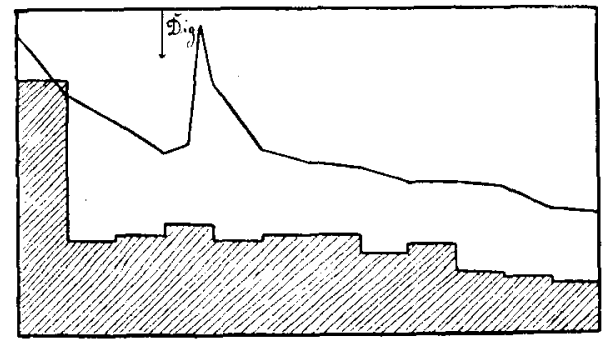

Versueh 23.

Kaninchen, 1750 g. $4 \mathrm{ccm}$ Urethan, künstliche Athmung. 0,007 Atropin. Rechter Unterlappen. Vagusreiz (10 cm R.-A.) erfolglos.

\begin{tabular}{c|c|c|c|c|c}
\hline $\begin{array}{c}\text { Nach } \\
\text { Min. }\end{array}$ & $\begin{array}{c}\text { Blutdruck } \\
\text { Carotis } \\
\mathrm{mm} \mathrm{Hg}\end{array}$ & $\begin{array}{c}\text { Pulse } \\
\text { in der } \\
\text { Minute }\end{array}$ & $\begin{array}{c}\text { Pulshöhe } \\
\text { maximal } \\
\mathrm{mm}\end{array}$ & $\begin{array}{c}\text { Hb-Gehalt } \\
\text { relativ }\end{array}$ & Bemerkungen \\
\hline & & & & & \\
1 & 34 & 170 & 0,5 & 10,0 & \\
2 & 34 & 170 & 0,5 & 10,0 & $1,0 \mathrm{ccm}$ Digalen in die Vena jug. \\
3 & 32 & 160 & 0,5 & 10,0 & \\
4 & 32 & 170 & 0,5 & 11,5 & \\
5 & 36 & 180 & 0,5 & 10,0 & Aussetzen der künstlichen Athmung, \\
& & & 0,5 & & Blutdruck steigt bis 86.
\end{tabular}

Man sieht aus dem ersten Versuch Nr. 22, dass trotz der Erhöhung des Blutdruckes im grossen Kreislauf einer Beeinflussung der Blutung der Lungenwunde nicht eintrat. Bei dem zweiten Thier, welches ich vorher atropinisirt hatte, ist gleichfalls eine Aenderung des Blutausflusses nicht zu bemerken. Ein dritter Versuch mit Digalen (ohne Atropin) perlief ebenfalls negativ inbezug auf eine Aenderung der Blutung. Das- 
selbe Resultat zeigt der folgende Versuch, in welchem ich ein 10procentiges Infus von Digitalisblättern injicirte. Nach kurzer Senkung des Blutdruckes während der Injection erhob sich derselbe auf das $1 \frac{1}{2}$ fache längere Zeit hindurch. Die Blutung nahm während der Normalzeit allmählich ab, diese Abnahme setzt sich bei der Senkung des Blutdruckes fort, dann fand wie in Normalversuchen ein ganz langsames weiteres Absinken der Blutung statt. Man kann also wohl annehmen, dass durch Digitalis der Zustrom von Blut zum rechten Herzen nicht in erheblicher Weise vermehrt wird, wenigstens nicht der Gesammtzufluss.

Versuch 24.

Kaninchen, weibl., 1800 g. 2 g Urethan intravenös. Die Lunge blutet. (Hierzu Curve 11.)

\begin{tabular}{|c|c|c|c|c|c|}
\hline $\begin{array}{l}\text { Nach } \\
\text { Min. }\end{array}$ & $\begin{array}{c}\text { Blutdruck } \\
\text { Carotis } \\
\mathrm{mm} \mathrm{Hg}\end{array}$ & $\begin{array}{l}\text { Pulse } \\
\text { in der } \\
\text { Minute }\end{array}$ & $\begin{array}{c}\text { Pulshöhe } \\
\text { maximal } \\
\text { mm }\end{array}$ & $\begin{array}{l}\text { Hb-Gehalt } \\
\text { relativ }\end{array}$ & Bemerkungen \\
\hline $\begin{array}{l}0 \\
1 \\
\cdot 2 \\
3 \\
4 \\
4,30 \\
5 \\
6 \\
7 \\
8 \\
9 \\
10 \\
11 \\
12\end{array}$ & $\begin{array}{l}58 \\
52 \\
57 \\
66 \\
60 \\
47 \\
60 \\
66 \\
84 \\
92 \\
92 \\
90 \\
86 \\
84\end{array}$ & $\begin{array}{l}200 \\
200 \\
190 \\
200 \\
200 \\
190 \\
190 \\
190 \\
190 \\
190 \\
170 \\
170 \\
160 \\
160\end{array}$ & $\begin{array}{l}3 \\
3 \\
3 \\
3 \\
3 \\
4 \\
4 \\
4 \\
4 \\
4 \\
4 \\
4 \\
4 \\
4\end{array}$ & $\begin{array}{r}38,5 \\
30,8 \\
28,4 \\
23,1 \\
16,5 \\
17,4 \\
17,4 \\
16,6 \\
\vdots \\
14,2 \\
11,2 \\
10,0\end{array}$ & $\left\{\begin{array}{l}8 \mathrm{ccm} 10 \text { proc. Inf. fol. Digitalis } \\
\text { in die Vena jugularis. }\end{array}\right.$ \\
\hline
\end{tabular}

Curve 11.

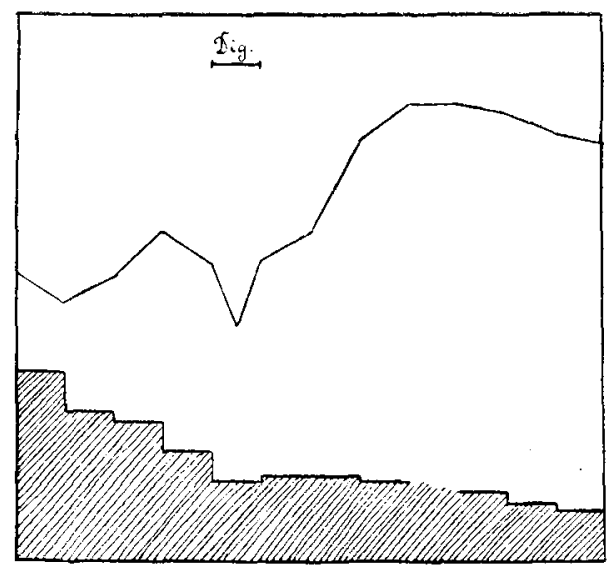

Dass damit jeder Einfluss der Digitalis auf eine Lungenblutung ausgeschlossen erscheint, möchte ich nicht ohne Weiteres folgern; soviel scheint sicher, dass die Lungengefässe direct nicht durch diese Stoffe in nennenswerther Weise verändert werden. Auch wird die directe Herzwirkung bei therapeutischen Dosen kaum ins Gewicht fallen. Aber es 
ist eine indirecte Beeinflussung einer Lungenblutung denkbar; wohl hauptsächlich nur dann, wenn es sich nicht um annähernd normale Circulationsbedingungen, sondern um pathologische handelt. Durch Verbesserung der darniederliegenden Circulation wird im allgemeinen die Blutdurchströmung der Lunge zunehmen, andererseits kann dadurch eine Staung in der Lunge zum Schwinden kommen. Man wird wohl je nach den Gründen des Darniederliegens der Blutbewegung einen verschiedenen Einfluss der Digitaliskörper aul die Lungenblutung zu erwarten haben, freilich nur einen indirecten und auch den nur, wie gesagt, bei pathologisch veränderter Circulation.

\section{Vagusreizung (und Erstickung).}

Im Anschluss an die vorhergehenden Versuche habe ich die Aenderung des Blutausflusses unter der Vaguswirkung studirt, hauptsächlich zur Controlle derjenigen Experimente, bei denen nach Einspritzung von Substanzen eine Vaguswirkung auftrat. Ob die Blutdurchströmung der Junge durch Vagusreizung beeinflusst wird, wenn man von der Herzwirkung des Vagus absieht, ist vielleicht zweifelhaft, jedenfalls erscheint eine directe Gefässwirkung des Vagus den Lungengefässen gegenüber unwahrscheinlich. Immerhin ist es ja denkbar, dass auf dem Umwege der anderen unter Nerveneinfluss stehenden musculösen Apparate des Lungengewebes, d. h. der Bronchialwand, auch die Blutdurchströmung der Lunge beeinflusst wird. Daher reizte ich erst den Vagus einer Seite, während ich die Blutung auf derselben Seite verfolgte, sodann den gleichen Vagus, während ich die Blutung auf der anderen Lungenseite bestimmte. Die Resultate waren verschieden und lassen einen Schluss nach irgend einer Richtung kaum zu. Einmal habe ich gesehen, dass die Vagusreizung gar keinen Einfluss auf die Blutung ausübt, trotzdem sich die Höhe und Zahl der Pulse änderte. Denn konnte ich eine Steigerung oder auch einen Abfall des Blutausflusses constatiren, ohne dass die Gründe dafür durchsichtig waren. Endlich trat manchmal ganz verspätet eine Zunabme der Blutung ein, wofür sich gleichfalls eine Ursache im Kreislauf nicht finden liess.

Versuch 25.

Kaninchen, männl., 2000 g. 6 g Paraidehyd.

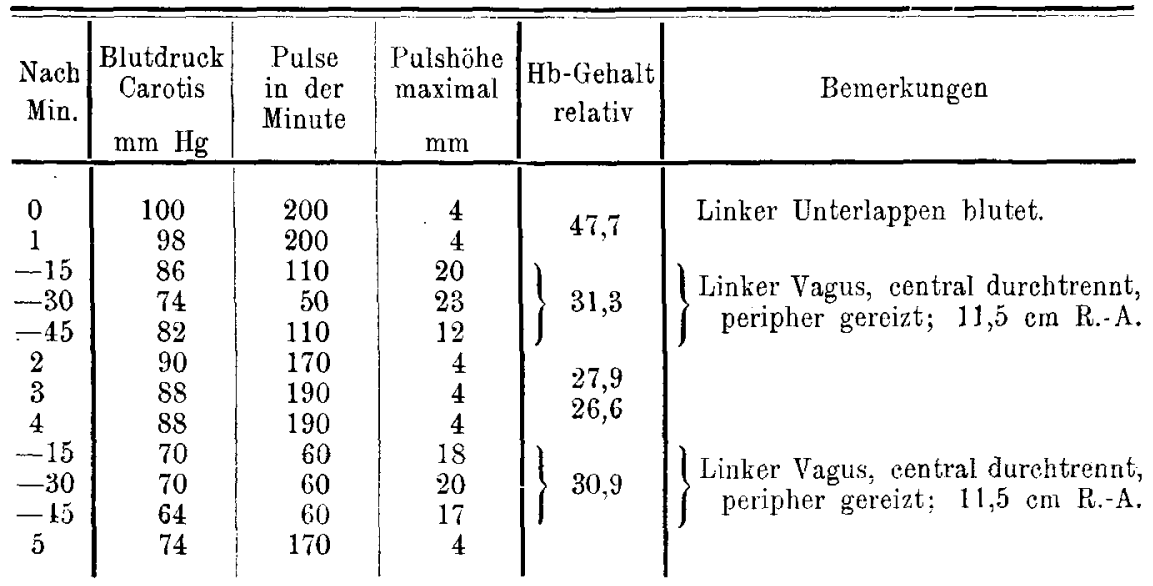


Die Blutdurchströmung der Lunge unter dem Einfluss einiger Arzneistoffe etc. 47

Versuch 26 .

Kaninchen, männl., $2150 \mathrm{~g}$. $4 \mathrm{~g}$ Urethan intravenös.

\begin{tabular}{|c|c|c|c|c|c|}
\hline $\begin{array}{c}\text { Nach } \\
\text { Min. }\end{array}$ & $\begin{array}{c}\text { Blutdruck } \\
\text { Carotis } \\
\mathrm{mm} \mathrm{Hg}\end{array}$ & $\begin{array}{l}\text { Pulse } \\
\text { in der } \\
\text { Minute }\end{array}$ & $\begin{array}{c}\text { Pulshöhe } \\
\text { maximal } \\
\mathrm{mm}\end{array}$ & $\begin{array}{c}\text { Hb-Gehalt } \\
\text { relativ }\end{array}$ & Bemerkungen \\
\hline $\begin{array}{l}0 \\
1 \\
2 \\
-15 \\
-30 \\
-45 \\
3 \\
4 \\
5 \\
-15 \\
-30 \\
-45 \\
6 \\
7 \\
8 \\
-15 \\
-30 \\
-45 \\
9 \\
10 \\
11 \\
-15 \\
-30 \\
-45 \\
12 \\
13 \\
14 \\
\end{array}$ & $\begin{array}{r}106 \\
104 \\
94 \\
94 \\
94 \\
96 \\
92 \\
78 \\
86 \\
96 \\
96 \\
92 \\
96 \\
90 \\
90 \\
92 \\
94 \\
90 \\
96 \\
87 \\
94 \\
96 \\
97 \\
94 \\
95 \\
64 \\
79 \\
92 \\
89 \\
94 \\
94 \\
\end{array}$ & $\begin{array}{r}210 \\
230 \\
210 \\
200 \\
200 \\
190 \\
180 \\
50 \\
110 \\
170 \\
190 \\
190 \\
180 \\
180 \\
190 \\
190 \\
180 \\
190 \\
180 \\
190 \\
190 \\
190 \\
180 \\
180 \\
180 \\
70 \\
110 \\
130 \\
190 \\
180 \\
180 \\
\end{array}$ & $\begin{array}{l}11 / 2 \\
11 / 2 \\
2 \\
2 \\
2 \\
2 \\
2 \\
12 \\
4 \\
4 \\
3 \\
3 \\
3 \\
3 \\
3 \\
3 \\
21 / 2 \\
2 \\
2 \\
21 / 2 \\
2 \\
2 \\
2 \\
2 \\
2 \\
7 \\
5 \\
3 \\
2 \\
2 \\
2 \\
\end{array}$ & $\left\{\begin{array}{r}51,6 \\
30,9 \\
20,1 \\
11,8 \\
25,0 \\
17,8 \\
16,7 \\
15,7 \\
14,6 \\
\\
21,0 \\
10,0 \\
10,0 \\
10,5 \\
23,0\end{array}\right.$ & $\begin{array}{l}\text { Linker Vagus, central durchtrennt, } \\
\text { peripher gereizt; } 20 \mathrm{~cm} \mathrm{R.-A.} \\
\left\{\begin{array}{l}\text { Linker Vagus, central durchtrennt, } \\
\text { peripher gereizt; } 13 \mathrm{~cm} \mathrm{R.-A.}\end{array}\right.\end{array}$ \\
\hline $\begin{array}{l}0 \\
1 \\
2 \\
-15 \\
-30 \\
-45 \\
3 \\
4 \\
5 \\
-15 \\
-30 \\
-45 \\
6 \\
7 \\
8 \\
-15 \\
-30 \\
-45 \\
9 \\
10 \\
11 \\
-15 \\
-30 \\
-45 \\
12 \\
13 \\
14\end{array}$ & $\begin{array}{l}91 \\
90 \\
90 \\
91 \\
89 \\
84 \\
86 \\
87 \\
88 \\
34 \\
55 \\
70 \\
78 \\
84 \\
86 \\
55 \\
54 \\
45 \\
60 \\
76 \\
74 \\
74 \\
72 \\
72 \\
76 \\
70 \\
56\end{array}$ & $\begin{array}{r}170 \\
180 \\
180 \\
170 \\
180 \\
170 \\
180 \\
170 \\
150 \\
60 \\
60 \\
70 \\
160 \\
170 \\
160 \\
80 \\
80 \\
80 \\
150 \\
160 \\
160 \\
160 \\
160 \\
160 \\
160 \\
150 \\
160\end{array}$ & $\begin{array}{r}2 \\
2 \\
2 \\
2 \\
2 \\
2 \\
2 \\
2 \\
2 \\
11 \\
9 \\
8 \\
2 \\
2 \\
2 \\
6 \\
5 \\
5 \\
2 \\
2 \\
2 \\
2 \\
2 \\
2 \\
2 \\
2 \\
2\end{array}$ & $\begin{array}{l}20,2 \\
18,1 \\
11,5 \\
11,0 \\
11,7 \\
15,5 \\
12,6 \\
12,2 \\
18,6 \\
13,6 \\
12,0 \\
10,8 \\
11,0 \\
10,0\end{array}$ & $\begin{array}{l}\text { Linker Vagus, central durchtrennt, } \\
\text { peripher gereizt; } 13 \mathrm{~cm} \mathrm{R.-A.} \\
\text { Linker Vagus, central durchtrennt, } \\
\text { peripher gereizt; } 20 \mathrm{~cm} \mathrm{R.-A.}\end{array}$ \\
\hline
\end{tabular}


Versuch 27.

Kaninchen, 1500 g. $3 \mathrm{~g}$ Urethan intravenös.

\begin{tabular}{|c|c|c|c|c|c|}
\hline $\begin{array}{c}\text { Nach } \\
\text { Min. }\end{array}$ & $\begin{array}{c}\text { Blutdruck } \\
\text { Carotis } \\
\mathrm{mm} \mathrm{Hg}\end{array}$ & $\begin{array}{l}\text { Pulse } \\
\text { in der } \\
\text { Minute }\end{array}$ & $\begin{array}{l}\text { Pulshöhe } \\
\text { maximal } \\
\mathrm{mm}\end{array}$ & $\mid \begin{array}{c}\text { Hb-Gehalt } \\
\text { relativ }\end{array}$ & Bemerkungen \\
\hline $\begin{array}{l}0 \\
1 \\
2 \\
3 \\
4 \\
-30 \\
-50 \\
5 \\
-30 \\
6 \\
7 \\
8 \\
9 \\
-30 \\
10 \\
11 \\
12 \\
13 \\
14 \\
\end{array}$ & $\begin{array}{l}94 \\
94 \\
94 \\
93 \\
92 \\
78 \\
84 \\
79 \\
76 \\
76 \\
80 \\
84 \\
79 \\
66 \\
60 \\
64 \\
62 \\
62 \\
60 \\
\end{array}$ & $\begin{array}{l}210 \\
210 \\
220 \\
210 \\
200 \\
170 \\
200 \\
190 \\
200 \\
200 \\
190 \\
190 \\
190 \\
150 \\
170 \\
180 \\
180 \\
180 \\
170 \\
\end{array}$ & $\begin{array}{l}1 \\
1 \\
1 \\
1 \\
1 \\
11 / 2 \\
1 \\
1 \\
1 \\
1 \\
1 \\
1 \\
1 \\
11 / 2 \\
11 / 2 \\
11 / 2 \\
11 / 2 \\
1 \\
1 \\
\end{array}$ & $\begin{array}{r}30,4 \\
29,7 \\
22,9 \\
17,5 \\
\} \\
30,0 \\
33,8 \\
22,2 \\
12,5 \\
15,3 \\
17,2 \\
18,8 \\
15,6 \\
19,2 \\
10,0\end{array}$ & $\begin{array}{l}\text { Linker Unterlappen blutet. } \\
\left\{\begin{array}{l}\text { Linker Vagus, eentral durchtrennt, } \\
\text { peripher gereizt; } 14 \mathrm{~cm} \mathrm{R},-A .\end{array}\right.\end{array}$ \\
\hline $\begin{array}{l}0 \\
1 \\
2 \\
-30 \\
3 \\
4 \\
-30 \\
5 \\
-30 \\
6 \\
7 \\
-30 \\
8 \\
9 \\
10\end{array}$ & $\begin{array}{l}39 \\
38 \\
34 \\
32 \\
32 \\
30 \\
35 \\
40 \\
40 \\
42 \\
43 \\
36 \\
36 \\
35 \\
32\end{array}$ & $\begin{array}{l}120 \\
120 \\
120 \\
120 \\
110 \\
110 \\
110 \\
110 \\
110 \\
120 \\
120 \\
120 \\
110 \\
110 \\
110\end{array}$ & $\begin{array}{l}11 / 2 \\
11 / 2 \\
1 \\
1 \\
3 / 4 \\
3 / 4 \\
1 \\
1 \\
3 / 4 \\
3 / 4 \\
3 / 4 \\
1 / 2 \\
3 / 4 \\
3 / 4 \\
3 / 4\end{array}$ & $\left\{\begin{array}{r}25,5 \\
22,2 \\
17,8 \\
10,0 \\
14,1 \\
\\
14,5 \\
16,8 \\
23,4 \\
17,7 \\
22,1\end{array}\right.$ & $\begin{array}{l}\text { Rechter Unterlappen blutet. } \\
\text { Linker Vagus, central durchtrennt, } \\
\text { peripher gereizt; } 14 \mathrm{~cm} \mathrm{R.-A.}\end{array}$ \\
\hline
\end{tabular}

Man geht wohl nicht fehl, wenn man annimmt, dass hauptsächlich die beiden Factoren der Herzthätigkeit, die grossen und die seltenen Pulse, die die Vagusreizung veranlasst, in dem Einfluss auf die Blutströmung in Concurrenz treten, und dass sich je nach dem Ueberwiegen des einen Momentes oder des anderen das Resultat ändert. Es lässt sich eben aus diesen verschieden gerichteten Aenderungen der Blutströmung von vornherein kaum ein Schluss ziehen, und deshalb stellte ich - zur Controlle - diese Versuche an. Bemerkenswerth ist es vielleicht, dass es häufig vorkommt, dass die Aenderung der Pulshöhe und Pulszahl in entgegengesetzter Richtung den Ausfluss des Blutes in keiner Weise verändert, sich also mit Rücksicht auf die Blutströmung compensirt. Und hierbei scheint sich denn eine gewisse Regelmässigkeit zu zeigen, die auf die Abhängigkeit des Lungenkreislaufs vom Körperkreislauf hinweist: Compensirt sich die Aenderung der Pulshöhe und Pulszahl hinsichtlich der Blutströmung, am Blutdruck des grossen Kreislaufes gemessen, so ist auch der Einfluss der Vagusreizung auf die 
Lungenblutung gering, d. b. erholt sich der Carotisdruck schnell wieder, so bleibt die Blutung der Lunge gleich. Sinkt dagegen der Blutdruck längere Zeit, so kommt es zu Rückstauung und damit zur Vermehrung des Blutausflusses. Eine directe Einwirkung auf die Lungengefässe anzunehmen, scheint wohl nach diesen Versuchen nicht nöthig.

Schliesslich sei hier noch ein Versuch angeführt, der die Wirkung des Erstickungsreizes des Vasomotorencentrums auf die Durchblutung der Lunge feststellen sollte. Fine Gefässverengerung in den Lungen wird durch die Erstickung nicht hervorgerufen, wie aus den klaren Auseinandersetzungen Th. Openchowski's') hervorgeht. Eine Erstickung lässt sich bei meiner Versuchsanordnung durch Abstellen der Wasserstrahlluftpumpe erreichen. Es stieg der Carotisdruck auf diesen Eingriff hin

$\begin{array}{ccccccccc}\text { in } & \text { Versuch } & 21 & \text { von } & 60 & \mathrm{~mm} & \text { auf } & 80 & \mathrm{~mm} \\ " & n & 23 & & 36 & & & 86 & \\ " & n & 38 & n & 89 & n & n & 124 & n \\ " & n & 43 & n & 91 & n & n & 118 & n \\ n & n & 48 & n & 47 & n & n & 58 & \end{array}$

Aber gleichzeitig collabirt die Junge; dadurch werden so tiefgreifende Aenderungen der Blutströmung gesetzt, dass ein Feststellen der Blutung illusorisch würde. Ich war daher gezwungen, die Erstickung so vorzunehmen, dass ich den Trichter des Athmungsapparates an seinem tiefsten Punkte fixirte, dabei blieb die Lunge aufgeblasen.

Versuch 28 .

Kaninchen, 1800 g. 7,0 Paraldehyd subcutan.

\begin{tabular}{c|c|c|c|c|c}
\hline \hline Nach & $\begin{array}{c}\text { Blutdruck } \\
\text { Carotis }\end{array}$ & $\begin{array}{c}\text { Pulse } \\
\text { in der } \\
\text { Min. }\end{array}$ & $\begin{array}{c}\text { Pulshöbe } \\
\text { maximal }\end{array}$ & $\begin{array}{c}\text { Hb-Gehalt } \\
\text { relativ }\end{array}$ & Bomertiungen \\
\hline mm Hg & minute & & \\
0 & 56 & 180 & 2,5 & 14,8 & \\
1 & 53 & 200 & 2 & 14,0 & \\
2 & 54 & 190 & 2 & 10,0 & \\
3 & 50 & 180 & 2 & 12,7 \\
4 & 52 & 180 & 2 & 13,6 & Trichter des Athemapparates an- \\
5 & 50 & 180 & 2 & 14,0 \\
6 & 52 & 180 & 2 & 11,7 & gehalten (-.- Erstickung ?). \\
7 & 51 & 180 & 2 & 11,8 &
\end{tabular}

Wic der Versuch zeigt, findet aber unter diesen Verhältnissen eine Erstickung gar nicht statt. Jedenfalls hat durch die Narkose auch das vasomotorisehe Centrum etwas gelitten, sodass es auf die Vorschlechterung der Arterialisation des Blutes noch nicht reagirt. In der That ist ja eine, wenn auch geringfügige Ventilation der Lunge unter diesen Verhältnissen noch vorhanden. Einmal entweicht eine gewisse, wenn auch

1) Th. Openchowski, Ueber die Druckverhältnisse im kleinen Kreislauf. Pflüger's Archiv. 1882. Bd. 27. S. 233. 
sehr kleine Menge Luft durch die Wunde der Lunge, sodann findet eine Art künstlicher Athmung durch das ruckweise Entweichen der Juftblasen vom Trichter her durch die Flüssigkeit des Athemapparates wenigstens in beschränktem Maasse statt, endlich streicht ein kräftiger Luftstrom unterhalb des Kehlkopfes an der Trachea vorbei, es kann zu Wirbeln etc. kommen. Daher lässt sich mit dieser Versuchsanordnung der Einfluss der Erstickung auf die Grösse der Lungenblutung nicht ermitteln.

\section{Kampfer (und Alkohol).}

Wenn ich den Kampfer in seiner Wirkung auf die Lungenblutung untersuchte, so waren es praktische Gesichtspunkte, die mich dazu veranlassten, Denn man wird z. B. bei Verletzungen der Lunge häufig vor die Frage gestellt, ob man zur Hebung der daniederliegenden Circulation zu diesem Mittel greifen soll oder ob man damit durch Vermehrung der Blutung Unheil stiftet. An sich wird durch Verbesserung der Circulation auch die Blutdurchströmung der Lunge zunehmen und damit auch eine Blutung an dieser Stelle. Auf der anderen Seite besteht aber sicherlich, wenn die Indication für die Kampferanwendung vorliegt, eine Stauung vom linken Herzen aus, deren Beseitigung blutstillend wirken kann. Man wird also in solchen Fällen theoretische Bedenken gegen die Kampferanwendung nicht ins Feld führen können, vorausgesetzt, dass ein Einfluss aul die Blutdurchströmung der Lungen bei normaler Circulation dem Kampfer nicht zukommt. Es ist also von Wichtigkeit zu wissen, ob die Blutung sich bei annähernd normalem Kreislauf, wie in diesen Versuchen, unter der Kampferwirkung ändert. Da ich den Kampfer in warmem verdünnten Alkohol gelöst langsam in die Vene einführte, so stellte ich zunächst die Wirkung des Alkohols in solehen Gaben auf die Lungenblutung fest.

$$
\text { Versueh } 29 .
$$

Kaninchen, männl., $1700 \mathrm{~g} .5 \mathrm{ccm}$ Paraldehyd subcutan. Einschnitt links. (Hierzu Curve 12.)

\begin{tabular}{|c|c|c|c|c|c|}
\hline $\begin{array}{l}\text { Nach } \\
\text { Min. }\end{array}$ & $\begin{array}{c}\text { Blutdruck } \\
\text { Carotis } \\
\mathrm{mm} \mathrm{Hg}\end{array}$ & $\begin{array}{l}\text { Pulse } \\
\text { in der } \\
\text { Minute }\end{array}$ & $\begin{array}{c}\text { Pulshöhe } \\
\text { maximal } \\
\mathrm{mm}\end{array}$ & $\begin{array}{c}\mathrm{Hb} \text {-Gehalt } \\
\text { relativ }\end{array}$ & Bemerkungen \\
\hline 0 & 46 & 160 & 1 & & \\
\hline 1 & 42 & 150 & 0.5 & 10,0 & \\
\hline 2 & 38 & 140 & 0,5 & 11,2 & \\
\hline 3 & 38 & 120 & 0,5 & 10,8 & 0,3 cem 30 proc. Alkohol in \\
\hline-15 & 33 & 140 & 1,5 & & dic Vena jugularis. \\
\hline-30 & 70 & 130 & 1 & 13,2 & \\
\hline-45 & 67 & 140 & 1 & & \\
\hline 4 & 64 & 150 & 1 & & \\
\hline 5 & 56 & 140 & 0,5 & 10,3 & \\
\hline-15 & 57 & 140 & 0,5 & & \\
\hline-30 & $\tilde{s} 1$ & 120 & 0,5 & 12,6 & $0,3 \mathrm{cem} 30$ proc. Alkohol in \\
\hline-45 & 61 & 130 & 0.5 & & die Vena jugularis. \\
\hline 6 & 64 & 140 & 0,5 & & \\
\hline-15 & 68 & 140 & 1 & & \\
\hline-30 & 63 & 140 & 1 & 19,9 & \\
\hline-45 & 57 & 130 & 1 & & \\
\hline 7 & 47 & 130 & $0, \check{\partial}$ & & \\
\hline
\end{tabular}


Curve 12.

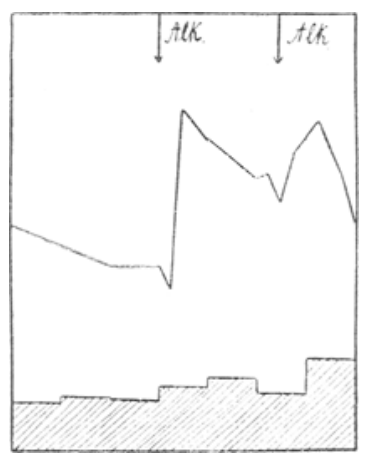

Die geringen Ausschläge, welche die Blutung nach intravenöser Zufuhr von mässigen Gaben von Alkohol aufweist, finden ihre lirklärung wohl durch das Anstejgen des Blutdruckes. Es mag dazu die (unbedeutende) Vergrösserung der Pulse oder auch die Zunahme derselben beitragen.' Ein irgend in die Wagschale fallender Einfluss des Alkohols ist aber nicht zu bemerken.

$$
\text { Versuch } 30 \text {. }
$$

Kaninchen, männl., $1900 \mathrm{~g} . \quad 4 \mathrm{~g}$ Paraldclydd subcutan. Linker Unterlappen. Künstliche Athmung.

\begin{tabular}{|c|c|c|c|c|c|}
\hline $\begin{array}{l}\text { Nach } \\
\text { Min. }\end{array}$ & $\begin{array}{c}\text { Blutdruck } \\
\text { Carotis } \\
\mathrm{mm} \mathrm{Hg}\end{array}$ & $\begin{array}{l}\text { Pulse } \\
\text { in der } \\
\text { Minute }\end{array}$ & $\begin{array}{l}\text { Pulshóne } \\
\text { maximal } \\
\text { mm }\end{array}$ & $\begin{array}{l}\text { Hb-Gehalt } \\
\text { relativ }\end{array}$ & Bemerkungen \\
\hline 0 & 92 & 280 & 2 & & \\
\hline 1 & 110 & 250 & 1,5 & & Thorax eröttnet. \\
\hline 2 & 78 & 250 & 1,5 & & Sternum resecirt. \\
\hline 3 & 79 & 270 & 1,5 & & \\
\hline 4 & 82 & 250 & 1,5 & & \\
\hline 5 & 68 & 250 & 1,5 & & \\
\hline 6 & 70 & 260 & 1,5 & & \\
\hline 7 & 68 & 230 & 1,5 & & \\
\hline 8 & 72 & 250 & 1,5 & $\infty$ & \\
\hline 9 & 71 & 250 & 2 & 21,0 & \\
\hline 10 & 72 & 240 & 1,5 & $\begin{array}{l}22,5 \\
92 .\end{array}$ & \\
\hline 11 & 68 & 240 & 1,5 & 22.2 & 0,02 Campher in die Vena jugularis. \\
\hline-20 & 60 & 210 & - & 913 & 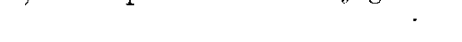 \\
\hline-40 & 76 & 210 & - & 21,3 & \\
\hline 12 & 68 & 220 & 2 & 19.7 & \\
\hline 13 & 62 & 230 & 1,5 & 10,0 & \\
\hline 14 & 64 & 220 & 1,5 & 12,1 & \\
\hline 15 & 64 & 220 & 1,5 & 18,1 & \\
\hline 16 & 70 & 230 & 1,5 & & \\
\hline 17 & 74 & 230 & 1,5 & & \\
\hline
\end{tabular}

Nach einer vorübergehenden Senkung hebt sich der Blutdruck etwas über die Norm auf die Injection von Kampfer hin; die Blutung zeigt keine Veränderung, die man als Wirkung auslegen könnte. Der Ausfluss des Blutes verläuft parallel mit dem Blutdruck: als sich dieser wieder etwas senkt, nimmt auch die Blutmenge etwas ab, und bei seinem späteren Steigen fliesst wieder reichlicher Blut aus der Wunde. (Die 
erste Angabe für die Blutung soll besagen, dass nach Anlegen der Wunde ganz unverhältnissmässig viel mehr Blut aus derselben floss als später.)

Versueh 31.

Kaninchen, männl., 2100 g. $7 \mathrm{ccm}$ Paraldehyd subcutan. (Hierzu Curve 13.)

\begin{tabular}{|c|c|c|c|c|c|}
\hline $\begin{array}{l}\text { Nach } \\
\text { Min. }\end{array}$ & $\begin{array}{c}\text { Blutdruck } \\
\text { Carotis } \\
\mathrm{mm} \mathrm{Hg}\end{array}$ & $\begin{array}{l}\text { Pulse } \\
\text { in der } \\
\text { Minute }\end{array}$ & $\begin{array}{c}\text { Pulshöhe } \\
\text { maximal } \\
\mathrm{mm}\end{array}$ & $\begin{array}{c}\mathrm{Hb} \text {-Gehall } \\
\text { relativ }\end{array}$ & Bemerkungen \\
\hline $\begin{array}{l}0 \\
1 \\
2 \\
3 \\
4 \\
-15 \\
-30 \\
-45 \\
5 \\
-15 \\
-30 \\
-45 \\
6 \\
7 \\
-15 \\
-30 \\
-45 \\
8 \\
-15 \\
-30 \\
-45 \\
9 \\
10 \\
11\end{array}$ & $\begin{array}{l}68 \\
66 \\
68 \\
65 \\
65 \\
64 \\
65 \\
66 \\
66 \\
62 \\
64 \\
63 \\
63 \\
62 \\
64 \\
60 \\
50 \\
43 \\
44 \\
45 \\
42 \\
42 \\
42 \\
42\end{array}$ & $\begin{array}{l}210 \\
200 \\
200 \\
210 \\
200 \\
200 \\
210 \\
200 \\
190 \\
190 \\
190 \\
200 \\
200 \\
200 \\
200 \\
170 \\
170 \\
170 \\
180 \\
180 \\
180 \\
180 \\
180 \\
180\end{array}$ & $\begin{array}{l}2 \\
2 \\
2 \\
2 \\
2 \\
2 \\
2 \\
2 \\
2 \\
2 \\
2 \\
2 \\
1,5 \\
1,5 \\
1,5 \\
1 \\
0,5 \\
0,5 \\
0,5 \\
2 \\
1 \\
0,5 \\
1 \\
1\end{array}$ & $\begin{array}{r}31,5 \\
17,0 \\
14,8 \\
10,6 \\
15,9 \\
15,7 \\
. \\
20,1 \\
18,2\end{array}$ & $\begin{array}{l}0,02 \text { g Campher in Alkohol } \\
\text { in die Vena jugularis. }\end{array}$ \\
\hline
\end{tabular}

Curve 13.

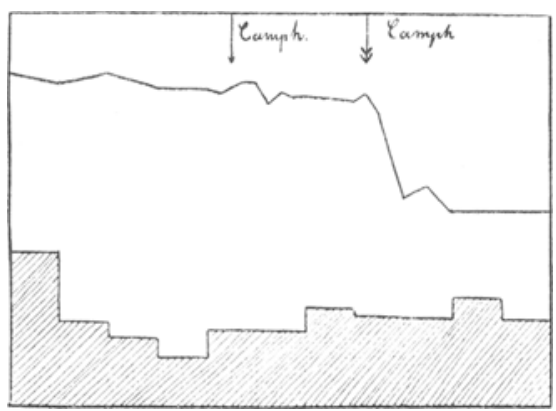

Hier hat die erste Injection von Kampfer eine nur unbedeutende Vermehrung der Blutung zur Folge; die zweite grössere Gabe bleibt ohne Einfluss. Nach dieser zweiten Injection fand eine Senkung des, Blutdruckes statt, wobei die Grösse der Pulse ein wechselndes Verhalten zeigte. - Man kann wohl den Sehluss ziehen, dass dem Kampfer ein Einfluss auf die Blutung der longe nicht zukom mt. 


\section{Amylnitrit.}

Schon Filehne ${ }^{2}$ ) fand beim Studium des Angriffspunktes der Amylnitritwirkung, dass die Farbe der Lunge durch ein Fenster der Thoraxwand bei erhaltener Pleura betrachtet, nicht die auffällige Aenderung im Sinne der Vermehrung des Blutgehaltes zejgte, wie sie sich im grossen Kreislauf durch starke Röthung kund giebt. v. Openchowski2) vermisste gleichfalls eine Gefässerweiterung in der Lunge. Er sah nach Amylnitrit anfangs den Druck in der Pulmonalarterie gar nicht oder nur etwas sinken, wohl, weil sich das Blut in den erweiterten Gefässen des. Unterleibes staut und auf diese Weise ein verminderter Zufluss zum rechten Herzen zu Stande kommt. Sodann aber bemerkte er eine Steigerung des Blutdruckes in der Lunge, weil bei dem gesunkenen Aortendruck das Blut nicht genügend vorwärts getrieben wird und so eine Rückstauung vom linken Herzen her resultirt. Auch Bradford und Dean (s. Tigerstedt S. 585) constatirten eine Drucksteigerung im kleinen Kreislauf. Sie führen ebenfalls diese Beobachtung auf Rückstauung vom linken Vorhof durch Schwächung der Thätigkeit des linken Ventrikels durch das Gift zurück ${ }^{3}$ ). Ein directer Einfluss den Lungengefässen gegenüber scheint also dem Amylnitrit nicht zuzukommen, und man könnte eine Vermehrung der Blutung durch Rückstauung erwarten.

Versuch 32.

Kaninchen, männl., 1400 g. 2,5 Urethan intravenös. (Hierzu Curve 14.)

\begin{tabular}{|c|c|c|c|c|c|}
\hline $\begin{array}{l}\text { Nach } \\
\text { Min. }\end{array}$ & $\begin{array}{l}\text { Blutdruck } \\
\text { Carotis } \\
\mathrm{mm} \mathrm{Hg}\end{array}$ & $\begin{array}{l}\text { Pulse } \\
\text { in der } \\
\text { Minute }\end{array}$ & $\begin{array}{c}\text { Pulshöhe } \\
\text { maximal } \\
\mathrm{mm}\end{array}$ & $\begin{array}{c}\text { Hb-Gehalt } \\
\text { relativ }\end{array}$ & Bemerkungen \\
\hline $\begin{array}{c}0 \\
1 \\
2 \\
-30 \\
3 \\
4 \\
5 \\
6 \\
7\end{array}$ & $\begin{array}{l}48 \\
45 \\
40 \\
38 \\
26 \\
23 \\
22 \\
24 \\
24\end{array}$ & $\begin{array}{l}140 \\
130 \\
130 \\
120 \\
120 \\
120 \\
120 \\
100 \\
100\end{array}$ & $\begin{array}{l}1 \\
1 \\
1 \\
1 \\
11 / 2 \\
1 \\
1 \\
1 \\
1\end{array}$ & $\begin{array}{r}23,6 \\
21,8 \\
18,5 \\
21,0 \\
12,2 \\
10,0 \\
11,5\end{array}$ & Amylnitriteinathmung. \\
\hline
\end{tabular}

Curve 14 .

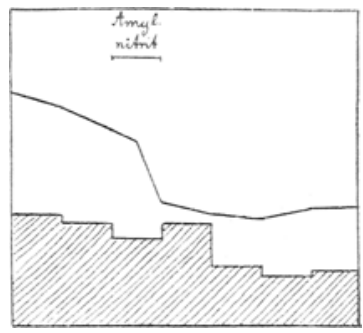

1) Filehne, Pflüger's Archiv. Bd. 9.

2) v. Openchowski, Zeitschrift f. klin. Medicin. 1889. Bd. 16. S. 201.

3) Die gleiche Ansicht vertritt Heinz, Handbuch der exp. Path. u. Pharm.

II. 1. S. 272. Jena, Gustar Fischer. 
Man kann in diesem Versuch von einer Beeinflussung der Lungenblutung durch die Amylnitrit-Inhalation kaum reden. Der Blutdruck sinkt allmählich $a b$, um sich später wieder etwas zu heben. Dabei scheint aber in der That nach dem Absinken des Blutdruckes eine Rückstauung von kurzer Dauer angedeutet.

\section{Versuch 33.}

Kaninchen, männl., 1900 g. 4 cem Paraldehyd subcutan, kiinstliche Athunung, linker Unterlappen. (Hierzu Curve 15.)

\begin{tabular}{|c|c|c|c|c|c|}
\hline $\begin{array}{l}\text { Nach } \\
\text { Min. }\end{array}$ & $\begin{array}{c}\text { Blutdruck } \\
\text { Carotis } \\
\mathrm{mm} \mathrm{Hg}\end{array}$ & $\begin{array}{l}\text { Pulse } \\
\text { in der } \\
\text { Minute }\end{array}$ & $\begin{array}{c}\text { Pulshöhe } \\
\text { maximal } \\
\mathrm{mm}\end{array}$ & $\begin{array}{c}\mathrm{Hb} \text {-Gehalt } \\
\text { relativ }\end{array}$ & Bemerkungen \\
\hline $\begin{array}{l}0 \\
1 \\
2 \\
3 \\
4 \\
41 / 2 \\
5 \\
6 \\
7 \\
8 \\
9 \\
10 \\
11 \\
12 \\
13 \\
14 \\
15\end{array}$ & $\begin{array}{l}68 \\
70 \\
68 \\
62 \\
63 \\
52 \\
41 \\
44 \\
47 \\
46 \\
47 \\
46 \\
44 \\
43 \\
39 \\
38 \\
36\end{array}$ & $\begin{array}{l}220 \\
220 \\
220 \\
220 \\
220 \\
220 \\
190 \\
200 \\
200 \\
200 \\
200 \\
210 \\
200 \\
210 \\
190 \\
200 \\
200\end{array}$ & $\begin{array}{l}1,5 \\
1,5 \\
1,5 \\
1,5 \\
1,5 \\
1,5 \\
2 \\
2 \\
1,5 \\
1,5 \\
1,5 \\
1,5 \\
1,5 \\
1,5 \\
1,5 \\
1,0 \\
1,5\end{array}$ & $\begin{array}{c}13,6 \\
11,0 \\
12,0 \\
11,8 \\
11,4 \\
13,0 \\
14,4 \\
11,4 \\
10,3 \\
10,0 \\
\vdots \\
10,0 \\
8,6 \\
8,8 \\
5,2\end{array}$ & $\begin{array}{l}\begin{array}{l}\text { Amylnitritinhalation } \\
\text { (tiefster Stand des Blutdrucks). }\end{array} \\
\left.\begin{array}{c}14,7 \\
11,4 \\
11,0 \\
10,0\end{array}\right\} \text { Controltitration, aufs } \\
\text { Doppelte verdünnte } \\
\text { Lösungen. }\end{array}$ \\
\hline
\end{tabular}

Curve 15.

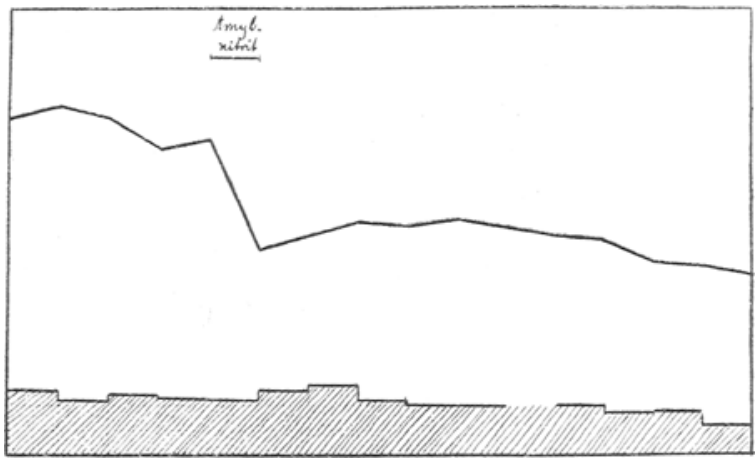

Auch hier trat eine deutliche Senkung des Aortendruckes auf. Die Blutung zeigte dabei eine unbedeutende Zunahme nach der Einathmung. von Amylnitrit. Auffällig ist vielleicht, dass eine solche Zunahme der Blutung fehlt oder doch nur sehr wenig ausgeprägt ist, wo doch die Autoren übereinstimmend eine Rückstauung von Blut gefunden haben. A ver vielleicht deutet der Befund von v. Openchowski, den ich oben anführte, diese geringen Ausschläge. Wonn nämlich gleichzeitig weniger 
Blut aus den Körpervenen dem rechten Herzen zufliesst, während es zu Rückstauung kommt, so compensiren sich diese beiden Einflüsse der Circulation in der Lunge, die Rückstaung hindert die Weiterbeförderung von Blut, đafür fliesst aber aus den Körpervenen auch weniger Blut der Lunge zu. In den meisten Fällen wird dieses gegensätzliche Verhalten die Ausschläge verkleinern, nur bei hoch gesteigertem Blutdruck in der Aorta könnte einmal gleichzeitig Rückstauung und vermehrter Zufluss aus den Körpervenen zu Stande kommen. Der hohe Blutdruck ist ein circulationsbeförderndes Moment, daher der vermehrte Zufluss, und trotz guter Hernarbeit, die den gesteigerten Anforderungen entspricht, könnte sich doch der Druck nach rückwärts vom Hinderniss fortpflanzen. Sonst schliessen sich - bei sinkendem Aortendruck - beide Factoren, die die Lungenblutung begünstigen, aus, vermehrter Zufluss und Rückstauung. Und thatsächlich sieht man ja in diesen Versuchen die grössten Ausschläge der Lungenblutung bei der Anwendung ron Suprarenin und $\mathrm{BaCl}_{2}$, die den Blutdruck in die Höhe treiben.

Es kommt also dem Amylnitrit ein wesentlicher Einfluss auf die Lungenblutung nicht zu; in geringer Weise vermehrt es den Blutausfluss durch Rückstaung. Eine solche Rückstaung scheint aber die Blutung nur sehr wenig zu erhöhen.

\section{Die Einwirkung von Salz und Coffein auf die Blutung der Lungenwunde.}

1. Lungenblutung.

Seit Alters ist die Eingabe von Salz bei Lungenblutungen in Gebrauch, und man hört häufig von den Mitgliedern der Familie eines Kranken, der einen Blutsturz gehabt hat, sie hätten dem Patienten sofort Salz oder Essig eingegeben. Die aus rein praktischen Gründen unternommenen Untersuchungen haben, wie sich später zeigte, auch ein theoretisches Interesse. Ausserdem ergab sich ein neuer praktischer Gesichtspunkt.

Die erhöhte Gerinnungsfähigkeit des Blutes, die v. d. Velden $\mathrm{n}^{1}$ ) neuerdings feststellte, konnte sich in meinen Versuchen nicht zeigen, da ich die Wunden mit Na. oxalicum spülte; sie scheint aber in praxi über die blutungsbegünstigende Wirkung des Salzes, die sich aus den folgenden Versuchen an der Junge zeigen wird, zu überwiegen, wie die Beobachtungen dieses Autors bei Blutsturz lehren. Meine Untersuchungen erstreckten sich lediglich auf die Wirkung von Gefässmitteln.

Die Eingabe einer kleinen Salzmenge, $0,3 \mathrm{ccm} 10$ proc. NaCl-Lösung, ruft eine geringe Steigerung des Blutausflusses nach einer Minute hervor, während direct nach der Injection die Blutung wie schon vorher weiterhin abnimmt. Da diese kleine Zunahme der Blutung mit einer, wenn auch geringfügigen, Blutdrucksteigerung in der Carotis zusammenfällt, so lässt sich mit Sicherheit die Salzgabe nicht als Ursache (wenigstens nicht als

1) R. v. d Velden, Die stomachale und intravenöse Behandlung innerer Blutungen mit Kochsalz. Dentsche med. Wochenschr. 1909. No. 5. S. 197. 
Versuch 34.

Kaninchen, männl., 2150 g. $8 \mathrm{~cm}$ Paraldehyd subcutan.

\begin{tabular}{c|c|cc|c|c}
\hline \hline $\begin{array}{c}\text { Nach } \\
\text { Min. }\end{array}$ & $\begin{array}{c}\text { Blutdruck } \\
\text { Carotis }\end{array}$ & $\begin{array}{c}\text { Pulse } \\
\text { in der } \\
\text { Minute }\end{array}$ & $\begin{array}{c}\text { Pulshöhe } \\
\text { maximal }\end{array}$ & $\begin{array}{c}\text { Hb-Gehalt } \\
\text { retativ }\end{array}$ & Bernerkungen \\
\hline 0 & 52 & 210 & & & \\
1 & 54 & 200 & 2 & 24,1 & \\
2 & 53 & 200 & 2 & 21,4 & \\
3 & 54 & 210 & 2 & 16,2 & 0,3 cem 10 proc, NaCl in die V. jug. \\
-15 & 52 & 210 & 2 & & \\
-30 & 50 & 200 & 2 & 10,0 & \\
-45 & 52 & 210 & 2 & & \\
4 & 56 & 210 & 1,5 & 16,0 & \\
5 & 63 & 210 & 1,5 & 13,6 & \\
6 & 54 & 220 & 1,5 & 11,3 & \\
7 & 51 & 200 & 2,5 & 10,4 &
\end{tabular}

directe) der vermehrten Blutung ansprechen. Denn wir haben gesehen, dass jede Erhöhung des Aortendruckes zu einer Zunahme des Blutausflusses führt. Ich gab daher eine grössere Menge Salzlösung.

Versuch 35.

Jianinchen, männl, $2150 \mathrm{~g} . \quad 8 \mathrm{ccm}$ Paraldehỵd subcutan. (Hierzu Curve 16.)

\begin{tabular}{|c|c|c|c|c|c|}
\hline $\begin{array}{l}\text { Nach } \\
\text { Min. }\end{array}$ & $\begin{array}{c}\text { Blutdruck } \\
\text { Carotis } \\
\text { mm Hg }\end{array}$ & $\begin{array}{l}\text { Pulse } \\
\text { in der } \\
\text { Minute }\end{array}$ & $\begin{array}{c}\text { Pulshïhe } \\
\text { maximal } \\
\mathrm{mm}\end{array}$ & $\begin{array}{c}\text { Hb-Gehalt } \\
\text { relatis }\end{array}$ & Bemerkungen \\
\hline $\begin{array}{l}0 \\
1 \\
2 \\
3 \\
-15 \\
-30 \\
-45 \\
4 \\
5 \\
6 \\
-15 \\
-30 \\
-45 \\
7 \\
8 \\
9\end{array}$ & $\begin{array}{l}38 \\
34 \\
31 \\
30 \\
36 \\
30 \\
30 \\
30 \\
31 \\
31 \\
36 \\
32 \\
33 \\
35 \\
36 \\
40\end{array}$ & $\begin{array}{l}170 \\
160 \\
160 \\
150 \\
150 \\
130 \\
130 \\
150 \\
160 \\
160 \\
150 \\
150 \\
150 \\
150 \\
160 \\
160\end{array}$ & $\begin{array}{l}3 \\
4 \\
4 \\
4 \\
4 \\
3 \\
4 \\
4 \\
4 \\
4 \\
4 \\
3 \\
4 \\
4 \\
3 \\
3\end{array}$ & $\begin{array}{l}30,6 \\
12,8 \\
10,0 \\
24,8 \\
\\
24,0 \\
16,2 \\
20,0 \\
\\
35,0 \\
27,1\end{array}$ & $\begin{array}{l}1,0 \mathrm{ccm} 10 \text { proc, } \mathrm{NaCl} \text { in die V. jug. } \\
1,0 \mathrm{~cm} 10 \text { proe. } \mathrm{NaCl} \text { in die V. jug. }\end{array}$ \\
\hline
\end{tabular}

Curve 16.

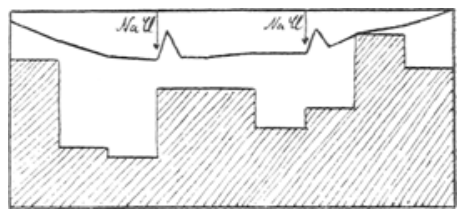

Hier tritt näch der jedesmaligen Salzzufuhr eine deutliche Vermehrung der Blutung ein, während der Blutdruck sich nur ganz vor- 
übergehend etwas hob. Dieses Jeichte Ansteigen des Blutdruckes kann aber nicht der Grund für die starke Zunahme der Blutung sein, denn abgesehen von der geringen Grösse und dem schnellen Verklingen der Druckzunahme zeigt der Schluss des Versuches, dass trotz einer grösseren und länger dauernden Erhebung die Blutung nachlässt, als die Salzwirkung schon in Abnahme begriffen ist. Ebenso zeigt der folgende Versuch, in welchem ich $7 \mathrm{ccm} 20$ proc. NaCl-Lüssung in die Leber spritate, eine Zunahme der Lungenblutung.

Versuch 36.

Kaninchen, mänal., 1500 g. 5 cem Paraldehyd subcutan. (Hierzu Curve 17.)

\begin{tabular}{|c|c|c|c|c|c|}
\hline $\begin{array}{l}\text { Nach } \\
\text { Min. }\end{array}$ & $\begin{array}{c}\text { Blutdruck } \\
\text { Carotis } \\
\mathrm{mm} \mathrm{Hg} \\
\end{array}$ & $\begin{array}{l}\text { Pulse } \\
\text { in der } \\
\text { Minute }\end{array}$ & $\begin{array}{c}\text { Pulshöhe } \\
\text { maximal } \\
\text { mm }\end{array}$ & $\begin{array}{c}\text { Hb-Gehalt } \\
\text { relativ }\end{array}$ & Bemerkungen \\
\hline $\begin{array}{l}0 \\
1 \\
2 \\
3 \\
4 \\
-30 \\
5 \\
6 \\
7 \\
8\end{array}$ & $\begin{array}{l}29 \\
30 \\
28 \\
27 \\
27 \\
29 \\
29 \\
30 \\
33 \\
32\end{array}$ & $\begin{array}{l}180 \\
170 \\
170 \\
170 \\
170 \\
170 \\
170 \\
160 \\
160 \\
160\end{array}$ & $\begin{array}{l}2 \\
2 \\
2 \\
2 \\
2 \\
2 \\
2 \\
2 \\
2 \\
2\end{array}$ & $\begin{array}{r}21,4 \\
14,7 \\
16,3 \\
10,9 \\
12,2 \\
26,1 \\
20,0 \\
19,4\end{array}$ & $7,0 \mathrm{erm} 10$ proc. $\mathrm{NaCl}$ in die Leber. \\
\hline
\end{tabular}

Curve 17.

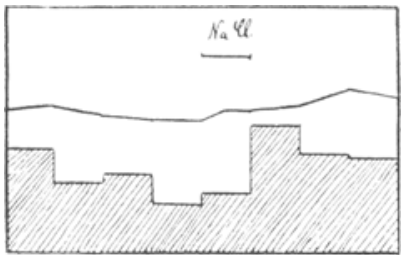

Auch. in diesem Versuch (No. 36) vermehrte die Salzgabe die Lungenblutung. Als der Blutdruck später etwas anstieg, nahm die ausfliessende Blutmenge schon wieder ab.

In dem nachstebenden Versuch 37 injicirte ich eine 10 proe. Glaubersalzlösung in die Darmvene. Man sieht sofort nach der ersten Injection - und auch schon während derselben - eine starke Zunahme der lungenblutung. Die Blutdrucksteigerung ist dabei recht unbedeutend. Auch nach der zweiten Injection derselben Gabe tritt eine Vermehrung der Blutung ein, die freilich sehr gering ist; aber schon der Umstand, dass die Blutung auf solcher Höhe weiterhin bleibt, lässt die gleiche Wirkung erkennen. Die dritte Injection, die bei inzwischen schon wieder stark vermindertem Blutausfluss gegeben wurde, führt zu einer Vermehrung der Blutung auf das 3 fache. Eine spätere Wassereingabe in die Darmvene hat keinen Einfluss auf die Blutung geäussert. Dagegen tritt nach der letzten Salzinjection wieder eine starke Zunahme des Blutausflusses hervor. Leider war bei diesem Thier der Aortendruck schon 
Versueh 37.

Kaninehen, männl., 1550 g. 5 ccm Paraldehyd subcutan. (Hierzu Curve 18.)

\begin{tabular}{|c|c|c|c|c|c|}
\hline $\begin{array}{l}\text { Nach } \\
\text { Min. }\end{array}$ & $\begin{array}{c}\text { Blutdruck } \\
\text { Carotis } \\
\mathrm{mm} \mathrm{Hg}\end{array}$ & $\begin{array}{l}\text { Pulse } \\
\text { in der } \\
\text { Minute }\end{array}$ & $\begin{array}{c}\text { Pulshöhe } \\
\text { maximal } \\
\mathrm{mm}\end{array}$ & $\begin{array}{l}\text { Hb-Gebalt } \\
\text { relativ }\end{array}$ & Bemerkungen \\
\hline $\begin{array}{l}0 \\
1 \\
2 \\
3 \\
4 \\
5 \\
6 \\
7 \\
8 \\
9 \\
10 \\
11 \\
12 \\
-30 \\
13 \\
14 \\
15 \\
16 \\
17 \\
18 \\
19 \\
20 \\
21 \\
22 \\
-30 \\
23 \\
-30 \\
24 \\
25 \\
26 \\
27\end{array}$ & $\begin{array}{l}16 \\
16 \\
16 \\
17 \\
18 \\
18 \\
18 \\
18 \\
20 \\
19 \\
20 \\
19 \\
20 \\
24 \\
21 \\
21 \\
20 \\
20 \\
20 \\
20 \\
20 \\
21 \\
20 \\
18 \\
26 \\
17 \\
19 \\
18 \\
18 \\
17 \\
17\end{array}$ & $\begin{array}{r}160 \\
150 \\
150 \\
150 \\
160 \\
150 \\
140 \\
130 \\
140 \\
120 \\
130 \\
130 \\
130 \\
130 \\
120 \\
110 \\
120 \\
110 \\
100 \\
120 \\
110 \\
110 \\
110 \\
110 \\
110 \\
100 \\
100 \\
90 \\
90 \\
90 \\
100\end{array}$ & $\begin{array}{l}1 \\
1 \\
1 \\
1 \\
1 \\
1 \\
11 / 2 \\
1 \\
1 \\
1 \\
1 \\
1 \\
1 \\
1 \\
1 \\
1 \\
11 / 2 \\
11 / 2 \\
11 / 2 \\
11 / 2 \\
11 / 2 \\
11 / 2 \\
11 / 2 \\
1 \\
2 \\
1 \\
2 \\
2 \\
1^{1} / 2 \\
1^{1} / 2 \\
1\end{array}$ & $\begin{array}{r}18,1 \\
18,9 \\
36,8 \\
42,0 \\
35,2 \\
27,3 \\
28,8 \\
30,0 \\
33,0 \\
31,0 \\
15,2 \\
10,0 \\
13,6 \\
33,0 \\
32,7 \\
26,7 \\
23,1 \\
25,1 \\
21,7 \\
24,2 \\
21,0 \\
17,4 \\
24,2 \\
\\
38,1 \\
28,5 \\
28,5 \\
21,6 \\
15,1\end{array}$ & $\begin{array}{l}5 \text { cem } 20 \text { proc. } \mathrm{Na}_{2} \mathrm{SO}_{4} \text { in } \\
\text { eine Darmpene. } \\
5 \text { cem } 20 \text { proc. } \mathrm{Na}_{2} \mathrm{SO}_{4} \text { in } \\
\text { eine Darmvene. }\end{array}$ \\
\hline
\end{tabular}

Curve 18.

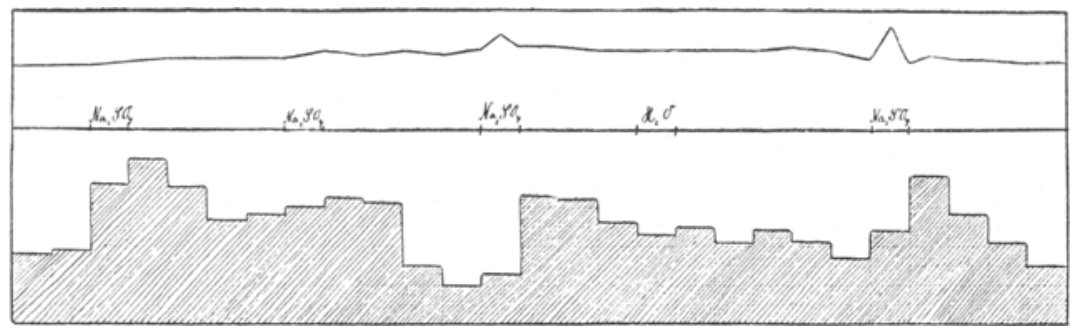

stark gesunken, ehe mit dem Versuch begonnen wurde; schon während der Operation hörte die Athmung auf und der Blutdruck war sehr niedrig. Auf die sofort eingeleitete künstliche Athmung hin, hob sich der Blutdruck, erreichte aber bei Weitem nicht annähernd normale Werthe. Es war daher wünschenswerth, die Resultate bei gleicher Versuchsanordnung bei hohem Blutdruck zu controlliren. Dies geschah in dem folgenden 
Die Blutdurchströmung der Lunge unter dem Einfluss einiger Arzneistoffe etc. 59

Versuch, indem ich Urethan, nicht Paraldehyd als Narcoticum verwendete.

Versuch 38 .

Kaninchen, männl., 1750 g. 2,3 g Urethan intravenös. (Hierzu Curve 19.)

\begin{tabular}{|c|c|c|c|c|c|}
\hline $\begin{array}{l}\text { Nach } \\
\text { Min. }\end{array}$ & $\begin{array}{c}\text { Blutdruck } \\
\text { Carotis } \\
\mathrm{mm} \mathrm{Hg}\end{array}$ & $\begin{array}{l}\text { Pulse } \\
\text { in der } \\
\text { Minute }\end{array}$ & $\begin{array}{c}\text { Pulshöhe } \\
\text { maximal } \\
\text { mm }\end{array}$ & $\begin{array}{l}\text { Hb-Gehalt } \\
\text { relatir }\end{array}$ & Bemerkungen \\
\hline $\begin{array}{r}0 \\
1 \\
2 \\
3 \\
4 \\
5 \\
6 \\
7 \\
8 \\
9 \\
10 \\
11 \\
12 \\
13 \\
14 \\
15 \\
16 \\
17 \\
18 \\
19 \\
20 \\
21 \\
22 \\
29 \\
24 \\
25 \\
26 \\
27\end{array}$ & $\begin{array}{r}104 \\
103 \\
105 \\
106 \\
104 \\
106 \\
102 \\
104 \\
102 \\
98 \\
101 \\
120 \\
106 \\
110 \\
104 \\
100 \\
102 \\
100 \\
119 \\
115 \\
110 \\
104 \\
102 \\
98 \\
96 \\
90 \\
92 \\
89\end{array}$ & $\begin{array}{l}180 \\
170 \\
180 \\
180 \\
170 \\
160 \\
170 \\
180 \\
170 \\
170 \\
170 \\
160 \\
170 \\
170 \\
170 \\
170 \\
160 \\
170 \\
120 \\
160 \\
150 \\
170 \\
150 \\
150 \\
150 \\
150 \\
150 \\
150\end{array}$ & $\begin{array}{l}1 \\
2 \\
2 \\
11 / 2 \\
2 \\
2 \\
2 \\
2 \\
2 \\
2 \\
2 \\
2 \\
3 \\
3 \\
21 / 2 \\
21 / 2 \\
21 / 2 \\
21 / 2 \\
3 \\
3 \\
21 / 2 \\
21 / 2 \\
21 / 2 \\
21 / 2 \\
21 / 2 \\
21 / 2 \\
21 / 2 \\
21 / 2\end{array}$ & $\begin{array}{l}25,0 \\
24,2 \\
19,3 \\
19,8 \\
19,3 \\
30,5 \\
22,5 \\
15,2 \\
15,8 \\
12,1 \\
13,1 \\
22,8 \\
20,4 \\
15,4 \\
12,5 \\
11,7 \\
10,8 \\
10,0 \\
16,5 \\
23,0 \\
23,4 \\
21,3 \\
19,5 \\
15,8 \\
17,5 \\
15,3 \\
12,9\end{array}$ & $\begin{array}{l}5 \text { cem } 20 \text { proc. } \mathrm{Na}_{2} \mathrm{SO}_{4} \text { in } \\
\text { eine Darmvene. } \\
5 \text { cem } 20 \text { proc. } \mathrm{Na}_{2} \mathrm{SO}_{4} \text { in } \\
\text { cine Darmvene. }\end{array}$ \\
\hline
\end{tabular}

Curve 19.

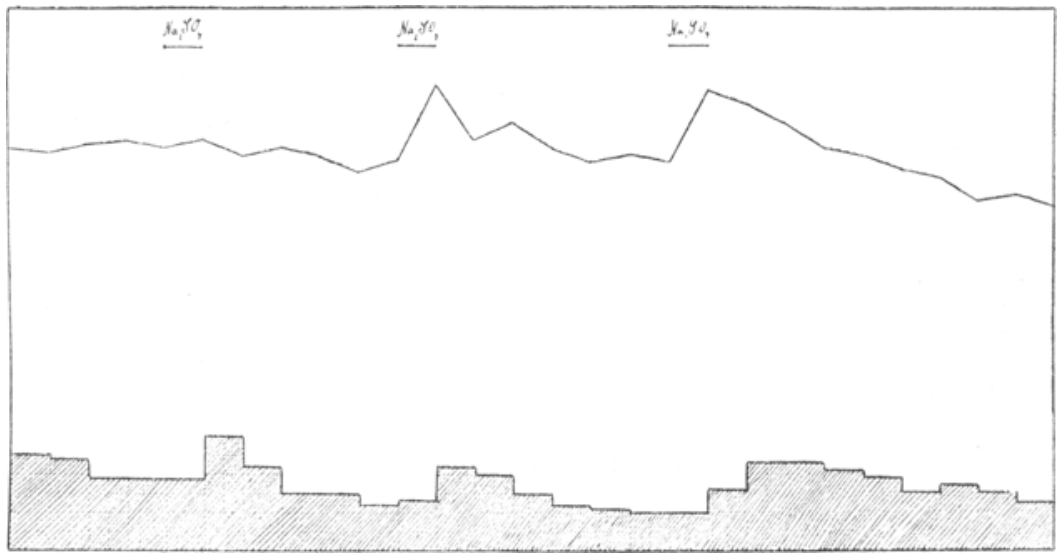


Wiederum ist jede Injection von Glaubersalzlösung von einer deutlichen Vermehrung des Blutausflusses gefolgt. Bemerkenswerth ist, dass der Blutdruck von Anfang bis zum Beginn der zweiten Injection sich nur in sehr engen Grenzen änderte, sodass hier von einem Einfluss des Blutdruckes auf die Blutung keine Rede sein kann; die späteren Injectionen führen zur Erhöhung des Aortendruckes, sodass der Einwand nicht von der Hand zu weisen ist, dass die Aenderung der Blutcirculation die Zunahme der Blutung herbeigeführt hat und nicht eine directe Salzwirkung vorliegt. Immerhin glaube ich nach dem regelmässigen Befund der Zunahme der Blutung nach Salzinjectionen schliessen zu können, dass intravenöse Salzzufuhr die Durchblutung der Lunge vermehrt. In späteren Versuchen, die ich anhangsweise beifüge, geht hervor, dass diese Vermehrung der Blutung nach Salz zu beobachten ist, gleichgültig, ob der Blutdruck fällt oder steigt.

\section{Blutung der Zunge.}

Bei der Zunahme der Blutung einer Lungenwunde nach Salzgaben war es von Interesse festzustellen, wie sich unter diesen Verhältnissen eine Wunde des grossen Kreislaufes verhielt. Ich wählte wieder die Zunge als blutende Stelle.

Versuch 39.

Kaninchen, 1700 g. $3 \mathrm{~g}$ Urethan intravenös. Finschnitt in der Zunge.

\begin{tabular}{r|c|c|c|c|c}
\hline $\begin{array}{c}\text { Nach } \\
\text { Min. }\end{array}$ & $\begin{array}{c}\text { Blutdruck } \\
\text { Carotis }\end{array}$ & $\begin{array}{c}\text { Pulse } \\
\text { in der } \\
\text { Ninute }\end{array}$ & $\begin{array}{c}\text { Pulshöhe } \\
\text { maximal } \\
\mathrm{mm}\end{array}$ & $\begin{array}{c}\text { Hb-Gehalt } \\
\text { relativ }\end{array}$ & Bemerkungen \\
\hline & & & & & \\
1 & 105 & 230 & $1 / 2$ & 14,5 & \\
2 & 106 & 240 & $1 / 2$ & 13,9 & \\
3 & 104 & 250 & $1 / 2$ & 13,3 & \\
4 & 104 & 250 & $1 / 2$ & 11,9 & \\
5 & 106 & 240 & $1 / 2$ & 12,9 & 5 ccm ges. $\mathrm{Na}_{2} \mathrm{SO}_{4}$ in die \\
6 & 104 & 250 & $1 / 2$ & 15,8 & Vena jugularis. \\
7 & 108 & 260 & $1 / 2$ & 16,5 & \\
8 & 106 & 240 & $1 / 2$ & 15,0 & \\
9 & 107 & 240 & $1 / 2$ & 14,9 & 5 cem ges. $\mathrm{Na}_{2} \mathrm{SO}_{4}$ in die \\
10 & 104 & 240 & $1 / 2$ & 14,2 & Vena jugularis. \\
11 & 108 & 240 & $1 / 2$ & 10,0 & \\
12 & 106 & 250 & $1 / 2$ & 10,0 &
\end{tabular}

Man sieht, dass eine ganz geringfügige Vermehrung der Blutung der Zungenwunde nach der ersten Injection eingetreten ist und zwar etwas verspätet; nach der zweiten Injection nimmt die Blutung in ebenso unbedeutendem Maasse ab. Man kann also einen Einfluss der Salzgabe auf die Blutung nicht constatiren.

Einen ähnlichen Verlauf nahm der folgende Versuch. 
Die Blutdurchströmung der Lunge unter dem Eintluss einiger Arzneistoffe etc. 61

Versueh 40.

Kaninchen, männl., 1250 g. 1,8 g Urethan intravenös. Dic Zunge blutet.

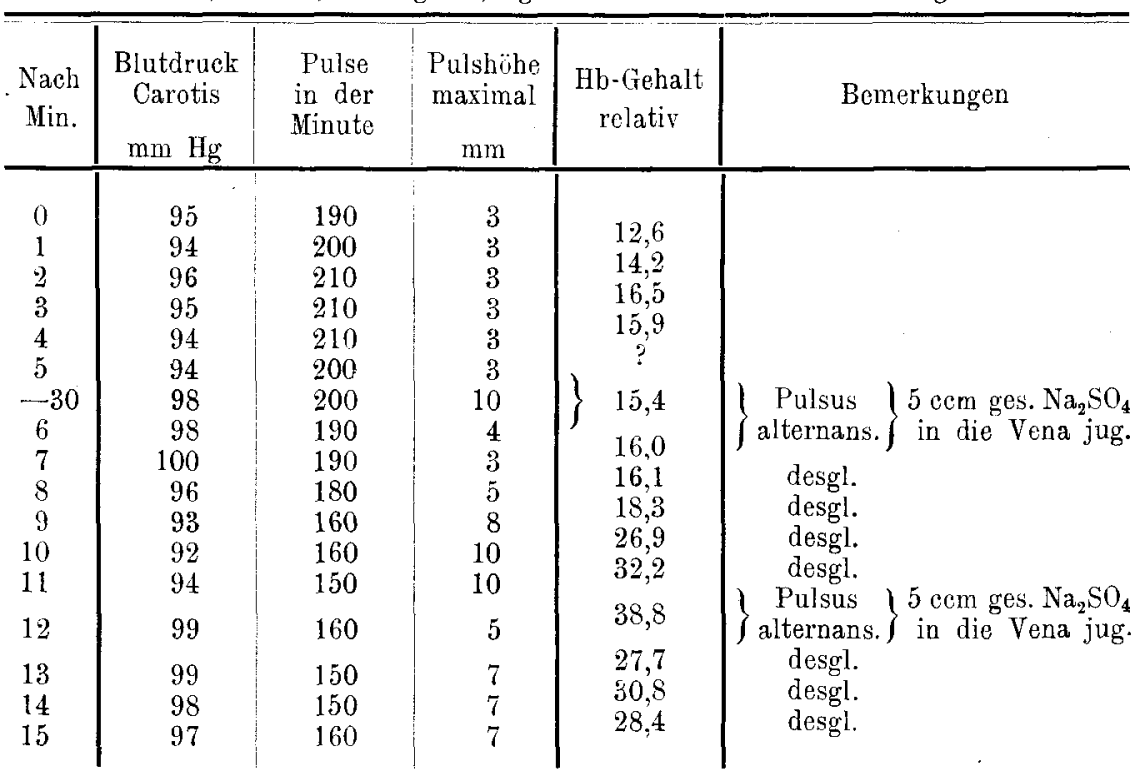

Auch hier bleibt die Blutung im Gegensatz zu der prompten Vermehrung der Lungenblutung dureh Salz nach der ersten Injection unverändert, nach der zweiten Injection fiel sie ab. Zwischen beiden Injectionen aber trat eine langsam zunehmende Vermehrung des Blutausflusses ein und zwar genau gleichzeitig mit einer Zunahme der Pulsgrösse, welcher der Blutfluss auch der Grösse nach parallel ging. Man geht wobl nicht fehl (s. auch oben), wenn man annimmt, dass die Veränderungen der Blutung von den Schwankungen der Pulshöhe in diesem Versuch abhängen. Die Wirkung des Salzes auf die Lungenblutung haben wir als verhältnissmässig schnell vorübergehend kennen gelernt, wie sie auf der anderen Seite auch sofort schon während der Injection einsetzte. Sie ähnelt also in keiner Weise der eben bemerkten Erhöhung des Ausflusses von Blut aus der Zungenwunde, die nur einmal verspätet in Abhängigkeit von der Pulsgrösse sich zeigte.

3. Ursache der Vermehrung der Lungenblutang durch Salz.

Was kann die Ursache dieser Vermehrung der Lungenblutung sein? Zunächst, würden hier wieder die beiden Momente, deren Wichtigkeit wir früher kennen gelernt haben, zu erwähnen sein, der vermehrte $\mathrm{Zu}$ fluss aus den Venen und die Rückstauung vom linken Herzen. Beides kommt aber nur in Betracht, wenn Aenderungen des Blutdruckes auftreten, die in den angeführten Versuchen mit Salz fehlen. Nach den späteren Experimenten sieht man aber auf Salz hin die Blutung zunehmen, wenn der Blutdruck gleichzeitig steigt oder fällt. In solchen Versuchen könnte man nun eines der beiden Momente jeweils der Blutungszunahme zu Grunde legen, doch wird gegenüber der Thatsache, dass bei gleichbleibendem, wie steigendem oder auch fallendem Blut- 
druck regelmässig die Zunahme der Durchblutung sich zeigt, diese Vermuthung hinfällig. Auch muss man den Gedanken einer Wirkung des Salzes auf die Blutflüssigkeit selbst, Viscositätsabnahme etc., fallen lassen, wenn man bedenkt, dass im grossen Kreislaufe eine Aenderung der Blutung unter denselben Bedingungen fehlt. Eine Zunahme des venösen Stromes zum rechten Herzen könnte aber in diesem Falle auch ohne Aenderung der Herzleistung und der Gefässweite eintreten, wenn man daran denkt, dass die Geschwindigkeit der Circulation auch von der Blutmenge abhängig ist. Es könnte durch Auffüllen des Gefässsystems derselbe Effect erreicht werden, wie durch Gefässcontraction. In der That hat ja Gerhardtin) gezeigt, dass nach schnellem intravenösen Einlauf von physiologischer Kochsalzlösung der Druck in der Lungenarterie zunimmt. Aber man muss bedenken, dass hier nicht die Drucke, sondern der Hb-Gehalt als Maass für die Blutmenge zu Grunde gelegt wurde. Und bei einem Einstrom von Wasser würde der $\mathrm{Hb}$ Gehalt der ausströmenden Blutmenge abnehmen, auch wenn die Flüssigkeitsmenge im Gefässsystem zunimmt, sodass gleich viel $\mathrm{Hb}$ in der Zeiteinheit die Lunge durchströmte. Davon abgesehen, lägen ja die Verhältnisse nach Injection von physiologischer Kochsalzlösung und von concentrirten Salzlösungen in kleiner Menge ähnlich, nur würden im zweiten Falle die Gewebe das Wasser ins Blut liefern. Aber dagegen sprechen ausser dem obigen Grunde auch die kleinen Salzmengen, die ebenfalls die Blutung in der Lunge vermehren (s. Versuch 22). Ausserdem müsste bei einer irgend erheblichen Auffüllung des Gefässsystems der Aortendruck steigen, was nicht der Fall ist, oder aber gleichzeitig mit der Flüssigkeitszunahme müsste sich compensatorisch ein Gefässgebiet erweitern. Und hier nähern wir uns bei diesen theoretischen Erwägungen wieder dem Gebiet der beobachteten Thatsachen. Wir wissen, dass die Salzzufuhr das grosse Stromgebiet der Nieren erweitert. Wenn also gleichzeitig der Blutdruck keine Aenderungen erfährt, so wird durch die Gefässerweiterung in der Niere mehr Blut in der Zeiteinheit zum rechten Herzen strömen. Diese Erweiterung der Nierengefässe tritt nach Salzgaben als das Primäre auf, auch wenn eine Diurese darnach ausbleibt, wie es nach Vergiftungen [Schlayer'²)] oder nach kurzer Abklemmung der Nierenarterie [A she $\mathrm{r}^{3}$ )] eintreten kann. Ob noch andere Stromgebiete durch das Salz erweitert werden, bleibt dahingestellt. Von der Niere ist es erwiesen. Und ich meine, dass als Erklärung für das Zustandekommen der Blutungsvermehrung der Lunge nach Salz die gesicherte Thatsache genügt, dass bei gleichbleibendem Blutdruck die Nierengefässe durch Salz erweitert werden und auf diese Weise ein vermehrter Zustrom von Blut zum rechten Herzen zu Stande kommt. Diese Anschauung wird noch dadurch wahrscheinlich gemacht, dass die

1) Gerhardt, Arch. f. exp. Path. u. Pharm. Bd. 44. S. 173. 1900.

2) Schlayer, Pflüger's Archiv. Bd. 120. S. 359. 1907.

3) Asher, Physiologisc̀he Permeabilität der Zelle. Biochem. Zeitschr. Bd. 14.

S. 1. 1908 . 
Die Blutdurchströmung der Lunge unter dem Einfluss einiger Arzneistofte etc. 63

deutlichen Steigerungen der Blutung der Lunge alle auf einer Vermehrung des Zustromes von Blut 7.um rechten Herzen beruhen. Und auch hier, nach Salzinjectionen, wird die Blutung stark vermehrt.

Ich suchte nun diese Anschauung dadurch zu erhärten, dass ich ein anderes Mittel, welches die Durchblutung der Niere steigert, in scinem Einfluss auf die Lungenblutung verfolgte. Ich wählte wegen der geringen Beeinflussung des Blutdruckes das Coffein.

Versuch 41.

Kaninchen, männl., 1500 g. 5 ccm Paraldehyd subcutan. (Hierzu Curve 20.)

\begin{tabular}{|c|c|c|c|c|c|}
\hline $\begin{array}{l}\text { Nach } \\
\text { Min. }\end{array}$ & $\begin{array}{l}\text { Blutdruck } \\
\text { Carotis } \\
\mathrm{mm} \mathrm{Hg} \\
\end{array}$ & $\begin{array}{l}\text { Pulse } \\
\text { in der } \\
\text { Ninute }\end{array}$ & $\begin{array}{c}\text { Pulshöhe } \\
\text { maximal } \\
\mathrm{mm}\end{array}$ & $\begin{array}{c}\text { Hb-Gehalt } \\
\text { relativ }\end{array}$ & Bemerkungen \\
\hline $\begin{array}{l}0 \\
1 \\
2 \\
3 \\
4 \\
-15 \\
--30 \\
-45 \\
5 \\
6 \\
7 \\
-15 \\
-30 \\
--45 \\
8 \\
9 \\
-15 \\
-30 \\
-45 \\
10 \\
11\end{array}$ & $\begin{array}{l}34 \\
33 \\
32 \\
34 \\
31 \\
33 \\
30 \\
30 \\
30 \\
30 \\
32 \\
32 \\
30 \\
29 \\
30 \\
30 \\
30 \\
30 \\
26 \\
28 \\
29\end{array}$ & $\begin{array}{l}180 \\
180 \\
180 \\
180 \\
170 \\
180 \\
170 \\
170 \\
180 \\
180 \\
170 \\
180 \\
170 \\
170 \\
180 \\
180 \\
180 \\
180 \\
170 \\
180 \\
180\end{array}$ & $\begin{array}{l}2 \\
2 \\
2 \\
2 \\
2 \\
2 \\
2 \\
2 \\
2 \\
2 \\
2 \\
2 \\
2 \\
2 \\
2 \\
2 \\
2 \\
2 \\
2 \\
2 \\
2\end{array}$ & $\begin{array}{l}38,1 \\
17,4 \\
17,8 \\
16,2 \\
28,8 \\
18,8 \\
15,9 \\
11,7 \\
10,0 \\
14,3 \\
20,2\end{array}$ & $\begin{array}{l}1,0 \mathrm{cem} \text { ges. Coffeinlösung in } \\
\text { die Vena jugularis. }\end{array}$ \\
\hline
\end{tabular}

Curve 20.

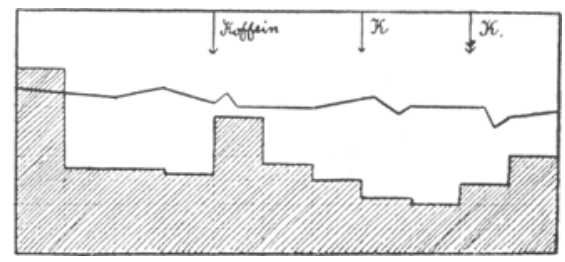

Deutlich nimmt nach der ersten Coffeininjection ohne Aenderung des Blutdruckes und des Pulsbildes dic Blutung zu. Nach der zweiten Injection bleibt die Blutung unbeeinflusst, sie sinkt weiter langsam ab. Das hat seinen Grund darin, dass die Niere gegenüber dem Cotfeinreiz ermüdet, wie Lö wi ${ }^{1}$ ) gezeigt hat. Erst eine grössere Gabe ruft zum Schluss wieder ein Anwachsen der Blutung hervor.

1) Löwi, Archiv f. exp. Path. u. Pharm. Bd. 53. 1905. 
Versuch 42 .

Kaninehen, männl., $2500 \mathrm{~g} . \quad 4,5 \mathrm{~g}$ Urethan intravenös. Die Lunge blutet. (Hierzu Curve 21.)

\begin{tabular}{|c|c|c|c|c|c|}
\hline $\begin{array}{l}\text { Nach } \\
\text { Min. }\end{array}$ & $\begin{array}{l}\text { Blutdruck } \\
\text { Carotis } \\
\mathrm{mm} \mathrm{Hg}\end{array}$ & $\begin{array}{l}\text { Pulse } \\
\text { in der } \\
\text { Minute }\end{array}$ & $\begin{array}{c}\text { Pulshöhe } \\
\text { maximal } \\
\text { mm }\end{array}$ & $\begin{array}{l}\text { Hb-Gehalt } \\
\text { relativ }\end{array}$ & Bemerkungen \\
\hline $\begin{array}{l}0 \\
1 \\
2 \\
3 \\
4 \\
-30 \\
5 \\
6 \\
7 \\
8 \\
9 \\
10 \\
11 \\
12\end{array}$ & $\begin{array}{r}114 \\
114 \\
110 \\
118 \\
120 \\
72 \\
56 \\
90 \\
120 \\
118 \\
125 \\
126 \\
125 \\
118\end{array}$ & $\begin{array}{l}240 \\
240 \\
230 \\
230 \\
210 \\
220 \\
220 \\
200 \\
230 \\
230 \\
220 \\
220 \\
210 \\
210\end{array}$ & $\begin{array}{l}5 \\
5 \\
5 \\
5 \\
5 \\
5 \\
5 \\
4 \\
5 \\
5 \\
5 \\
6 \\
5 \\
5\end{array}$ & $\begin{array}{r}31,2 \\
15,5 \\
12,6 \\
10,0 \\
33,0 \\
38,6 \\
46,6 \\
39,8 \\
39,4 \\
33,8 \\
30,0 \\
20,0\end{array}$ & $\left\{\begin{array}{l}10 \mathrm{ccm} 1 \text { proc. Coffein pur. } \\
\text { in die Vena jugularis. }\end{array}\right.$ \\
\hline
\end{tabular}

Curve 21.

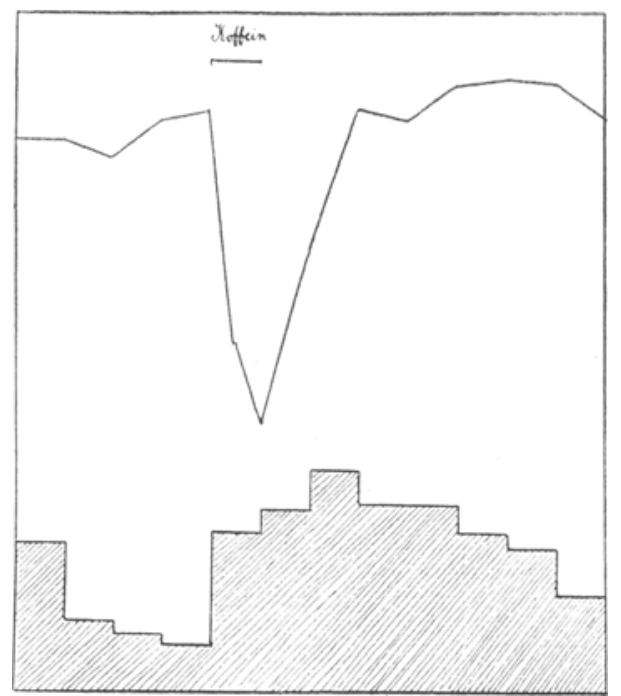

Auch in diesem Versuch wächst die ausfliessende Blutmenge auf die intravenöse Coffeingabe ausserordentlich an, und zwar ziemlich unabhängig vom Aortendrucke, der Anfangs fällt und später über die Norm steigt.

Also auch nach Coffeinzufubr findet eine Vermebrung der Blutung einer Lungenwunde statt. Will man nicht eine directe Beeinflussung der Thätigkeit des rechten Herzens annehmen, wogegen sich vielerlei cinwenden liesse, so bleibt nur übrig, die Ursache der Blutungsvermehrung in dem vermehrten Zustrom zu suchen, der auf dem Wegeder Niere erwiesenermaassen zum rechten Herzen hin stattfindet. Denn da eine Vermehrung der Blutdurchströmung der Lange, die 
Die Blutdurehströmung der Lunge unter dem Einfluss einiger Arzneistoffe etc. 65

einen Gesammtquerschnitt des Kreislaufes darstellt, nur möglich ist, wenn in der Zeiteinheit mehr Blut in Umlauf gesetzt wird, so muss irgendwie auch dieses schnellere Strömen im grossen Kreislauf vorhanden sein; mit anderen Worten, man kann eine locale Wirkung auf den kleinen Kreislauf diesen Stoffen nicht zusprechen, sondern Salz und Coffein können nur durch Beschleunigung der Blutbewegung im Ganzen die Blutdurchströmung der Lunge vermehren. Sie wirken also im Princip analog wie Suprarenin und Chlorbarium, nur dass sie die Wirkung auf den Lungenkreislauf entfalten, ohne gleichzeitig in so erheblicher Weise wie die letztgenannten Stoffe den Blutdruck zu erhöhen.

Die Annahme, dass nur solche Substanzen die Blutdurchströmung in der Lunge vermehren, welche auch im grossen Kreislaufe in seiner Gesammtheit das Blut schneller in Umlauf setzen, lässt sich experimentell

$$
\text { Versueh } 48 .
$$

Kaninchen, männl., $2800 \mathrm{~g}$. $6 \mathrm{~g}$ Urethan intravenös. Nierengefässe beiderseits abgebunden. Die Lunge blutet. (Hierzu Curve 22.)

\begin{tabular}{|c|c|c|c|c|c|}
\hline $\begin{array}{l}\text { Nach } \\
\text { Min. }\end{array}$ & $\begin{array}{c}\text { Blutdruck } \\
\text { Carotis } \\
\mathrm{mm} \mathrm{Hg}\end{array}$ & $\begin{array}{l}\text { Pulse } \\
\text { in der } \\
\text { Minute }\end{array}$ & $\begin{array}{c}\text { Pulshöhe } \\
\text { maximal } \\
\text { mm }\end{array}$ & $\begin{array}{c}\text { Hb-Gehalt } \\
\text { relativ }\end{array}$ & Bemerkungen \\
\hline 0 & 76 & 210 & $\bullet$ & & \\
\hline 1 & 79 & 200 & 2 & 39,0 & \\
\hline 2 & 72 & 210 & $\begin{array}{l}2 \\
2\end{array}$ & 37,5 & \\
\hline 3 & 70 & 200 & 2 & 31,9 & \\
\hline 4 & 68 & 210 & 2 & 34,1 & \\
\hline--15 & 70 & 200 & 2 & & $5 \mathrm{ccm} 10$ aroc $\mathrm{NaCl}$ in die \\
\hline-30 & 68 & 200 & 4 & 27,8 & $\left\{\begin{array}{l}\text { cem } \\
\text { Vena jugularis. }\end{array}\right.$ \\
\hline-45 & 56 & 200 & 5 & & \\
\hline 5 & 72 & 200 & 6 & & \\
\hline-15 & 90 & 200 & 6 & & \\
\hline-30 & 106 & 210 & 5 & 25,2 & \\
\hline-45 & 106 & 200 & 5 & & \\
\hline 6 & 110 & 200 & 5 & 336 & \\
\hline 7 & 109 & 190 & 5 & $\begin{array}{l}33,6 \\
33,9\end{array}$ & \\
\hline 8 & 103 & 180 & 4 & $\begin{array}{l}33,3 \\
18,3\end{array}$ & \\
\hline 19 & 100 & 190 & 4 & $\begin{array}{l}10,0 \\
14,8\end{array}$ & \\
\hline 0 & 94 & 180 & 3 & & \\
\hline-15 & 94 & 180 & 4 & & I5 ecm 10 proc. $\mathrm{NaCl}$ in die \\
\hline-30 & 94 & 180 & 4 & 14,3 & Vena jugularis. \\
\hline-45 & 74 & 180 & 5 & & \\
\hline 11 & 94 & 180 & 6 & & \\
\hline-15 & 99 & 180 & 7 & & \\
\hline-30 & 112 & 180 & 6 & 19,7 & \\
\hline-45 & 114 & 180 & 6 & & \\
\hline 12 & 114 & 190 & 6 & 20,0 & \\
\hline 13 & 114 & 180 & 6 & 14,3 & \\
\hline 14 & 110 & 180 & 6 & 13,2 & \\
\hline 15 & 104 & 190 & 4 & & \\
\hline-15 & 94 & 190 & 4 & 115 & (5 cem 1 proc. Colfein in die \\
\hline-30 & 79 & 190 & 4 & $11, b$ & Vena jugularis. \\
\hline-45 & $\begin{array}{l}84 \\
92\end{array}$ & $\begin{array}{l}190 \\
190\end{array}$ & $\begin{array}{l}4 \\
4\end{array}$ & & \\
\hline 17 & 92 & 180 & 4 & 10,0 & \\
\hline 18 & 91 & 180 & 4 & & $\begin{array}{l}\text { Athmung abgestellt, Blut- } \\
\text { druck steigt bis } 118 \text {. }\end{array}$ \\
\hline
\end{tabular}


prüfen. Wenigstens müsste dies bei Kochsalz und Coffein der Fall sein, deren circulationsbeschleunigende Wirkung in der Niere ihren Angriffspunkt hat, einem Organ, das sich für die Zeitdauer dieser Versuche aus der Circulation ohne Schädigung des Thieres ausschalten lässt. Ich habe daher diese Stoffe Thieren eingegeben, welehen ich vorher die Nierengefässe unterbunden hatte: an diesen Thieren müsste Coffein und Salz die Lungenblutung unbeeinflusst lassen. Die Versuche stellte ich so an, dass ich einem Thier zunächst 5 ccm 10 proc. Kochsalzlösung und darauf Coffein injicirte, einem zweiten Kaninchen in umgekehrter Reihenfolge erst Coffein und dann Salz gab.

Curve 22.

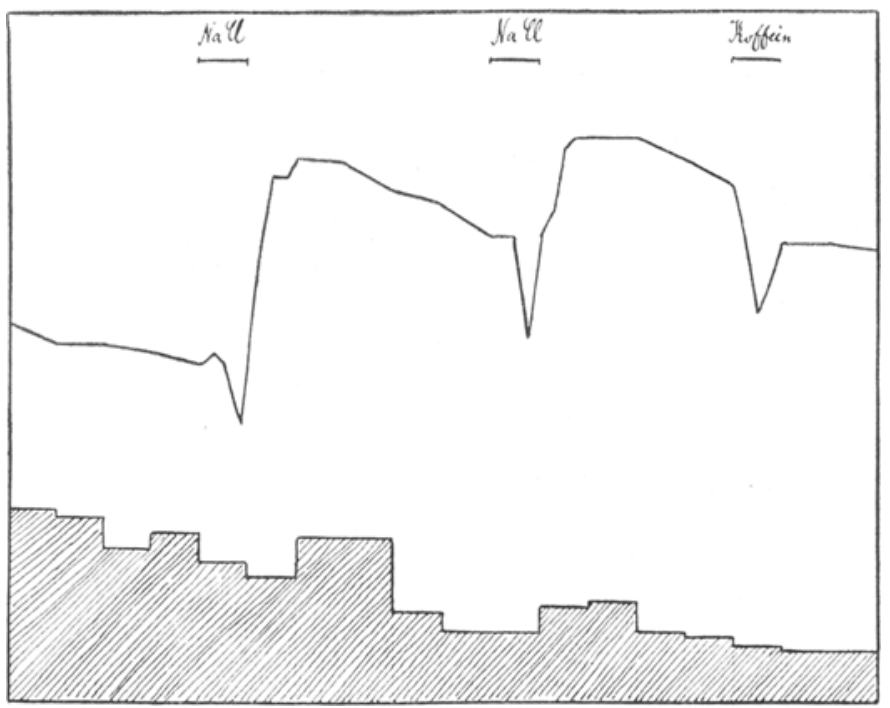

Der Ausfall der Versuche 43 und 44 ist bei Coffein schlagend: in beiden Fällen zeigte sich am Thier mit unterbundenen Nierengefässen die Coffeingabe völlig wirkungslos auf die Blutung der Lungenwunde. Es bleibt also die sonst constatirte Vermehrung der Durchblutung der Lunge durch Coffein aus. Damit ist dargethan, dass nur die Erweiterung der Nierengefässe mehr Blut in der Zeiteinheit in Umlauf setzt und dass daraus die vermehrte Blutdurchströmung der Junge folgte.

Bei den Salzgaben ist der Ausfall der Versuche nicht so eindeutig. Es kommt als störend die starke Hebung des Blutdruckes in Betracht, die ihrerseits die allgemeine Circulation begünstigt. Schon bei den Versuchen an der Zunge ist durch Steigcrung des Blutdruckes nach Salzgaben eine Vermehrung der Blutung eingetreten. Eine solche Steigerung des Blutdruckes - die wohl durch Auffüllen des Gefässsystems bedingt wird, weil die hypertonische Lösung Gewebswasser in die Blutgefässe hineinzieht - macht sich am deutlichsten dort bemerkbar, wo der Blutdruck stark gesunken ist, und das ist besonders in diesen Versuchen mit Unterbindung der Nierengefässe der Fall. Man sieht bei der Operation zur Freilegung der Lange immer den Blutdruck sinken, wenn das Abdomen 
Die Blutdurchströmung der Lunge unter den Einfluss einiger Arzneistoffe etc. 67

Versueh 44.

Kaninchen, männl., $1300 \mathrm{~g} . \quad 3 \mathrm{~g}$ Urethan intravenös. Nierengefässe beiderseits abgebunden. Die Lunge blutet. (Hierzu Curve 23.)

\begin{tabular}{|c|c|c|c|c|c|}
\hline $\begin{array}{l}\text { Nach } \\
\text { Min. }\end{array}$ & $\begin{array}{c}\text { Blutdruek } \\
\text { Carotis } \\
\mathrm{mm} \mathrm{Hg}\end{array}$ & $\begin{array}{l}\text { Pulse } \\
\text { in der } \\
\text { Minute }\end{array}$ & $\begin{array}{c}\text { Pulshöhe } \\
\text { maximal } \\
\mathrm{mm}\end{array}$ & $\begin{array}{c}\text { Hb-Gehalt } \\
\text { relativ }\end{array}$ & Bemerkungen \\
\hline $\begin{array}{l}0 \\
1 \\
2 \\
-15 \\
-30 \\
-45 \\
3 \\
4 \\
5 \\
6 \\
7 \\
-15 \\
-30 \\
-45 \\
8 \\
-15 \\
-30 \\
-45 \\
9 \\
10 \\
11 \\
12 \\
-15 \\
-30 \\
-45 \\
13 \\
14 \\
15 \\
16 \\
17\end{array}$ & $\begin{array}{l}26 \\
25 \\
26 \\
28 \\
26 \\
24 \\
25 \\
24 \\
24 \\
26 \\
24 \\
27 \\
33 \\
32 \\
42 \\
46 \\
46 \\
47 \\
48 \\
46 \\
41 \\
39 \\
42 \\
41 \\
40 \\
40 \\
46 \\
44 \\
47 \\
44\end{array}$ & $\begin{array}{l}170 \\
180 \\
170 \\
160 \\
160 \\
170 \\
170 \\
180 \\
180 \\
170 \\
170 \\
150 \\
130 \\
130 \\
160 \\
170 \\
180 \\
180 \\
180 \\
170 \\
170 \\
180 \\
170 \\
150 \\
160 \\
160 \\
170 \\
170 \\
170 \\
170\end{array}$ & $\begin{array}{l}4 \\
4 \\
4 \\
5 \\
5 \\
4 \\
4 \\
4 \\
3 \\
3 \\
4 \\
5 \\
6 \\
7 \\
6 \\
6 \\
6 \\
6 \\
5 \\
5 \\
5 \\
5 \\
6 \\
7 \\
6 \\
6 \\
5 \\
4 \\
4 \\
4\end{array}$ & $\begin{array}{l}61,3 \\
38,9 \\
26,8 \\
18,0 \\
12,0 \\
10,0 \\
10,0 \\
13,0 \\
\\
30,0 \\
30,5 \\
31,2 \\
40,7 \\
31,8 \\
41,0 \\
31,8 \\
31,8 \\
42,9\end{array}$ & $\begin{array}{l}4 \mathrm{ccm} 1 \text { proc. Coffein in die } \\
\text { Vena jugularis. } \\
\left\{\begin{array}{l}5 \mathrm{cem} 10 \text { proc. NaCl in die } \\
\text { Vena jugularis. }\end{array}\right.\end{array}$ \\
\hline
\end{tabular}

Curve 23.

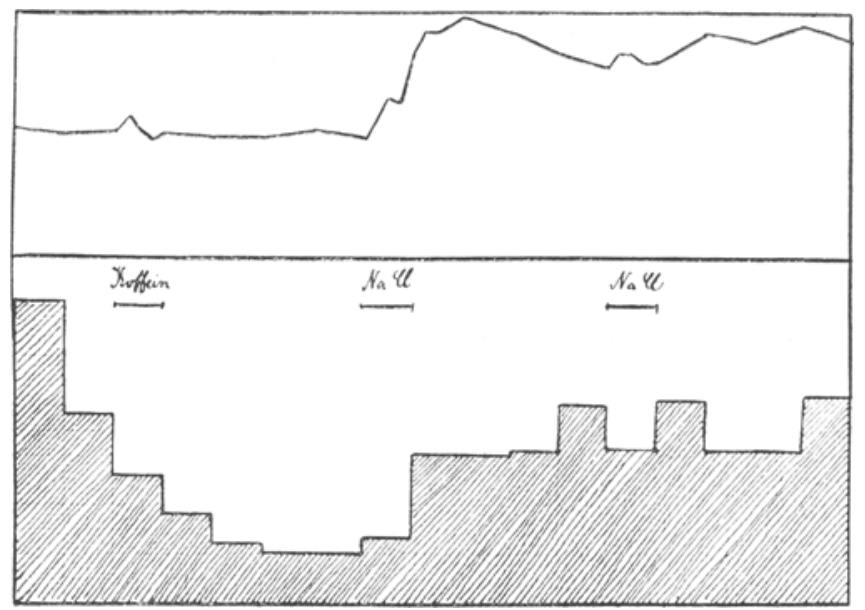


geöffnet wird, während die Eröffnung der Brusthöhle meistens gar keinen Einfluss auf den Blutdruck ausübt. Hat man dann durch Anlegen der Knopfnähte zwischen Zwerchfell und unterem Wundrand der queren Bauchwunde die Bauchhöhle wieder geschlossen, so steigt gewöhnlich der Blutdruck allmählich wieder an. Es ist also nicht die Abkühlung als solche oder anderes mehr, was den Blutdruck herabdrückt, sondern die Lähmung der Unterleibsgefässe. Auch sinkt bei weit eröffnetem Thorax der Blatdruck während langer Zeit fast gar nicht, wohl aber, wenn, auch nur für kurze Zeit, Luft in die Bauchböhle eintritt. Und so ist es nicht $\mathrm{zu}$ verwundern, wenn gerade in den Versuchen, bei denen die Nieren abgebunden wurden, eine noch stärkere Schädigung des Blutdruckes zu beobachten war, als sonst schon bei der eingreifenden Operation zur Freilegung der Lunge. Daher entfaltet gerade in diesen Versuchen das Kochsalz eine günstige Wirkung auf die Circulation durch Hebung des Blutdruckes. Dadurch werden aber die Ausschläge der Durchblutung der Lunge verschleiert. Die Hebung der Circulation verbessert auch die Blutdurchströmung der Lunge. Im ersten Versuch ist die Steigerung des Carotisdruckes sehr erheblich; dagegen wächst die ausfliessende Blutmenge nur wenig. Beide Injectionen von concentrirter Salzlösung zeigen hier also trotz erheblicher Steigerung des Blutdruckes einen nur geringen Einfluss auf die Blutung, jedenfalls nicht vergleichbar mit der Zunahme der Lungenblutung bei freier Nierencirculation. Der zweite Versuch dagegen lässt dieses Verhältniss nicht klar hervortreten. Es findet hier eine deutliche Zunahme der Blutung statt, die ich auf die starke Hebung des tief gesunkenen Blutdruckes zurückführe; aber einen Beweis für diese Annahme bringt der Versuch nicht. Die zweite Kochsalzgabe scheint die Blutung ebensowenig zu beeinflussen wie den Blutdruck. Und dies kann schon eher zur Stütze dieser Auffassung dienen. Aus den obigen Gründen, d. h. wegen der starken Senkung des. Blutdruckes durch die Operation und das gleichzeitige Abbinden der Nieren wird nach Salzgaben wohl immer eine Erhöhung des Blutdruckes stattfinden, und somit versprechen auch weitere Versuche mit dieser Anordnung keine deutlicheren Resultate. Immerhin glaube ich, dass durch den Austall der Versuche mit Coffein genügend dargethan ist, dass durch die Erweiterung der Nierengefässe die Blutdurchströmung der Lungen eine Vermehrung erfährt und dass man nach dem Ausfall von Versuch 1 und 2 in seinem letzten Abschnitt unbedenklich diese bei Coffein gefundenen Verhältnisse auch auf Salzinjectionen übertragen kann.

Es bleibt also nach Coffeininjectionen die Vermehrung der Lungenblutung aus, wenn man den Thieren vorher die Nierengefässe abbindet. Dasselbe gilt vom Kochsalz, nur trübt hier die gleichzeitige Blutdrucksteigerung das Bild. Man kann also durch diese Mittel auf dem Wege der Erweiterung der Nierengefässe die Blutdurchströmung der Lunge vergrössern. 
Die Blutdurchströmung der Lunge anter dem Einfluss einiger Arzneistoffe etc. 69

\section{Anhang.}

Im Interesse der objectiven Wiedergabe der Resultate will ich noch einige Versuche mit Salz wiedergeben, deren Ausfall nicht ganz eindeutig ist, und aus denen ich den Schluss auf den blutungsbefördernden Einfluss des Salzes nicht gezogen hätte. Sie bestätigen zwar durchweg die oben angeführten Versuche, stets hat es nach Salzinjection stärker geblutet, aber der Blutdruck ist dabei nicht constant geblieben, sodass man eine Rückstauung nicht ganz ausschliessen kann. Aber diese Versuche sind von Wichtigkeit für die Beurtheilung der Grösse der jeweiligen Einflüsse, der Rückstaung, des Blutdruclies etc. und so sollen sie zur Controlle, d. b. zur Beurtheilung der Technik und der Grösse der Ausschläge dienen.

Versuch 45.

Kaninchen, männl., 1600 g. 4,5 cem Paraldehyd subeutan.

\begin{tabular}{|c|c|c|c|c|c|}
\hline $\begin{array}{c}\text { Nach } \\
\text { Min. }\end{array}$ & $\mid \begin{array}{c}\text { Blutdruek } \\
\text { Carotis } \\
\mathrm{mm} \mathrm{Hg}\end{array}$ & $\begin{array}{l}\text { Pulse } \\
\text { in der } \\
\text { Minute }\end{array}$ & $\begin{array}{c}\text { Prishöe } \\
\text { maximal } \\
\mathrm{mm}\end{array}$ & $\begin{array}{l}\mathrm{Hb} \text {-Gehalt } \\
\text { relativ }\end{array}$ & Bemerkungen \\
\hline $\begin{array}{l}0 \\
1 \\
2 \\
3 \\
4 \\
5 \\
6 \\
7 \\
8 \\
-15 \\
-30 \\
-45 \\
9 \\
-15 \\
-30 \\
-45 \\
10 \\
-15 \\
-30 \\
-45 \\
11 \\
-15 \\
-30 \\
-45 \\
12 \\
-15 \\
-30 \\
-45 \\
13\end{array}$ & $\begin{array}{l}72 \\
72 \\
72 \\
70 \\
68 \\
67 \\
66 \\
60 \\
68 \\
88 \\
64 \\
78 \\
76 \\
64 \\
34 \\
29 \\
78 \\
82 \\
82 \\
82 \\
82 \\
68 \\
84 \\
81 \\
58 \\
40 \\
26 \\
18 \\
14\end{array}$ & $\begin{array}{r}250 \\
240 \\
250 \\
240 \\
230 \\
240 \\
250 \\
240 \\
240 \\
220 \\
90 \\
150 \\
140 \\
140 \\
100 \\
130 \\
140 \\
140 \\
140 \\
140 \\
140 \\
130 \\
130 \\
120 \\
100 \\
80 \\
50 \\
30 \\
20\end{array}$ & $\begin{array}{l}1 \\
1 \\
1 \\
1 \\
1 \\
1 \\
1 \\
1 \\
1 \\
1 \\
3 \\
2 \\
2 \\
11 / 2 \\
1 / 2 \\
1 / 2 \\
1 \\
1 / 2 \\
1 / 2 \\
1 / 2 \\
1 \\
5 \\
3 \\
3 \\
3 \\
2 \\
1 \\
1 / 2 \\
1 / 2\end{array}$ & $\begin{array}{l}55,0 \\
30,8 \\
24,0 \\
14,4 \\
15,0 \\
14,4 \\
15,0 \\
10,0 \\
25,8 \\
\\
71,2\end{array}$ & $\begin{array}{l}\text { 9cm } 20 \text { proc. } \mathrm{Na}_{2} \mathrm{SO}_{4} \text { in die } \\
\text { Vena jugularis. } \\
\text { Eine krampf hafte Zusammen- } \\
\text { 2iehung der Bauchmuskeln. } \\
\text { Nur wenige Pulse, Zahl ungenau. } \\
\text { Athmung abgestellt, Blutdruck } \\
\text { hebt sich nicht, Herz schlägt } \\
\text { noch langsam und schwach. }\end{array}$ \\
\hline
\end{tabular}

Auf die Salzgabe hin tritt eine starke Vermehrung der Blutung ein; der Blutdruck weist grosse Schwankungen auf, hält sich dann einige Zeit auf normaler Höhe, um am Schluss steil abzufallen. Trotz dieses Abfalles nimmt die Blutung ab, d. h. die Rückstauung tritt in den Hintergrund gegenüber dem Einfluss der Zuströmung aus den Venen, die die Blutungsgrösse allein beherrscht. 
Versueh 46.

Kanibchen, münnl., 1400 g. $2,5 \mathrm{~g}$ Urethan intravenös.

\begin{tabular}{|c|c|c|c|c|c|}
\hline $\begin{array}{l}\text { Nach } \\
\text { Min. }\end{array}$ & $\begin{array}{l}\text { Blutdruck } \\
\text { Carotis } \\
\mathrm{mm} \mathrm{Hg}\end{array}$ & $\begin{array}{l}\text { Pulse } \\
\text { in der } \\
\text { Minute }\end{array}$ & $\begin{array}{l}\text { Pulsbühe } \\
\text { maximal } \\
\mathrm{mm}\end{array}$ & $\begin{array}{c}\text { Hb-Gehalt } \\
\text { relativ }\end{array}$ & Bemerkungen \\
\hline $\begin{array}{l}0 \\
1 \\
2 \\
-30 \\
3 \\
4 \\
-30 \\
5 \\
--30 \\
6 \\
7 \\
8 \\
-15 \\
-30 \\
-45 \\
9 \\
10 \\
11 \\
12 \\
13 \\
14 \\
15 \\
16 \\
-15 \\
-30 \\
-45 \\
17 \\
18 \\
19 \\
20 \\
21\end{array}$ & $\begin{array}{l}34 \\
34 \\
40 \\
40 \\
31 \\
21 \\
42 \\
61 \\
42 \\
31 \\
37 \\
44 \\
46 \\
49 \\
58 \\
41 \\
52 \\
52 \\
52 \\
53 \\
50 \\
50 \\
46 \\
46 \\
50 \\
60 \\
56 \\
54 \\
60 \\
54 \\
50\end{array}$ & $\begin{array}{r}120 \\
110 \\
120 \\
120 \\
120 \\
70 \\
60 \\
100 \\
100 \\
100 \\
110 \\
110 \\
110 \\
110 \\
120 \\
110 \\
130 \\
120 \\
140 \\
140 \\
140 \\
140 \\
140 \\
140 \\
140 \\
150 \\
130 \\
140 \\
140 \\
140 \\
140\end{array}$ & $\begin{array}{l}11 / 2 \\
11 / 2 \\
11 / 2 \\
2 \\
11 / 2 \\
2 \\
8 \\
3 \\
2 \\
11 / 2 \\
11 / 2 \\
11 / 2 \\
11 / 2 \\
2 \\
11 / 2 \\
11 / 2 \\
11 / 2 \\
2 \\
2 \\
2 \\
11 / 2 \\
11 / 2 \\
11 / 2 \\
11 / 2 \\
11 / 2 \\
11 / 2 \\
11 / 2 \\
11 / 2 \\
11 / 2 \\
1 \\
1\end{array}$ & $\begin{array}{r}13,6 \\
12,0 \\
12,0 \\
18,8 \\
19,2 \\
21,7 \\
20,3 \\
14,5\end{array}$ & $\left\{\begin{array}{l}5 \text { cem } 20 \text { proc. } \mathrm{Na}_{2} \mathrm{SO}_{4} \text { in } \\
\text { die Vena jugularis. }\end{array}\right.$ \\
\hline
\end{tabular}

Versuch 47.

Kaninchen, weibl., 2100 g. 7,0 ccm Paraldehyd subcutan.

\begin{tabular}{|c|c|c|c|c|c|}
\hline $\begin{array}{l}\text { Nach } \\
\text { Min. }\end{array}$ & $\begin{array}{c}\text { Blutaruek } \\
\text { Carotis } \\
\mathrm{mm} \mathrm{Hg}\end{array}$ & $\begin{array}{l}\text { Pulse } \\
\text { in der } \\
\text { Minute }\end{array}$ & $\begin{array}{c}\text { Pulshöhe } \\
\text { maximal } \\
\mathrm{mm}\end{array}$ & $\begin{array}{l}\mathrm{Hb} \cdot \text { Gebalt } \\
\text { relativ }\end{array}$ & Bemerkungen \\
\hline $\begin{array}{l}0 \\
1 \\
2 \\
3 \\
4 \\
5 \\
6 \\
-15 \\
-30 \\
-45 \\
77 \\
8 \\
9\end{array}$ & $\begin{array}{l}22 \\
21 \\
22 \\
21 \\
20 \\
21 \\
19 \\
18 \\
15 \\
15 \\
12 \\
10 \\
10\end{array}$ & $\begin{array}{r}140 \\
130 \\
130 \\
130 \\
120 \\
120 \\
120 \\
60 \\
90 \\
90 \\
70 \\
70 \\
60\end{array}$ & $\begin{array}{l}3 \\
3 \\
3 \\
3 \\
4 \\
4 \\
3 \\
4 \\
2 \\
2 \\
1 \\
1 / 2 \\
1 / 2\end{array}$ & $\begin{array}{l}27,7 \\
15,4 \\
12,8 \\
12,4 \\
10,4 \\
12,2 \\
\\
25,2 \\
\\
22,1 \\
18,6\end{array}$ & $\begin{array}{l}9 \text { cem } 10 \text { proc. NaCl in die } \\
\text { Vena jugularis warm aus } \\
\text { der Bürette. }\end{array}$ \\
\hline
\end{tabular}


Bei grossen Schwankungen des Blutdruckes tritt nach der ersten Salzzufuhr eine Vermehrung der Blutung ein, die sich in mässigen Grenzen hält. Die zweite Injection der concentrirten Glaubersalzlösung hat nur eine vorübergehende Blutdruckschwankung zur Folge. Gleichzeitig nimmt die Menge des ausströmenden Blutes ausserordentlich zu. Dieselbe Wirkung zeigt auch die intravenöse Injection von 0,9 proc. Kochsalzlösung, die gleichfalls die Nierengefässe erweitert ${ }^{1}$ ) (Versuch 46 ).

Auch hier nimmt die Blutung stark zu, während gleichzeitig der Blutdruck nach der Zuführung der 10 proc. NaCl-Lösung sich bis 0 senkt (Versuch 47 ).

$$
\text { Versuch } 48 .
$$

Kaninchen, männl., 2200 g. 9 ccm Paraldehyd subcutan.

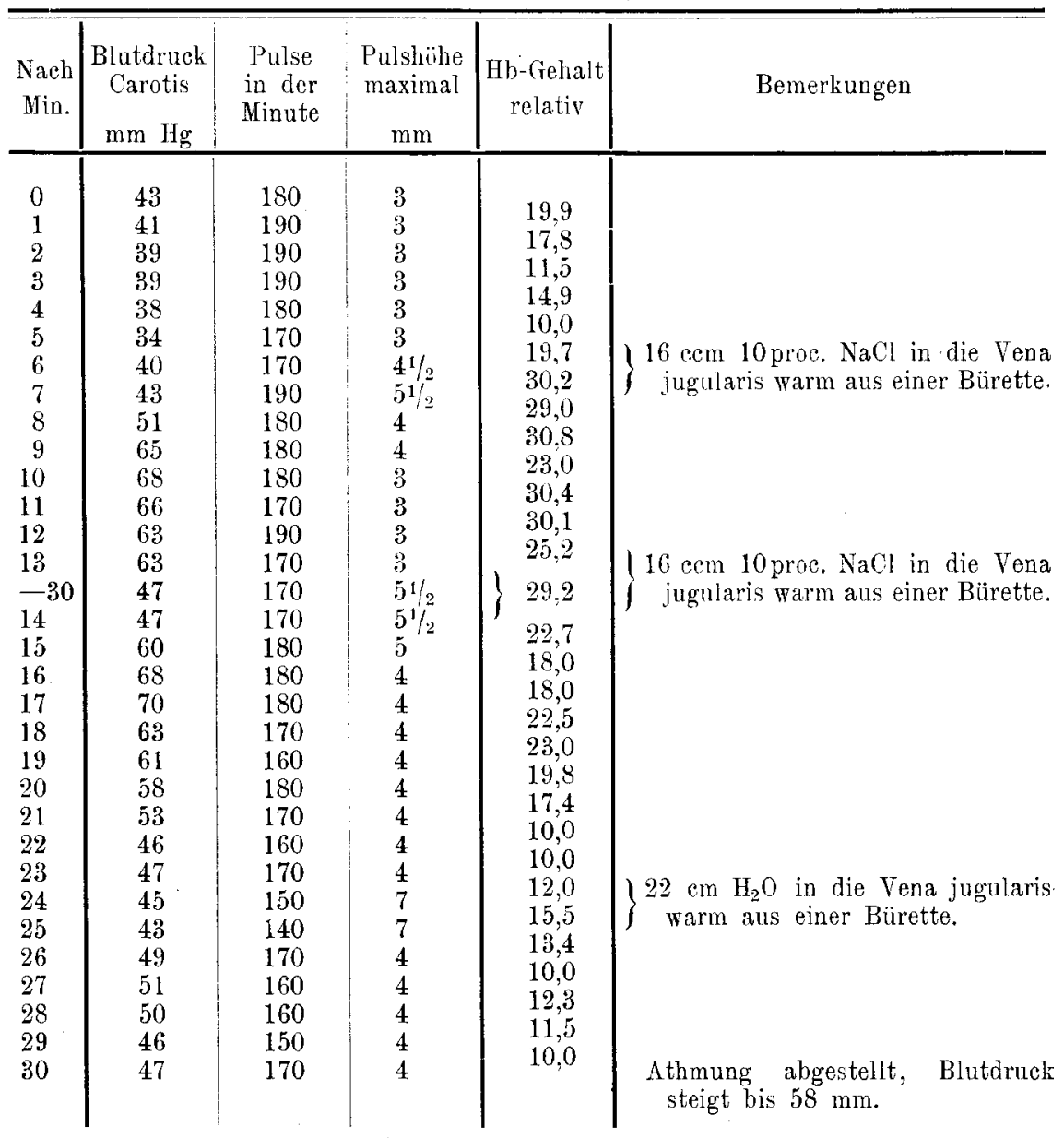

In diesem Versuch trüben die Blutdruckschwankungen das Bild erheblicher. Nach der ersten Injection nimmt die Blutung zwar wie früher stark zu, aber gleichzeitig steigt der Aortendruck merklich an, sodass sich ein strenger Schluss aus diesem Versuch allein nicht ziehen lässt. Die zweite Gabe bringt bei starkem Abfall des Druckes nur zuerst eine schwache Vermehrung der Blutung. Erst als sich der Blutdruck wieder bedeutend gehoben hat, nimmt die Blutung etwas zu. Die nachfolgende Wasserinjection hat nur einen geringen Einfluss auf die Blutung.

1) Frey, Was giebt bei gleichzeitiger Salz- und Wasserzufuhr den Reiz zur Diurese ab? Pflüger's Archiv, 1907. Bd. 120. S. 93. 
Versueh 49.

Kaniachen, männl., 2000 g. 7 ccm Paraldehyd subcutan.

\begin{tabular}{|c|c|c|c|c|c|}
\hline $\begin{array}{l}\text { Nach } \\
\text { Min. }\end{array}$ & $\begin{array}{c}\text { Blutdruck } \\
\text { Carotis } \\
\mathrm{mm} \mathrm{Hg}\end{array}$ & $\begin{array}{l}\text { Pulse } \\
\text { in der } \\
\text { Minute }\end{array}$ & $\begin{array}{c}\text { Pulshohe } \\
\text { maxinal } \\
\text { mm }\end{array}$ & $\begin{array}{l}\text { Hb-Gebalt } \\
\text { relativ }\end{array}$ & Bemerkungen \\
\hline $\begin{array}{c}0 \\
1 \\
2 \\
3 \\
-15 \\
-30 \\
-45 \\
4 \\
-15 \\
-30 \\
-45 \\
5 \\
-15 \\
-30 \\
-45 \\
6 \\
-15 \\
-30 \\
-45 \\
7\end{array}$ & $\begin{array}{l}56 \\
51 \\
44 \\
38 \\
30 \\
29 \\
25 \\
36 \\
27 \\
28 \\
27 \\
26 \\
32 \\
21 \\
22 \\
21 \\
20 \\
22 \\
18 \\
14\end{array}$ & $\begin{array}{l}210 \\
190 \\
200 \\
190 \\
180 \\
170 \\
180 \\
180 \\
190 \\
180 \\
170 \\
170 \\
160 \\
160 \\
150 \\
150 \\
130 \\
130 \\
120 \\
120\end{array}$ & $\begin{array}{l}2 \\
2 \\
2 \\
2 \\
1 \\
1 \\
1 \\
1 \\
1 \\
1 \\
1 \\
1 \\
11 / 2 \\
11 / 2 \\
11 / 2 \\
11 / 2 \\
1 / 1 / 2 \\
1 / 2 \\
11 / 2 \\
11 / 2\end{array}$ & $\begin{array}{l}15,1 \\
12,9 \\
19,2 \\
13,1 \\
12,2 \\
15,2 \\
48,2\end{array}$ & $\begin{array}{l}\text { Einlauf von } 12 \text { cem } 10 \text { proc. } \\
\text { NaCi aus einer Bürette } \\
\text { körperwarm in die Vena } \\
\text { jugularis. } \\
\text { Einlauf abgestellt. Gleich } \\
\text { darauf Herzstillstand. Sen- } \\
\text { kung d. Blutdruckes auf } 0 .\end{array}$ \\
\hline
\end{tabular}

In diesem Versuch sank der Blutdruck des Thieres, das offenbar etwas zu viel Paraldehyd (in zwei Dosen) erhalten hatte, gradlinig von Anfang des Versuches an bis zum Schluss auf 0. Aber auch hier setzte auf die Salzinjection hin eine äusserst starke Vermehrung des Blutausflusses ein.

Im Versuch 50 tritt nach den beiden ersten Salzgaben eine Vermehrung der Blutung deutlich hervor; auffallend ist, dass die zweite 10 mal grössere Dosis, deren Wirkung schon erfolgt, als die der ersten Injection noch nicht vorüber ist, nicht sonderlich intensiver wirkt als die orste. Allerdings hat sich bei der zweiten Injection der Blutdruck etwas gesenkt, wodurch der Zufluss zum rechten Herzen abnimmt. Würde es sich bei der Salzwirkung um Rückstauung handeln, so müsste die Blutdrucksenkung die Lungenblutung begünstigen. Dio dritte Salzgabe hält nur 1-2 Minuten lang die Blutung auf der Höhe, dann findet ein allmähliches Abfallen statt. Auffallenderweise zejgen hier die beiden Wasserinjectionen eine Zunahme der Blutung, aber beide erst verspätet. Vielleicht hängt das mit der gefässverengenden Wirkung ${ }^{1}$ ) des Wassers auf die Nierengefässe zusammen, nach deren Anfhören erst wieder der Salzreichthum des Thieres zur früheren Erweiterung der Nierengefässe führt.

\section{Schluss.}

Für die Grösse des Blutdruckes in der Arteria pulmonalis hatte sich neben der Arbeit des lechten Ventrikels als wichtig erwiesen: einmal der Zustrom von Blut aus den Körpervenen zum rechten Herzen, zweitens eine Rückstauung von Blut vom linken Vorhof her, wenn der

1) Frey, Die Reaktion der Niere auf Blutverdünnung. Beitrag VII. Pflüger's Archiv, 190\%. Bd. 120. S. 117. 
Die Blutdurchströmung der Lunge unter dem Einfluss einiger Arzneistoffe etc. 73

Versuch 50.

Kaninchen, 1800 g. 7,0 ccm Paraldehyd subcutan.

\begin{tabular}{|c|c|c|c|c|c|}
\hline $\begin{array}{l}\text { Nach } \\
\text { Min. }\end{array}$ & $\begin{array}{c}\text { Blutdruck } \\
\text { Carotis } \\
\text { mm Hg }\end{array}$ & $\begin{array}{l}\text { Pulse } \\
\text { in der } \\
\text { Minute }\end{array}$ & $\begin{array}{c}\text { Pulshöhe } \\
\text { maximal } \\
\text { mm }\end{array}$ & $\begin{array}{c}\text { Hb-Gehalt } \\
\text { relativ }\end{array}$ & Bemerkungen \\
\hline 0 & 36 & 210 & 1 & & \\
\hline 1 & 38 & 220 & 1 & 103,8 & \\
\hline 2 & 40 & 220 & 1 & 34,0 & \\
\hline 3 & 40 & 220 & 1 & 26,1 & \\
\hline 4 & 45 & 230 & 1 & 29,1 & f $1,0 \mathrm{ccm} 10$ proc. $\mathrm{NaCl}$ in die Venajug. \\
\hline 5 & 44 & 210 & 1 & 37,6 & \\
\hline 6 & 44 & 230 & 1 & $\begin{array}{l}41,9 \\
380\end{array}$ & \\
\hline 7 & 44 & 230 & 1 & & \\
\hline$-\cdots 15$ & 42 & 220 & 1,5 & & $10 \mathrm{cem} 10$ proc. $\mathrm{NaCl}$ in die Vena \\
\hline $\begin{array}{l}-30 \\
-45\end{array}$ & 40 & 220 & 3 & 47,9 & jugularis. \\
\hline$\frac{-45}{8}$ & $\begin{array}{l}38 \\
38\end{array}$ & $\begin{array}{l}230 \\
220\end{array}$ & $\begin{array}{l}3 \\
3\end{array}$ & & \\
\hline 9 & 48 & 230 & 1 & 50,9 & \\
\hline 10 & 50 & 220 & 1 & 41,7 & \\
\hline 11 & 54 & 250 & 1 & & \\
\hline-15 & 56 & 200 & 2 & & $10 \mathrm{ccm} 10$ proe. $\mathrm{NaCl}$ in die Vena \\
\hline $\begin{array}{l}-30 \\
-45\end{array}$ & $\begin{array}{l}44 \\
46\end{array}$ & $\begin{array}{l}200 \\
200\end{array}$ & $\begin{array}{l}3 \\
4\end{array}$ & 47,4 & jugularis. \\
\hline 12 & 50 & 210 & 4 & & \\
\hline 13 & 58 & 210 & 3 & 47,9 & \\
\hline 14 & 60 & 210 & 3 & 30,2 & \\
\hline 15 & 60 & 200 & 1,5 & $\begin{array}{l}30,0 \\
21,8\end{array}$ & \\
\hline 16 & 61 & 200 & 2,5 & & \\
\hline $\begin{array}{l}-15 \\
-30\end{array}$ & $\begin{array}{l}62 \\
61\end{array}$ & $\begin{array}{l}210 \\
200\end{array}$ & $\begin{array}{l}2,5 \\
2,5\end{array}$ & 18,8 & $10 \mathrm{ccm} \mathrm{H}_{2} \mathrm{O}$ in die Vena jugularis. \\
\hline-45 & 60 & 200 & 2,5 & & \\
\hline 17 & 61 & 190 & 2,5 & & \\
\hline 18 & 62 & 200 & 2,5 & 20,1 & \\
\hline 19 & 60 & 190 & 2,5 & 2,1 & \\
\hline 20 & 60 & 200 & 2,5 & & \\
\hline-15 & 59 & 190 & 2,5 & & \\
\hline-30 & 59 & 190 & 2,5 & 12,5 & $10 \mathrm{~cm} \mathrm{H}_{2} \mathrm{O}$ in die Vena jugularis. \\
\hline-45 & 57 & 190 & 2,5 & & \\
\hline 21 & 60 & 190 & 2,5 & 161 & \\
\hline $\begin{array}{l}22 \\
23\end{array}$ & $\begin{array}{l}60 \\
58\end{array}$ & 190 & $\begin{array}{l}2,5 \\
2,5\end{array}$ & 22,6 & \\
\hline & 50 & 190 & & & \\
\hline
\end{tabular}

linke Ventrikel erlahmt oder gegen den stark erhöhten Aortendruck nicht alles Blut weiter befördern kann.

Dabei hatte sich gezeigt, dass die Lungengefässe unter dem Einfluss von Arzneimitteln, die im grossen Kreislauf stark wirksam sind, ihre Weite nicht ändern, und dass die Schwankungen des Blutdruckes in der Lungenarterie nur passiver Art sind, herbeigeführt durch Aenderungen im grossen Kreislaufe.

Betrachtet man, wie es in vorliegender Arbeit geschah, die Blutdurchströmung der Lunge, so muss man stets vor Augen haben, dass die Lunge einen Gesammtquerschnitt des Blutgefässsystems darstellt und dass eine Vergrösserung der Blutmenge, die in der Zeiteinheit die Lunge durchfliesst, nur dadurch möglich wird, dass die gleiche Beschleunigung der Blutströmung im grossen Kreislaufe (in seiner Gesammtheit) vorhanden sein muss. Dies kann dadurch geschehen, dass bei un- 
gefähr gleich bleibendem Blutdruck ein bestimmtes Gefässgebiet sich erweitert, wie die Nierengefässe nach Coffein und Salz, oder dass ein stark erhöhter Blutdruck durch ein weniger oder gar nicht verengtes Gebiet sehr viel mehr Blut treibt, sodass eine Beschleunigung der gesainmten Blutströmung resultirt. Das ist der Fall, wenn nach Suprarenin, und in etwas geringerem Maasse, wenn nach $\mathrm{BaCl}_{2}$ der Blutdruck steigt und wohl durch die Hirngefässe das Plus an Blut seinen Weg nimmt.

Für die Grösse der Blutung einer Lungenwunde scheint die Rückstauung nur in beschränktem Maasse in Betracht zu kommen. Sie ist nach der Eingabe von Amylnitrit vorhanden und documentirt sich durch eine geringe Zunahme der Blutung. Hauptsächlich blutungsbefördernd hat sich der gesteigerte Blutzufluss zur Lunge erwiesen, wie er nach Suprarenin und Bariumchlorid, ferner nach Salz und Coffein eintritt. Secale, Hydrastinin, Kampfer und Digitalis haben einen Einfluss auf die Blutung einer Lungenwunde nicht gezeigt.

In the ra pe utis ch erBeziehung ergiebt sich aus diesen Untersuchungen, dass keines der angewandten Nittel die Blutung einer Lungenwunde herabsetzen kann. Da die Lunge einen Gesammtquersehnitt des Kreislaufes darstellt, so ist eine Verminderung der Blutung sowobl wie der Blutdurchströmung nur möglich, wenn der gesammte Umlauf des Blutes sich verlangsamt, also auch in dem Theil des Umlaufes, den wir den grossen Kreislauf nennen. Und auch, wenn ein Stoff bekannt würde, welcher die Gefässe der Lunge zur Contraction brächte, so könnte dieser Stoff darum doch nicht die Lungenblutung vermindern, solange der rechte Ventrikel nicht erlahmt. Denn das rechte Herz müsste in der Zeiteinheit trotz der Gefässverengerung dieselbe Menge Blut durch die Lungen treiben, die das linke Herz im grossen Kreislauf in Bewegung setzt, soll es nicht zu einer Stauung kommen. Könnten wir also die Lungengefässe verengern, so würden wir dadurch die Durchblutung der Lunge nicht ändern und auch die Blutung einer Lungenwunde nicht stillen können, weil dieselbe Menge Blut als vorher durch die Lunge fliessen würde jetzt nur bei verengten Gefässen und erhöhtem Druck in der Arteria pulmonalis - solange der Blutkreislauf im ganzen normal bliebe. Wir können also nur durch Schädigung des Blutumlaules eine Jungenblutung vermindern. Es ist wichtig, dies festzustellen, weil häufig gefässverengernde Mittel bei Lungenblutungen angewandt und empfohlen werden. Abgesehen davon, dass im grossen Krcislauf stark wirksame Stoffe wie Suprarenin direct ungünstig auf die Lungenblutung wirken, und dass wir kein Mittel kennen, welches die Lungengefässe verengt, ist auch die für erstrebenswerth gehaltene Gefässverengerung in der Lunge entweder unnütz oder sogar für den Blutumlauf schädlich.

Es hat sich ferner zeigen lassen, dass die Einwirkung eines Stoffes auf eine noch blutende Wunde und auf eine schon gestillte Blutung verschieden sein kann. Es kommt vor, dass ein gefässverengerndes Mittel eine Wunde im grossen Kreislaufe weniger bluten lässt und doch an derselben Stelle eine geronnene Wundfläche wieder zur Blutung ent- 
facht, vielleicht dadurch, dass ein Gerinnsel durch die Gefässcontraction und den erhöhten Blutdruck herausgequetscht wird.

Andererseits lässt sich die Blutdurchströmung der Lunge steigern, und man könnte an eime therapeutische Benutzung dieser Thatsache bei Erkrankungen der Lunge, z. B. an Tuberculose, denken bei welcher eine Erhöhung der Durchblutung von Nutzen erscheint. Da diese Erhöhung der Durchblutung sich aber - wie oben auseinandergesetzt - auch im grossen Kreislauf zeigen muss, so wird man von der Anwendung der blutdrucksteigernden Substanzen wie Suprarenin absehen. Es käme also nur Salz und Coffein in Frage, die durch Erweiterung der Nierengefässe mehr Blut in der Zeiteinheit circuliren lassen. Man könnte also an ein diätetisches Regime denken, welches gesalzene Speisen einerseits und Kaffee, Thee, Cacao andererseits bevorzugte. Jedenfalls handelt es sich um Mittel, die sich bei dauernder Anwendung im grossen Maassstabe als relativ unsehädlich erwiesen haben und deren Anwendung von diesem Gesichtspunkte aus nichts im Wege steht. Man wird aber einwenden, dass es sich bei der Empfehlung solcher indirect wirkender Stoffe doch nur um kleine Mittel handelt, mit denen man den Kampf gegen eine solche Krankheit führen will. Immerhin können sie aber - vielleicht neben der specifischen Therapie - in den diätetischen Vorsehriften mit Vortheil Beachtung finden. Wenden wir doch jetzt die gleichen Mittel empirisch an, den Aulenthalt an der See oder den Gradierwerken.

Auch bei Benutzung des Höhenklimas handelt es sich um ähnliche Einwirkungen, nur besteht der Effect desselben in einer Vermehrung der Blutfülle der Lungen, ohne dass es dabei zu einer besseren Durchblutung des Organs zu kommen braucht. Bei Salz und Coffein dagegen besteht die Wirkung in einer Vermehrung der Menge Blut, die in der Zeiteinheit durch die Lungen fliesst. Dabei wird wohl sowohl der Druck in der Arteria pulmonalis etwas anwachsen, wie es bei vermehrtem Zustrom von Blut zum rechten Herzen durch andere Stoffe erwiesen ist; es wird aber auch bei der Nachgiebigkeit der Jungengefässe eine Gefässerweiterung mit im Spiele sein, also auch eine etwas vermehrte Blutfülle der Lunge resultiren. Denn ${ }^{2}$ der Zweek der wohlausgebildeten Gefässmusculatur" der Lungen ndürfte wohl in Anpassung des Gefässlumens an reichlicheren und spärlicheren Blutzufluss zu suchen sein," wie Gerhardt') sagt.

Fragen wir zum Schluss noch, ob sich die am Thier erhobenen Befunde auf den Menschen übertragen lassen, so ist zu bemerken, dass die Fleischfresser, denen der Mensch ja näher steht, auf Salz und Coffein ebenso reagiren wie das Kaninchen, nur graduell schwächer. Die Frage, ob die erkrankten Gefässe bei einem Blutsturz sich ebenso verhalten wie die angeschnittenen Lungengefässe des normalen Thieres, erübrigt sich bei der fehlenden Wirkung auf die Lungengefässe. Es kommen hier lediglich die Verhältnisse des Zustromes, der Rückstauung u. s. f. in

1) Gerhardt, Verbandlungen des XX. Congresses für innere Medicin. 1902. s. 336 . 
Betracht, und man nimmt allgemein an, dass die Kreislaufwirkungen der untersuchten Stoffe an Thier und Mensch gleichartig sind, wenigstens soweit Suprarenin, Chlorbarium, Hydrastinin, Kampfer, Secale und Amylnitrit in Frage kommen; nur bei der Digitalis liessen sich Zweifel geltend machen, um so mehr (s. o.), als bei Anwendung dieses Stoffes meistens Veränderungen der Circulation vorliegen, sodass der Einfluss der Digitalis auf die Lungenblutung je nach der Ursache der Kreislaufstörung ein verschiedener sein kann.

\section{Zusammenfassung.}

An mit Urethan oder Paraldehyd tief narkotisirten Kaninchen hat sich die Blutung einer mit oxalsaurem Na bespülten Lungenwunde, gemessen am Hb-Gehalt der Spülflüssigkeit, durch keines der untersuchten Mittel vermindern lassen. Dagegen steigert Amylnitrit in ganz geringfügigem Maasse die Blutung der Lungenwunde, wohl durch eine Rückstaunng von Blut vom linken Vorhof aus. - Stark vermehrt wird die ausfliessende Blutmenge nach Eingabe von Suprarenin und $\mathrm{BaCl}_{2}$, was jedenfalls auf Hebung der Blutströmung im grossen Kreislauf (in seiner Gesammtheit) beruht, offenbar weil der erhöhte Blutdruck durch die weniger oder gar nicht verengten Hirngefässe mehr Blut als vorher treibt. Ebenso verursacht Salz und Coffein durch Erweiterung der Nierengefässe einen vermehrten Zustrom zum rechten Herzen, wodurch der Blutkreislauf im ganzen beschleunigt wird und daher auch in der Lunge, welche einen Gesammtquerschnitt des Blutgefässsystems darstellt. Es blutet daher nach Salz und Coffein eine Lungenwunde stärker; bei unterbundenen Nieren bleibt die Vermehrung der Lungenblutung nach Salz und Coffein aus. - Ein Einfluss von Secale, Kampfer, Hydrastinin and Digitalis hat sich nicht gezeigt.

Wie bekannt, sind den Lungengefässen gegenüber die Gefässmittel des grossen Kreislaufes unwirksam; aber auch, wenn ein Mittel die Blutgefässe der Lunge verengern würde, so könnte man es zur Stillung einer Lungenblutung doch nicht verwenden, da die Lunge einen Gesammtquerschnitt der Blutbahn darstellt und daher eine Gefässverengerung in der Lunge die Blutdurchströmung daselbst nicht ändert, solange der Gesammtkreislauf nicht leidet.

Wenn auch die Lungenblutung sich durch kein Mittel vermindern lässt, so kann man eine andere gefundene Thatsache therapeutisch benutzen. Auf dem Wege der Vermehrung der Blutdurchströmung der Lunge durch Salz und Coffein könnte eine günstige Beeinflussung der Lungentuberculose stattfinden, wenn man in geeigneten Fällen in den diätetischen Vorschriften auf diese Punkte achtet.

Zu bemerken ist noch, dass im grossen Kreislauf die Blutung einer Wunde durch gefässverengernde Mittel verringert wird und dass an derselben Stelle eine schon gestillte Blutung durch die gleichen Stoffe wieder angefacht werden kann, wohl durch Herausquetschen von Blutgerinnseln.

Die künstliche Athmung wurde bei diesen Versuchen durch einen einfachen Apparat "Pendeltrichter" unterhalten. 